\title{
WestVirginiaUniversity
}

THE RESEARCH REPOSITORY @ WVU

Graduate Theses, Dissertations, and Problem Reports

1998

\section{Computational models of particle size effects on brittle oxide scale erosion}

\author{
Ravi S. Tangirala \\ West Virginia University
}

Follow this and additional works at: https://researchrepository.wvu.edu/etd

\section{Recommended Citation}

Tangirala, Ravi S., "Computational models of particle size effects on brittle oxide scale erosion" (1998). Graduate Theses, Dissertations, and Problem Reports. 937.

https://researchrepository.wvu.edu/etd/937

This Thesis is protected by copyright and/or related rights. It has been brought to you by the The Research Repository @ WVU with permission from the rights-holder(s). You are free to use this Thesis in any way that is permitted by the copyright and related rights legislation that applies to your use. For other uses you must obtain permission from the rights-holder(s) directly, unless additional rights are indicated by a Creative Commons license in the record and/ or on the work itself. This Thesis has been accepted for inclusion in WVU Graduate Theses, Dissertations, and Problem Reports collection by an authorized administrator of The Research Repository @ WVU. For more information, please contact researchrepository@mail.wvu.edu. 
Ravi Tangirala

West Virginia University

Master of Science

Mechanical Engineering

Kenneth Means, Ph.D., Chair

Bruce Kang, Ph.D.

Gregory J. Thompson, Ph.D.

November 13, 1998

Morgantown, West Virginia

Key Words: Finite Element Analysis, Erosion, Brittle Oxide Scale, LS-Dyna3D, Particle Impact, Volume Loss 


\title{
COMPUTATIONAL MODELS OF PARTICLE SIZE EFFECTS ON BRITTLE OXIDE SCALE EROSION
}

\author{
Ravi Tangirala
}

\begin{abstract}
(ABSTRACT)
Metals and alloys designed for machines at elevated temperatures have microstructures and chemistries optimized to provide strength and resistance to oxidation. The majority of the commercial high temperatures metal or alloys intended to use at temperatures below $850^{\circ} \mathrm{C}$ or so rely on the formation of a continuous surface layer of essentially oxide scale for further oxidation resistance. Erosion of these machine parts by the small solid particle entrained in the liquid or gaseous working environment is a serious problem in many industrial applications. Numerous experiments have been conducted to obtain empirical relations for predicting material loss during erosion and to arrive at an appropriate material for a particular working environment. Arrival of many new materials and surface coatings being used for different applications demand analytical models that are more generic in applying and predicting the volume loss due to erosion. The current thesis work is focused on finite element modeling that takes into account various boundary conditions and predicts the loss of material due to erosion.

Two models, aluminum oxide model and iron/iron-oxide model were developed using IDEAS and analyzed using LS-DYNA3D. The aluminum oxide model was used to validate the computational model with the experimental work of Allan Levy. The results indicated the correlation with the experimental observations. The same procedure is extended to estimate the material loss for iron/iron-oxide model. Several parameters such
\end{abstract}


as size of the erodent, temperature, velocity of the erodent, angle of attack were varied and the influence on volume loss of oxide layer was studied. The results were presented in the form of stress contours and the graphs between the volume loss in $\mathrm{mm}^{3}$ and the parameter affecting erosion. 


\section{ACKNOWLEDGMENTS}

I would like to express my sincere gratitude to my thesis advisor Dr. Kenneth Means for his excellent guidance, understanding, and patience that allowed me to appreciate my work and at the same time fulfilled my academic goals.

I would also like to thank my other committee members, Dr. Bruce Kang and Dr. Gregory Thompson for being in my committee and encouraging me with their valuable suggestions and help.

This gives me a great opportunity to express my eternal gratitude, to my parents Mr. and Mrs. Murthy for being a constant source of emotional strength and support. They always believed that I would find my way, and I think that I finally have. I thank my sister Padma, brother-in-law Ravi Kumar and their kids for the love and affection. A special thanks goes to my brother Murali, who is more of a friend than a brother to me.

Thanks to my great roomies and officemates who helped me learn a lot in these two years. Last but not the least, I thank Chandra Yalammanchili for helping me to overcome many of the problems I faced with the understanding of LS-DYNA3D software.

I dedicate all my work to my mother, Mrs. Nirmala Tangirala. 


\section{TABLE OF CONTENTS}

\section{Page}

Title Page

Abstract $\quad$ ii

Acknowledgments $\quad$ iv

Table of Contents $\quad$ V

List of Figures viii

List of Tables $\quad$ X

1. Introduction 1

2. Literature Review 6

2.1 Classification of Erosion -Corrosion Process 6

$\begin{array}{ll}\text { 2.2 Spallation Mechanism } & 11\end{array}$

$\begin{array}{ll}2.3 \text { Erosion Mechanism } & 13\end{array}$

2.3.1 Erosion Mechanism of Ductile Materials 13

2.3.2 Erosion Mechanism of Brittle Materials 17

2.4 Parameters that Influence Erosion 22

$\begin{array}{ll}2.5 \text { Erosion Models } & 27\end{array}$

2.5.1 Single Particle Erosion 27

2.5.2 Multiple Particle Erosion $\quad 29$ 
3 Theory of LS-DYNA3D 31

3.1 Introduction 31

3.2 Governing Equations in LS-DYNA3D 32

3.3 Solid Element $\quad 35$

\begin{tabular}{ll}
3.4 & Volume Integration \\
\hline
\end{tabular}

3.5 Hourglass Control 40

3.6 Contact-Impact Algorithms 41

3.6.1 Kinematic Constraint Method $\quad 41$

3.6.2 Penalty Method 42

3.6.3 Distributed Parameter Method $\quad 42$

3.7 Time Step Control 43

$\begin{array}{ll}3.8 \text { Time Integration } & 44\end{array}$

3.9 Numerical Analysis $\quad 48$

4. Model Development: Preliminary Conditions 50

4.1 Introduction $\quad 50$

4.2 Material Properties $\quad 51$

4.2.1 Metal Oxide Scales $\quad 52$

4.2.2 Metal/Metal-Oxide Interface $\quad 55$

4.2.3 Particle
-56

$\begin{array}{lr}4.3 \text { Assumptions } & 59\end{array}$

5. Model Development: Finite Element Analysis $\quad 60$ 
$\begin{array}{ll}\text { 5.1 Introduction } & 60\end{array}$

$\begin{array}{ll}\text { 5.2 Mesh Generation } & 60\end{array}$

$\begin{array}{ll}\text { 5.3 Material Models } & 61\end{array}$

5.4 Initial and Boundary Conditions $\quad 65$

$\begin{array}{ll}\text { 5.5 Model Solution } & 66\end{array}$

$\begin{array}{ll}\text { 5.6 Post Processing } & 67\end{array}$

$\begin{array}{ll}\text { 5.7 Erosion Loss Estimation } & 68\end{array}$

6. Results and Discussions 73

$\begin{array}{ll}\text { 6.1 Introduction } & 73\end{array}$

6.2 Aluminum Oxide Model 74

6.3 Iron/Iron Oxide Model $\quad 81$

6.3.1 Influence of Size $\quad 83$

6.3.2 Effect of Velocity on Erosion Mechanism 84

6.3.3 Effect of Impact Angle $\quad 85$

$\begin{array}{ll}\text { 7. Conclusions and Recommendations } & 102\end{array}$

$\begin{array}{lr}7.1 \text { Conclusions } & 102\end{array}$

$\begin{array}{lc}\text { 7.2 Future Recommendations. } & 103\end{array}$

$\begin{array}{ll}\text { Bibliography } & 105\end{array}$

$\begin{array}{ll}\text { Appendix A } & 111\end{array}$

$\begin{array}{lr}\text { Appendix B } & 120\end{array}$

$\begin{array}{ll}\text { Approval of the Examining Committee } & 121\end{array}$ 


\section{LIST OF FIGURES}

Figure

Page

2.1 Erosion Corrosion Regimes

2.2 Different Regimes of Erosion-Corrosion as Corrosive Aggressiveness

Vs Erosive Aggressiveness.

2.3 Sequence of Ductile Erosion.

4.1 Different Types of Impact Damages

5.1 Iron/Iron-Oxide System

62

5.2 Stress-Strain Plot of Elastic-Plastic Material Type

64

5.3 Views of Iron/Iron-Oxide System

66

5.4 A Graph from GLSTAT File, Energies Vs Time

5.5 A Graph from MATSUM File, Energies of Particle and Oxide Scales Vs Time

5.6 Effective Stress Vs Element Numbers

6.1 Aluminum/Aluminum Oxide System

6.2 Volume loss Vs Size of Particle Impacting at Normal Incidence with $50 \mathrm{~m} / \mathrm{s}$ Velocity

6.3 The Stress Contour of Aluminum Oxide Model

6.4 The effect of particle size effects on volume loss through contour plots

6.5 Iron/Iron-Oxide System

6.6 Comparison of Size Effects at 743 and $674^{\circ} \mathrm{C}$

6.7 Stress Contours for Particle Impact at $674^{\circ} \mathrm{C}$ 
6.8 Stress Contours for Particle Impact at $674^{\circ} \mathrm{C}$

6.9 Stress Contours for Particle Impact at $743^{\circ} \mathrm{C}$

6.10 Stress Contours for Particle Impact at $674^{\circ} \mathrm{C}$

6.11 Volume Loss Vs Velocity for $100 \mu \mathrm{m}$ Impacting Particle 92

6.12 Volume Loss Vs Angle of Attack for $100 \mu$ m Particle 93

6.13 Sequence of Steps of Particle Impact onto Target Surface at $50 \mathrm{~m} / \mathrm{s}$

6.14 Sequence of Steps of Particle Impact onto Target Surface at $50 \mathrm{~m} / \mathrm{s}$

6.15 Volume Loss Vs Velocity for $100 \mu \mathrm{m}$ Particle

96

6.16 Volume Loss Vs Angle of Attack for $100 \mu \mathrm{m}$

97

6.17 Volume Loss Vs Velocity for $100 \mu \mathrm{m}$ Particle

98

6.18 Volume Loss Vs Velocity for $100 \mu \mathrm{m}$ Particle

99

6.19 Comparison of Velocity Effects at Three Different Temperatures

100

6.20 Comparison of Effects of Angle of Attack at Three Different Temperatures

101 


\section{LIST OF TABLES}

Table

Page

6.1 Material Properties of the Aluminum Oxide model

75

6.2 Material Properties of Silicon Carbide Particles Required Dyna input Format 75

6.3 Mechanical Properties of Iron Oxide and the Iron Substrate at Different

$\begin{array}{lr}\text { Temperatures } & 82\end{array}$ 


\section{CHAPTER 1}

\section{INTRODUCTION}

Erosion and corrosion are important material degradation mechanisms encountered in many engineering systems. Erosion is a complex phenomenon involving not only material deformation but also its fracture. The degradation of rocks lying on the seashore is a typical example of pure erosion. While erosion happens to be a physical phenomenon, corrosion is a chemical one in which, metals or alloys when subjected to elevated temperatures or exposed to various environments undergo oxidization. The damage caused by the combined effect of both erosion and corrosion can be enormous and catastrophic.

The erosion of materials by surface impact of hard particles is one of several forms of material degradation classified as wear and also known as solid particle erosion. Erosion and corrosion are serious problems in many industrial operations such as thermal power plants, aircraft gas turbine engines, pneumatic bulk transport systems, coal liquification or gasification plants, ore or coal slurry pipe lines. These systems may work at high temperatures and involve the transport of solids in liquids or gases. But this damage is more predominant in gaseous medium than in liquid medium. In some situations erosion is a useful application as a cutting process. Basically, the material removal processes in erosion are similar to that of grinding or single tool cutting. An individual tool or particle displacing or fracturing the work surface removes material. The erosion prone joints, corners, and attachment of components in machinery and other devices impart severe life limitations due to the progression of wear. As such, material 
loss determination becomes very important in predicting the failure of the component parts.

Components operating at high temperatures are frequently subjected to stresses generated by thermal cycling or externally applied tensile loads. Combustion generates most of the high temperature applications, and the component is protected from the environment by a surface oxide scale. These scales are ceramic materials and do not have the ductility of the underlying metallic component. If they should crack under applied loading or by particle impact, then the environment will have direct contact with the metallic component that will cause enhanced corrosion. Hence, the manner of failure is also very important.

The eroded material is commonly given as a function of the impacting particle velocity as well as particle diameter. It is also termed as mass or material removed per unit mass of the impacting particle. It is given by the equation: [1]

$$
\mathrm{W}=\mathrm{K} \mathrm{V}{ }^{\mathrm{a}} \mathrm{D}^{\mathrm{b}}
$$

Where $\quad \mathrm{W}=$ erosion wear per impacting particle,

$\mathrm{V}=$ impacting particle velocity,

$\mathrm{D}=$ impacting particle diameter, and $\mathrm{a}$ and $\mathrm{b}$ are constants.

The velocity exponent generally depends on the material and the erosion conditions and is in the range of 2.3 to 2.9 . The exponent values are different for ductile and brittle materials therefore the phenomena by which they erode is also different. In a ductile 
material, large plastic strains precede fracture and material is removed by the displacement action of the cutting tool or impacting particle. By contrast, in an ideally brittle material plastic deformation is not present, and the material is removed by the propagation and intersection of cracks ahead of and around the cutting tool or impacting particle.

The properties and structures of the most commonly used metals or alloys have relatively small effects on their erosion resistance [2]. There are various parameters that influence the erosion-corrosion process. They are erodent velocity, mass of erodent, temperature of the system, mechanical properties of the erodent and the target, angle of attack of the erodent, impact duration, shape of the erodent and its size. These parameters have different effects on ductile and brittle materials.

The velocity of the erodent has direct impact on the erosion rate. High momentum and kinetic energy are associated with the high velocity erodents, consequently they have the potential to cause more degradation to the impacting surface. The impact duration is a function of the velocity of the erodent. The mass of the erodent also effects in the same manner, the more the mass the more the erosion rate.

The temperature and the environment are major parameters that affect the oxidation. The target surface becomes soft and ductile at elevated temperatures, which facilitates the betterment of fracture properties and also Young's Modulus is a function of temperatures.

The elastic impact and the duration of the impact develops impulsive force is a function of mechanical properties such as modulus of elasticity, bulk modulus, Poisson ratio etc. of both the erodent and target. The failure mode due to impact is decided on the 
basis of material behavior, such as brittle and ductile of the oxide scale as well as the metal substrate.

The effect of angle of attack of the erodent is different for ductile and brittle materials. In brittle materials, the erosion loss is more at normal incidence where as in the ductile materials maximum loss is at shallow angles. During impact the normal and the shear stresses are induced on the surface.

Numerous experiments have been conducted to get many empirical relations for predicting material loss during erosion. Arrival of many new materials and surface coatings being used for different applications demand analytical models that are more generic in applying and predicting the volume loss due to erosion. Hence the current work is focused on finite element modeling of Iron/Iron Oxide which takes into account appropriate loading and various boundary conditions for predicting material loss due to erosion. The same procedure can be adopted in calculating erosion loss for various metal oxides and various erodent particle shapes, velocities and angle of attack.

Chapter 2 deals with the literature review explain the process of erosion and corrosion. It also explains the theorems and empirical formulae dealing with the brittle and ductile materials. An in-depth review of the parameters affecting erosion is also a part of chapter 2.

Theory of LS-DYNA3D software is described in chapter 3. Initial sections explain the preliminaries and the equations that support LS-DYNA3D. The later sections deal with the solid elements, hour glassing, contacts, material models and time integration. 
Methodology used to develop the model is given in chapter 4. The mechanical properties of the oxide scale, particle, the metal substrate and the behavior of the metal/metal-oxide are described. The major assumptions involved in the modeling of the system are listed.

Chapter 5, which deals with finite element modeling, explains, clearly, the different steps involved in the analysis of solid particle erosion. At the end of the chapter, the procedure used in calculating the erosion loss due to impact is explained.

The size effects of the impacting particle on erosion loss are explained in the results. The chapter 6 also has the results due to impact of the various velocities, different temperatures and the angle of attack.

Finally, the conclusions drawn out of the result section are presented in chapter 7. The recommendations for the future work were discussed at the end of the chapter. 


\section{CHAPTER 2 \\ LITERATURE REVIEW}

To understand erosion and corrosion it is often convenient to separate materials into two categories: ductile and brittle. In a ductile materials large plastic strains precede fracture, where as in brittle materials no plastic deformation is present and the material is removed by the propagation of cracks ahead of particle impact. Oxide scales on metallic components are examples of brittle materials. There have been several experimental and laboratory studies of erosion-corrosion to explain their affect on ductile and brittle materials. The similarities and differences between those theories and mechanisms are discussed in this chapter.

\subsection{Classification of Erosion - Corrosion Process}

Metals and alloys designed for machines at elevated temperatures have microstructures and chemistries optimized to provide strength and resistance to oxidation. The majority of the commercial high temperature metals or alloys intended to use at temperatures below $850^{\circ} \mathrm{C}$ or so rely on the formation of a continuous surface layer of essentially oxide scale for further oxidation resistance. This oxide scale is slow growing and reasonably adherent to the alloy. Depending on the intended use of the temperature, and to some extent on the chemistry of the metal, minimum levels of oxide scale have been expected in order that can form a continuous protective external oxide layer. In the simplest terms, erosion-corrosion phenomenon can be separated into two regimes pure erosion or pure corrosion. Erosion of metallic surfaces at room temperature can be 
characterize as pure erosion where material degradation is dominated by highly erosive conditions for very low corrosion rates. Where as at high corrosion rates and mild erosion conditions, corrosion dominates and is termed as pure corrosion. In 1987 Kang et al. [3] described the response of erosion-corrosion of material in terms of four regimes. These include

\section{Pure Erosion}

\section{Erosion Enhanced Oxidation}

\section{Oxidation affected Erosion}

\section{Pure Corrosion}

The erosion at low temperatures or in inert gas medium is pure erosion. The oxide growth rate is comparable with the erosion rate in pure erosion. In this regime oxide can grow into a continuous and protective scale, and the damage caused by the particle impact is confined to the oxide scale. Further a study state can be reached where the rate of oxide formation approaches the rate of oxide loss, and the thickness of oxide remains constant. In the third regime, oxidation affected erosion, the damage caused by the particle impact extends not only to the thickness of the oxide scale but also to the metal substrate. The substrate is plastically deformed and a significant amount of erodent fragments are embedded in the metal substrate forming a composite of embedded particles, oxide scale and extruded metal.

Similar to the proposal of Kang et al., in an another model Hogmark et al. [4] identified six different regimes of material removal depending on the relative aggressiveness of the corrosive and erosive atmospheres. They divided the region of combined effect into four distinguishable regimes. The defined six regimes are 


\section{Pure Corrosion}

\section{Erosion Affected Corrosion}

3. Erosion of Corrosive film without flaking

4. Flaking of Corrosive film at individual impacts

5. Simultaneous Erosion of Corrosive layer and metallic substrate.

\section{Pure Erosion}

Hogmark et al. considered flaking or spallation of the oxide scale to play major role in material degradation. In the second regime, erosion affected corrosion, the material is removed by corrosive flaking from the metal substrate influenced by a relative mild erosion which induces additional internal stresses in the scale. In the regime, erosion of the corrosive film without flaking, material removal occurs by erosion of corrosive layer, which can behave in brittle or ductile manner. In this regime no material loss would have occurred without erosion. In the fourth regime, corrosion/erosion process was balanced and the local flaking of the corrosive film at individual impacts was observed. The rate of material removal is found highly sensitive to adhesion and the brittleness of the layer when compared to the pure erosion or pure corrosion of the base material. In the fifth one, erosion dominates and impinging particle penetrates into the substrate to detach oxide scale as well as metallic fragments. Pure erosion in principle, should be restricted to conditions of zero corrosion rate but in practice, slightly corroded layer is also taken into consideration. If the oxide adhesion is poor, an increase in the material degradation rate or spallation can be expected for the erosion-corrosive conditions of four and five regimes. 


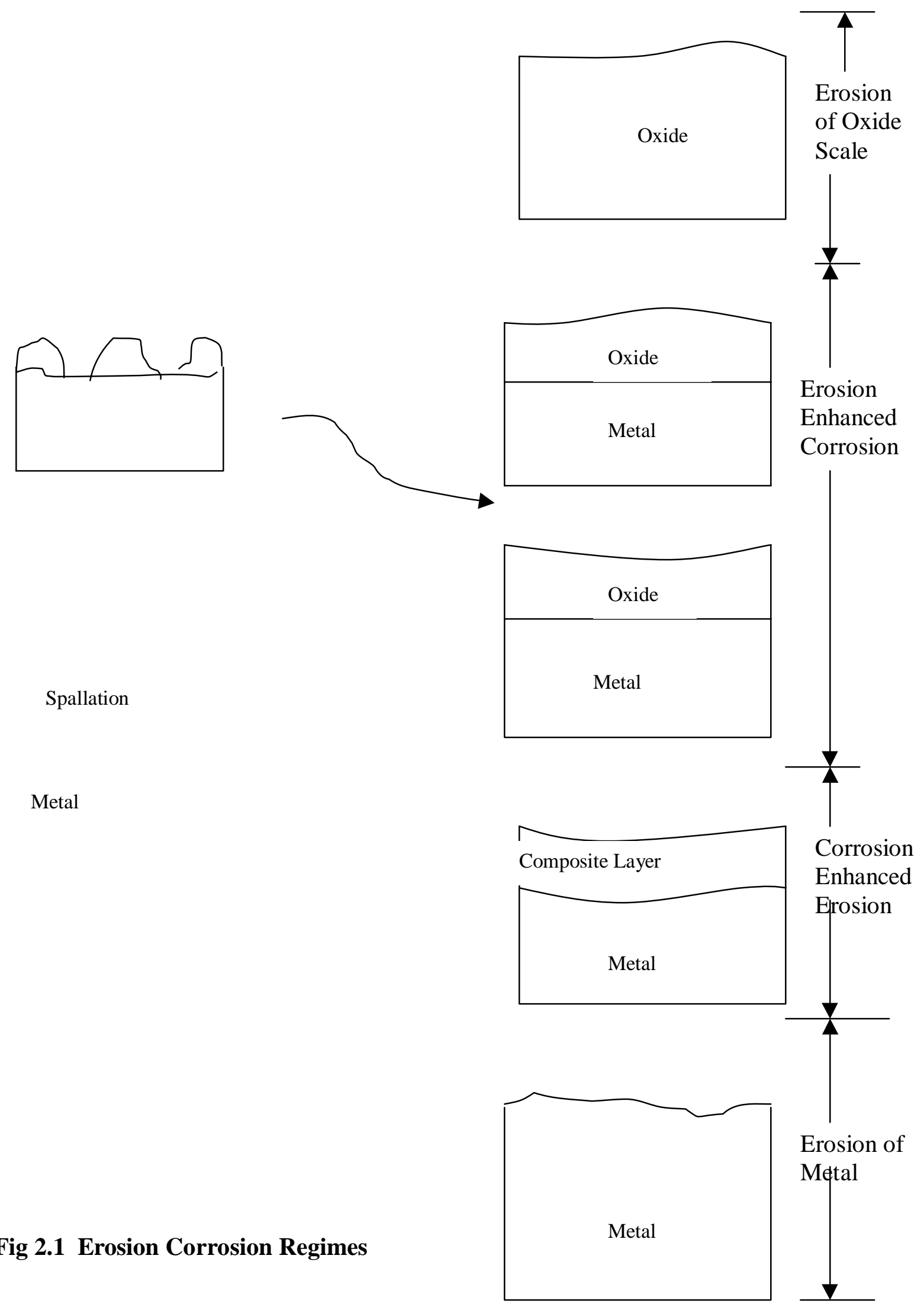




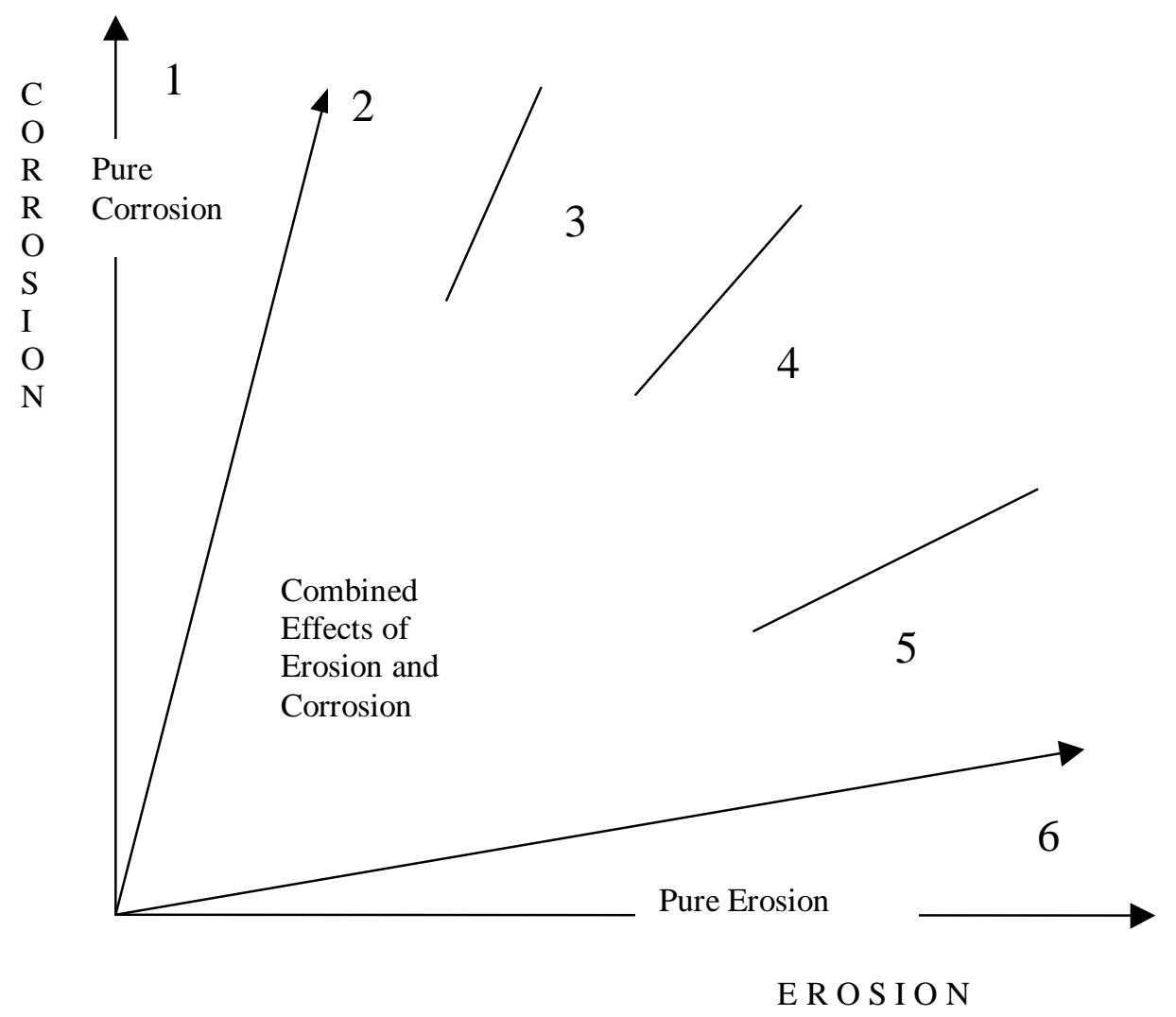

Fig. 2.2 Different Regimes of Erosion-Corrosion as Corrosive Aggressiveness Vs Erosive Aggressiveness [4]. 
While all these experimental and laboratory studies contribute to an understanding of combined affect of erosion and corrosion, there is still a need to correlate the various regimes since the boundaries of these regimes are not well defined. This is especially the case for spalling of oxide which should be a subdivision of erosion enhanced oxidation regime.

\subsection{Spallation Mechanism}

Spallation is highly detrimental to the erosion-corrosion process, as such understanding its mechanism is very important. Simple mechanisms, which may account for spalling are related to the immediate physical and mechanical effects of the impacting particles. These mechanisms are dependent upon how deep the impacting particle penetrates into the scale and through the metal substrate. The stream of erosive particles impacting on the specimen surface forms the simple model of spalling.

Evans et al. [5] analyzed and quantified the modes of coating failure by assembling the basic information regarding residual stresses, failure mechanics, and mechanical properties of the coatings, and found that it is dependent on the stress state of the coating. The residual stresses developed during film formation and upon subsequent changes in temperature will tend to induce film fracture normal to the interface whereas residual compressive stresses provide a driving force for scale and eventual spallation. The prerequisite for this analysis is the presence of an interface separation prior to buckling of the scale. Such separation may occur by localized void coalescence. 
Single-impact technique, was used by Stephenson et al. [6] to investigate the particle surface interactions during the erosion of a typical turbine blade material by pyrolytic carbon particles. Though substantial damage to the oxide layer was observed at $700^{\circ} \mathrm{C}$, due the particle impact, there was no deformation caused to the alloy substrate. The occurrence of limited plastic deformation of the oxide scale is attributed to the low temperature. At $850^{\circ} \mathrm{C}$ a decrease in alloy hardness resulted in some target deformation. In addition the thin oxide surface formed was more plastic at $850^{\circ} \mathrm{C}$ than at $700^{\circ} \mathrm{C}$ and could thus, generally accommodate deformation resulting in limited oxide removal. Thicker scales were formed at $950^{\circ} \mathrm{C}$ and the situation gave rise to fracture of oxide and extensive scale removal. The thicker oxide scales and hard alumina internal oxidation zone prevent any substrate deformation.

Levy et al. [7] interpreted that spalling' phenomenon was a result of the hot pressing action caused by the force of erodent particle striking the surface. Internal stresses are thus formed as a result of thermal and mechanical gradients, that are of sufficient magnitude to cause microscopic spalling when combined with the stresses caused by the impacting particles. The scales that are removed by this phenomenon are larger than those removed by cracking and chipping.

Van der Zwaag et al. [8] used a finite element program to examine the effect of thin rigid coatings on the stress field generated by the spherical indentation on the flat half space. It was shown that a stiff coating reduced radial displacements (a body element displaced in the radial direction away from the point of contact) at the coating substrate interface and thus, the radial stresses in the substrate. However, for the coating parameters studied, the maximum shear stress at the coating-substrate interface was more 
than doubled. This is an important point, since coating de-bonding may result if the interfacial shear stress is of sufficient magnitude. This critical condition of de-bonding is also dependent on the magnitude of the pre-existing stresses at the interface. They also showed that the maximum shear stress is weakly dependent on the coating thickness but reaches a maximum value for a coating thickness of about $10 \%$ of the indentor contact radius. Also for very thin coatings, the region of high shear stress is localized around the contact edge, whereas for thicker coatings, the high stresses are generated over much larger areas.

\subsection{Erosion Mechanism}

Small particle impact erosion of materials occurs by the removal of material from a surface by a micromechanical deformation or fracture process. Solid particle erosion occurs on exposed components in many different types of equipments. It occurs by itself or in conjunction with other surface degrading mechanisms such as abrasion or aqueous or elevated temperature corrosion. Erosion mechanisms are different for ductile and brittle materials.

\subsubsection{Erosion Mechanism of Ductile Material}

On ductile materials, the impacting material cause severe, localized plastic strain to occur that eventually exceeds the strain to failure of the deformed material. These deformations are produced by loss of kinetic energy and by work during the impact by external forces on the particle. 
Finnie [9] experimentally showed that the manner of material removal varies with the direction and the velocity of erodent particles and predicted the velocity exponent as $n=2$. . Assuming the constant values of depth of cut and the ratio of vertical force component on the particle face to the horizontal force component, Finnie derived an expression for material removal, as given by the equations below

$$
\begin{array}{ll}
\mathrm{Q}=\left(\mathrm{M} \mathrm{V}^{2} / 8 \mathrm{p}\right)\left[\sin 2 \propto-3 \sin ^{2} \propto\right] & \propto<18.5 \\
\mathrm{Q}=\left(\mathrm{M} \mathrm{V}^{2} / 24 \mathrm{p}\right) \cos ^{2} \propto & \propto>18.5
\end{array}
$$

The two expressions worked well in finding the erosion rate for angles below $45^{\circ}$. However for angles above $45^{\circ}$, the equations estimated a lower volume loss with a zero loss at normal incidence.

The phenomenon of volume loss at angles above $45^{\circ}$, which were not explained by the Finnie's equations, was better accounted by Bitter [10]. Depending on the angle of impact he explained erosion as cutting wear, deformation wear and as the combination of the two. For ductile materials at low angles, the cutting wear predominates, while at acute angle deformation wear predominates. Later Nelson et al., [11] simplified the expressions that gave a good fit to the experimental data.

Unlike the previous theories Sheldon et al. [2] in 1972 gave the velocity exponent as 3 and showed that the results matched closely with the experimental work. He used indentation theory and energy balance equation to explain the deformation and machining action. He also showed that material removal action has the same characteristics as multiple-particle erosion of surface by particles larger than $100 \mu \mathrm{m}$.

Hutchings et al. [12] in 1974 explained the material removal mechanism of aluminum surface impacted obliquely by $3 \mathrm{~mm}$ steel ball at velocities up to $250 \mathrm{~m} / \mathrm{s}$. They 
showed the formation of overhanging lip in the direction of motion of the projectile and removed subsequently. They also showed that material is more readily removed from work hardened copper than from annealed copper. The deformation is concentrated in the surface layers aiding the formation of fragile lip for the work hardened, whereas in annealed metal the impact energy is spread through a large volume. In one of his theoretical studies in 1981, Hutchings [13] proposed the erosion of metals by spheres at normal incidence employing critical plastic strain as the failure criterion. $\mathrm{He}$ incorporated two material strength properties: dynamic hardness and ductility, the high values of which are needed for good resistance to erosion and also predicted a velocity exponent of 3.0.

In 1981 Bellman et al. [14] observed the formation of three distinct types of craters; indentation, ploughing and smear craters on the stress free surface, due the impact of the particles. Depending on the impingement angles, the frequency of occurrence of these craters varies. The author provided experimental evidence to show that the material removal during erosion involves the deformation of surface material into platelets by repeated impacts, that eventually detaches from the metal surface.

In 1983 Rao et al. [15] investigated the influence of exposure time on volume loss rate and found a direct relation between erosion versus time curves and pit morphology (width, depth, and width-depth ratio) for both of glass erodents. Through analysis they showed four types of erosion rate versus time curves, owing to the different combinations of incubation, acceleration/deceleration, and steady state periods. The same year Levy [16] studied the erosion mechanism of both brittle and ductile materials and found that the behavior to be completely different. He explained the ductile erosion 
Initial Condition

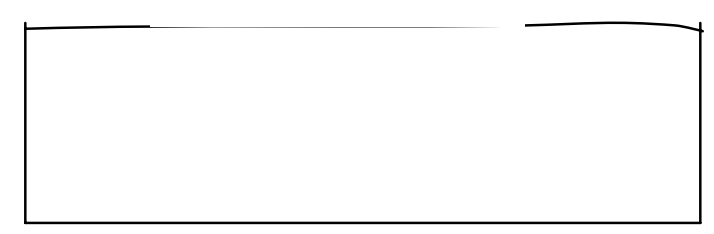

First Impact

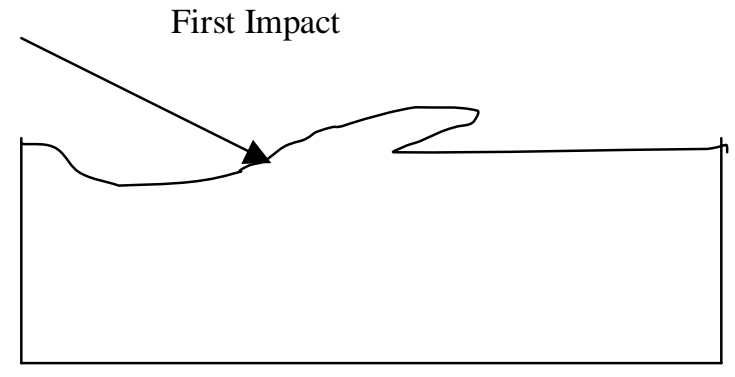

Second Impact
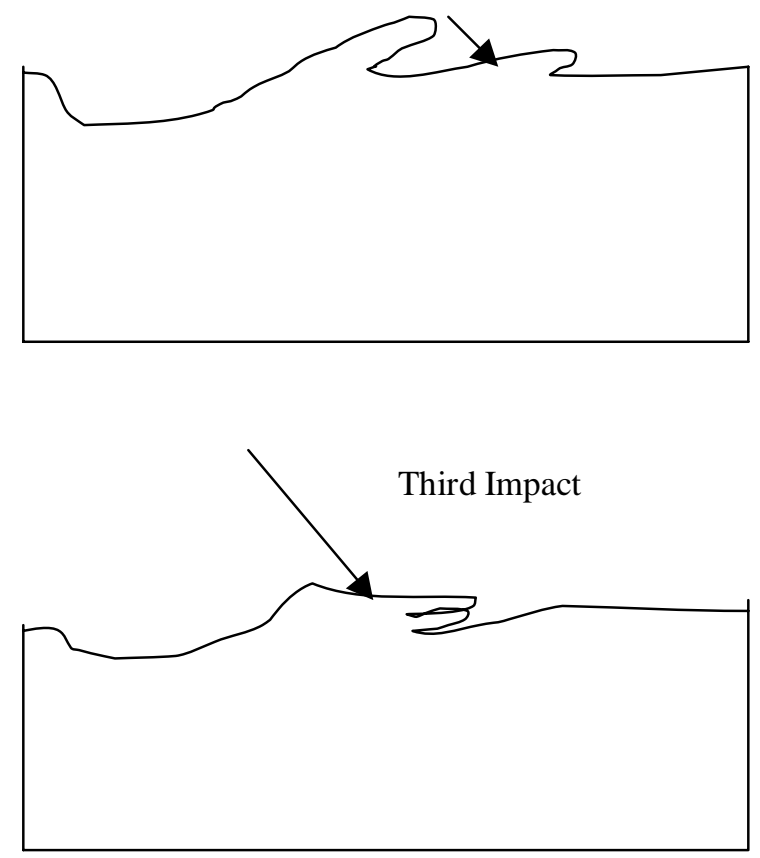

Fig2.3. Sequence of Ductile Erosion [19]. 
mechanism in the same manner as that of Bellman et al., in 1981. In 1986, Hutchings et al. [17] considered that during high velocity impact, the surface temperature increases, that leads to the softening of near surface region, and a work hardened material beneath acts as an anvil against which the softer material is deformed. They estimated the temperature rise and considered published evidence for and against softening and concluded that it was not necessary to postulate a thermal softened surface layer as an essential feature of erosion mechanism under all conditions.

In 1994 Shimizu et al. [18] performed various tests on austempered ductile iron (ADI), ferritic ductile iron (FDI), and pearlitic ductile iron, to observe the mechanism of erosive wear and concluded that ADI has excellent erosion resistance. In 1995 Levy [19] made an effort to combine all his experimental and theoretical results correlating with other theories in a book. He explained the erosion mechanism in ductile metals as a series of operations resulting in the formation of platelets and craters. Initial impacts produce platelets without material loss. Adiabatic shear heating occurs on the impacted surface causing the formation of work hardened zone, beneath its surface, which acts as an anvil increasing the efficiency of the hammer like impacting particles. When the anvil is fully in place and the platelets are fully formed, maximum, steady state, material removal condition occurs.

\subsubsection{Erosion Mechanism of Brittle Materials}

The majority of current and potential applications of brittle materials in mechanical components are either through the use of composite materials or in 
conjunction with the relatively higher ductility materials to form bimaterial and multimaterial components with joints. Brittle material erosion is due to the crack formation in the surface and the resultant chipping of the material [20]. The material is removed by the intersection of the crack, which radiate out from the point of impact of the eroding particle. Many engineering materials such as glass, iron oxide, nickel oxide aluminum oxide, etc. fall in this category.

In 1960, Finnie [21] conducted several experiments at a variety of velocities with an elastic sphere impacting perpendicularly onto a brittle material like glass, which remains elastic until fracture occurs. He proposed the equations for maximum radial stress, which included the influence of the elastic modulus and poisson's ratio of the surface, and the density, velocity, poisson's ratio, modulus of elasticity of the impacting sphere. He also showed that the maximum tensile stress occurs at the surface in the radial direction around the periphery of the contacted area. He observed an expected ring crack in glass, formed at right angles to the maximum tensile stress (around the circumference of the contact area). The cone shaped fracture surfaces intersected with the ring cracks, with an increasing number of impacts and the material was removed.

Sheldon et al. [22] in 1966 extended the classical Hertz equations for static loading of a continuous plane surface by a sphere to impact conditions and assumed that erosion occurs as a result of a contact stress. They proposed an equation that enabled the dependence of material removal in erosion on the radius and velocity of the impacting particle, through bending tests. They included constants $\mathrm{m}$ and $\sigma$ in the equation to calculate erosion rate $\mathrm{W}$, shown as 


$$
\mathrm{W}=\mathrm{K}_{1} \mathrm{r}^{\mathrm{a}} \mathrm{V}_{\mathrm{o}}^{\mathrm{b}}
$$

Where $\mathrm{r}$ the radius and $\mathrm{V}_{\mathrm{o}}$ the velocity of the impacting particle, and exponents $\mathrm{a}$ and $\mathrm{b}$ are given by

b is velocity exponent 2 or 3 depending on the shape of the particle

$$
\begin{array}{ll}
\mathrm{a}=3(\mathrm{~m}-0.67) /(\mathrm{m}-2) & \text { for round particles. } \\
\mathrm{a}=3.6(\mathrm{~m}-0.67) /(\mathrm{m}-2) & \text { for angular particles. } \\
\mathrm{a}=2.1(\mathrm{~m}-0.67) /(\mathrm{m}-2) & \text { for either shapes. }
\end{array}
$$

For particles much stiffer than the target, the constant $\mathrm{K}_{1}$ is given by:

$$
\mathrm{K}_{1}=\mathrm{E}^{0.8(\mu+1) /(\mu-2)} \rho^{1.2(\mu-0.67) /(\mu-2)} \sigma^{-2.0 /(\mu-2)}
$$

Where $\quad E$ is modulus of elasticity of the target

$\rho$ is the density of the particle

$\mathrm{m}$ is the mass of the particle.

These predicted equations were compared with numerous tests on a variety of brittle materials and found to be applicable over a wide range of particle sizes and velocities. In another study [22], authors observed plastic deformations in indentation, scratching and microcutting on the brittle surface when the loaded region is sufficiently small, which is erosion mechanism of ductile materials. They found silica glass and hardened steel to behave as typical ductile materials when eroded by silicon carbide particle, and aluminum showed very little evidence of ductile behavior. 
According to Zambelli et al, [23] $\mathrm{NiO}$ scales formed at higher temperature consisted of two distinct layers, a columnar outer layer and a fine-grained inner layer, which have different erosion mechanism and rate of erosion. Using fracture propagation concepts they proposed a two-step erosion mechanism. Plastic flow indentation and lateral crack growth in the columnar outer layer as the first step, and subsequent formation of pits from Hertzian cone fractures in the inner layer as the second step. The microstructure, mechanical properties and the bonding state of the oxide layers were found to be important parameters in the erosion behavior of the oxide scales.

In later years, Mehrothra et al. [24] found that material removal proceeds initially by the interaction of cone cracks followed by chipping. Sharp and angular particles generally produce radial cracks, which lie perpendicular to the surface and are semicircular in shape. These cracks were formed during loading. Upon unloading, the stresses generated by the plastically compressed zone cause the formation of lateral vent cracks approximately parallel to the surface. These stresses initiated beneath the indentation travels upward to the surface, resulting in material removal from the surface.

Hockey et al. [25], in 1978, used transmission electron microscope to observe the dislocation structures beneath impact craters in magnesium oxide and aluminum oxide. They observed dislocation densities in all cases, although the relative extents of dislocation damage and crack propagation compared with indentation size varied with the material. In the same year, Evans et al. [26] explained erosion in terms of experimental crack behavior during single particle impact events, taking into account lateral crack formation during erosion. The erosion model developed by Evans et al., assumes that the 
erosion rate is proportional to the amount of material removed by each impact. The volume lost per impact is proportional to the product given by

$$
\mathrm{V}_{\mathrm{o}}{ }^{19 / 6} \mathrm{r}^{11 / 3} \rho^{19 / 12} \mathrm{~K}_{\mathrm{c}}^{-4 / 3} \mathrm{H}^{-1 / 4}
$$

The elastic-plastic theory used by Wiederhorn et al. [27] in 1979 assumed that the lateral crack size to be proportional to the radial crack size, and that the depth of the lateral cracks be proportional to the maximum particle penetration. The volume loss predicted by them, is proportional to the product given by

$$
\mathrm{V} \propto \mathrm{V}_{\mathrm{o}}{ }^{22 / 9} \mathrm{r}^{11 / 3} \rho^{11 / 9} \mathrm{~K}_{\mathrm{c}}{ }^{-4 / 3} \mathrm{H}^{1 / 9}
$$

Where $\quad \mathrm{V}$ is volume lost per particle impact.

$\mathrm{V}_{\mathrm{o}}$ is the particle velocity.

$r$ is the radius of the particle.

$\rho$ is the density of the particle.

$\mathrm{K}_{\mathrm{c}}$ is the material toughness.

$\mathrm{H}$ is the material hardness.

Wada and Wantanabe [28] in 1987, through their experiments on brittle materials at constant $80^{\circ}$ impact angle, found that the particle-hardness to target-hardness ratio much greater than unity results in extensive target erosion. When the particles were 
softer than the target, significant erosion was seen only when the target fracture toughness was small.

Levy [19] investigated duplex nickel oxide scale and found that they erode sequentially down their thickness by cracking and chipping mechanism rather than being knocked off the metal in pieces at the scale metal interface. He observed that the harder, denser, columnar grain outer scale protected the inner porous, equiaxed scale from erosion as long as it was present.

\subsection{Parameters that Influence Erosion}

The various parameters that influence the erosion process are listed below [1]

- Mechanical properties of the erodent and the target.

- Temperature

- Exposed environment

- Erodent size

- Erodent velocity

- Angle of incidence

- Shape of the erodent.

The mechanical properties of metals are highly dependent on the temperature for large temperature ranges. The modulus of elasticity of metals decreases as the temperature increases and vice versa. Elevated temperature values of elastic modulus of 
metals may be determined by tensile testing at the designated test temperatures. The mechanical properties are discussed in detail in later sections.

The temperature and the environment to which metal is exposed are major factors that affect the oxidation process. The oxide scales formed at high temperatures have fewer imperfections, which facilitates the betterment of the fracture properties of the oxide.

In 1976, Golightly et al. [29] observed the behavior of iron alloys with and without the presence of $0.82 \%$ yttrium in 1 atm oxygen at $1200^{\circ} \mathrm{C}$. He found a lateral growth of oxide, resulting from the formation of oxide within the oxide layer leading to the detachment from the alloy at temperatures and extensive spalling during cooling, on the yttrium free alloy. Additions of yttrium hindered the formation of oxide with in the oxide layer and prevented the detachment and spall. Young et al., [30] reported the different effects on oxide formation at different temperatures. They showed the large increase in erosion of steel when the temperature raised from $25^{\circ}$ to $975^{\circ} \mathrm{C}$. In a study on the effect of temperature on the erosion, Levy [19], observed one order of magnitude difference in erosion rates between $480^{\circ} \mathrm{C}$ and $978^{\circ} \mathrm{C}$. At temperatures above $875^{\circ} \mathrm{C}$ formation of sulfides were observed, that subverts the physical integrity of the scale. In extreme cases damage is further intensified by the formation of liquid phases (metal-sulfide eutectics), that leads to complete destruction by alloy melt down. Hockey et al. [31] measured the erosion rate of glass and aluminum oxide as a function of temperature and impingement angle using silicon carbide particle as an erodent and also demonstrated the occurrence of plastic flow processes during brittle material erosion.

The size of the particle has little effect on the erosion rate of ductile material but is directly proportional to erosion rate of brittle material until a limiting value, which in 
most cases is $200 \mu \mathrm{m}$. Goodwin et al. [32] in 1969 observed the increase in erosion with increasing particle size up to a limiting size of $100 \mu \mathrm{m}$, above which the volume loss was found to be constant. This critical particle size (dp) above which erosion is not influenced by size appears to be increasing linearly with velocity. Compared to the particle shape and hardness, Levy [33] in 1989 observed a significant effect of the particle size on wear rate. The effect of particle sizes above $200 \mu \mathrm{m}$ and up to about $500 \mu \mathrm{m}$ remains essentially constant. Based on the microscopic studies on the particle tracks, he observed that they traverse along the metal or scale for distances from a few microns up to $200 \mu \mathrm{m}$ at most at a singular relationship with the surface. A computational model of oxide layer was developed by Veluswamy et al., [34] in 1995. They showed the relationship between volume loss to the erodent size ranging from $20 \mu \mathrm{m}$ to $200 \mu \mathrm{m}$.

Mills et al. [35] studied the wear rate in tube bends due to the conveying of abrasive sand. They reported depth of penetration for small particles was much greater than that for large particles. Misra et al. [36] discussed many theories on the effect of particle size on wear rate and concluded that that this was probably due to the actual increase in flow stress with decreasing indentation size. Liebhard et al. [37] found that the erosion rate became constant for silicon carbide particle sizes above $200 \mu \mathrm{m}$ on 1018 steel, but after certain size it continued to increase up to $850 \mu \mathrm{m}$ particle sizes.

Erosion rates are related directly and are proportional to the particle velocity, higher the velocity the greater the erosion. As the velocity increases the initial kinetic energy of the particle increases, that has more potential to degrade the surface than a particle with less velocity. Experiments were conducted to determine the erosion loss per impact with change in velocity, on a various number of materials with about three orders of 
magnitude of velocity. The erosion rate was found to increase as $\mathrm{V}^{2}$ to $\mathrm{V}^{3}$ in most cases. Sheldon et al., [38] showed that for normal impact the erosion rate brittle material is proportional to $\mathrm{V}^{\mathrm{b}}$, and found that the power function of velocity $\mathrm{b}$ was not same. He concluded that tangential forces contribute to the wear of brittle materials. Through a series of tests conducted on 1018 steel for different velocities, Levy [19] found the study state erosion to be constant and related directly to the particle velocity. Even at high velocity of $130 \mathrm{~m} / \mathrm{s}$, the pattern of the incremental erosion rate curve was the same.

In 1995, Veluswamy et al. [34] observed the relationship of the volume loss for two velocity ranges, low velocity range from $1 \mathrm{~m} / \mathrm{s}$ to $20 \mathrm{~m} / \mathrm{s}$ and high velocity range from $10 \mathrm{~m} / \mathrm{s}$ to $100 \mathrm{~m} / \mathrm{s}$ in their two dimensional computational model. Yalamanchili et al., [39] in 1996, developed a three dimensional model using INGRID and LS-DYNA3D, and observed the effect of particle velocity for different shapes of erodents at different temperatures and for different angle of incidence on erosion rate. They found the variation of volume loss with velocity as non linear through out the range from $0 \mathrm{~m} / \mathrm{s}$ to $100 \mathrm{~m} / \mathrm{s}$, also observed the volume loss for velocity ranges from 0 to $50 \mathrm{~m} / \mathrm{s}$ was more at $570^{\circ} \mathrm{C}$ than at $743^{\circ} \mathrm{C}$ and for velocities from 50 to $100 \mathrm{~m} / \mathrm{s}$, the volume loss was much more at temperature $743^{\circ} \mathrm{C}$ than at $570^{\circ} \mathrm{C}$.

Angle of incidence on to the target surface by the impacting particle is another parameter that influences the erosion rate. It effects differently for ductile and brittle materials. For ductile materials the volume loss is more at shallow angles and for brittle materials the loss is more at normal incidence (sometimes referred as angle of attack in some theories). For given erosion model many quantitative procedures were developed to evaluate the relative amounts of brittle and ductile erosion. Sheldon and Finnie [40] 
observed the ductile behavior of nominally brittle materials during erosive cutting. They showed that volume loss was higher at an angle $\alpha$, near normal incidence for brittle materials that decreases with decrease in the angle $\alpha$. By contrast, ductile materials showed maximum volume loss at angles about 20 to 30 degrees. They observed that the silica glass and fully hardened tool steel to behave in a typically ductile material when eroded with the silicon carbide particles, where as a slight change towards ductile behavior showed by magnesia and graphite. On the other hand, high-density aluminum oxide exhibited brittle erosion for all particle sizes and velocities when eroded by 1000 mesh silicon carbide particles. Yalamanchili et al. [39] observed similar relationship between volume loss and angle of attack by the impacting particle on the target surface. They explained that the steep variation of volume loss at angles $40^{\circ}$ and $50^{\circ}$ is due to the effect of both sliding and impact forces.

The shape of the impacting particle also had a greater influence on the erosion rate. The shape determines the contact area between the particle and the target surface during an impact. Numerous experiments were done on the impact of spherical particle on to the target surface, which represents point contact. Sheldon et al. [40] conducted experiments on brittle materials like glass, aluminum oxide and magnesium oxide, impacting them by spherical and angular silicon carbide particles and observed that erosion rate was more in case of angular particles, compared to spherical particles.

In order to investigate the type of impact that occurs in case of erosion by solid particle, Hutchings [41] studied theoretically and experimentally the impact of rigid square plates onto ductile steel targets. He classified them according to the sense of rotation of plate after impact. Depending on the orientation of the plate on impact, he 
observed two different types of damages, cutting a chip from the surface when the plate rotates backward during impact and formation of crater lip that removed by impact of subsequent projectiles when the plate rotates forward during impact. He calculated energy loss, crater volume and rotational energy after impact from the experimental data that were in good agreement with theoretical predictions. In another study, Hutchings et al. [42] used two different types of particles, steel sphere and square steel plates, accelerating them using a compressed gun. These experiments were designed to investigate two classes of surface deformation that occurred at oblique impact angles. They are termed as ploughing deformation, caused by spherical particles and cutting deformation caused by angular particles.

In their three dimensional computational model, Yalamanchili et al. [39] investigated the volume loss for three different types particle shapes, representing line contact, quadrilateral area of contact and point contact. They compared the volume loss of three particle shapes based on the initial kinetic energy and observed that volume loss depends on contact area, the more the contact area, the more the loss of material due to erosion.

\subsection{Erosion Models.}

\subsubsection{Single Particle Erosion.}

Erosive wear of materials in practice generally involves long times of exposure under study state conditions. However, by its nature, solid particle erosion is a discrete, accumulative process and the single impact is worth of as accurate an understanding as possible. Various experimental techniques were used in the past to cause single particles 
to impact on a target surface under controlled conditions and the erosion loss was calculated. Large particles are directly accelerated while the micrometer particles are indirectly accelerated using a carrier on to the target surface.

Sheldon and Kanhere [2] used a gas projectile gun to accelerate individual particles of silicon carbide, steel and glass shot at various velocities from about $130 \mathrm{~m} / \mathrm{s}$ to $400 \mathrm{~m} / \mathrm{s}$ on to both eroded and uneroded surfaces. They noted considerable evidence of deformation adjacent to the crater in annealed material. Observations of the impact craters showed that the displaced crater material appear to have flowed in the direction of the particle incidence until the material fractured at high-accumulated strains. They found a small difference in the velocity dependence of erosion between eroded and uneroded surface. The displaced lip material detached earlier on previously eroded surfaces. Hutchings and Winter [12] studied the erosion process by emphasizing on the geometry and the mechanism of material removal. They impacted large steel sphere (3 $\mathrm{mm}$ ) on to the aluminum surface. They showed that the characteristic deformation pattern resulting from particle impact consisted of a depression and a lip of a displaced material.

Ives et al. [43], did transmission electron microscope studies of the damage associated with particle impact in 1978. They observed zone of high dislocation density typically few micrometers thick around an impact crater. They also found the localization of damage near the craters from the measurements using electron-channeling method. In Further studies Hutchings used a compressed gas gun system to accelerate two shapes of projectiles: steel spheres of $9.5 \mathrm{~mm}$ diameter and $8 \mathrm{~mm}$ square plates onto a target surface. These experiments were designed to investigate two modes of surface 
deformation that occurred at oblique angles. He showed that the erosion efficiency of the angular particles as more compared to round particles. The angular particles either displaces more material into the crater lip when it becomes vulnerable to further erosion or actually detaches material from the target surface.

\subsubsection{Multiple Particle Erosion.}

Technological concern with the erosion of materials usually involves with multiple particle impacts in a study state long term regime. Complex aspects are added to the basic problem, when flux of particles impact a target surface. These include particle impact with in the stream, a wide range of simultaneous attack angles, particle fragmentation, particle embedding and surface shielding due to rebounding particles. Some of these effects also occur in single particle impact. Clearly multiple particle erosion exposures must be conducted in order to measure meaning full erosion rates of materials for application purpose and also to search for new significant effects due to multiple impacts.

Two basic types of design techniques have been used in many experiments on the multiple particle impact erosion. In one, the specimen is moved under controlled velocity through a slowly moving erosive stream. The exposure may be intermittent but can continue for a long period of time. The second one involves exposing a stationary specimen to a stream of particles. In order to confine the erosive stream a nozzle or flight tube is used. Since the erosion rate is proportional to the square or cube of the particle velocity, accurate measurement of impact velocity is necessary in both cases. 
Grant et al., [44] used type I model, moving the specimen under controlled velocity through a slowly moving stream of erosive particles. This design allowed for an accurate measurement of impact velocity since the principal velocity component is that of the specimen. They predicted the erosion loss for impact velocities ranging from $85 \mathrm{~m} / \mathrm{s}$ to $137 \mathrm{~m} / \mathrm{s}$ and angle of attack ranging from $30^{\circ}$ to $60^{\circ}$ for various metals. Hutchings et al. considered erosion model that had spherical particles impacting a target surface at normal incidence. They assumed that the material removal was due to the formation and subsequent removal of the platelets from the material surface and detachment occurs when the plastic strain reaches the maximum value. 


\section{CHAPTER 3}

\section{THEORY OF LS-DYNA3D}

\subsection{Introduction}

The finite element method is a numerical analysis technique for obtaining approximate solutions to a wide variety of engineering problems. Although originally developed to study the stresses in complex airframe structures, it has since been extended and applied to the broad field of continuum mechanics. Because of its diversity and flexibility as an analysis tool, it is receiving much attention in engineering schools and in industry.

LS-DYNA3D is an explicit 3-D finite element program for analyzing the large deformation dynamic response of elastic and inelastic solids and structures. The program is extensively used by (i) aircraft analysis and improved methods for manufacturing aircraft wings, (ii) Analysis of shipping containers for radioactive material (iii) automobile design and crash tests, and (iv) train accident analysis. A wide range of material types and interfaces enable the efficient mathematical modeling of many engineering problems. The explicit time integration algorithms used in LS-DYNA3D [51] are much less sensitive to machine precision than other finite element solution methods.

LS-DYNA3D - dynamics in three dimensions - is a nonlinear structural dynamics code that can analyze the complex structural response of mechanical systems to high-rate loading and impacts. Basically, the program simulates the effect

of stress on structures. Like many other engineering codes, LS-DYNA3D is based on 
finite-element analysis, a method of examining physical systems by breaking them into discrete but interconnected pieces.

LS-DYNA2D and LS-DYNA3D are explicit finite element codes for solving two and three-dimensional nonlinear solid mechanics problems, respectively. LSDYNA3D relies on mesh generators for creation of input files. INGRID [49] is the recommended method of generating LS-DYNA3D input format since it provides complete support for all slide surface data, boundary conditions, loads, material properties and control parameters. The input format can also be generated by HYPERMESH, software developed by ALTAIR Inc. Models can also be generated using I-DEAS software and the file is transferred to LS-DYNA3D input format with the help of IDEADYN (Aida, 1994) translator, developed by department of Mechanical and Aerospace Engineering, West Virgina University.

\subsection{Governing Equations in LS-DYNA [51]}

(The following sections are taken from the LS-DYNA3D theory manual.)

The governing equations of DYNA can be derived from the momentum equation as follows [50].

$$
\sigma_{\mathrm{ij}, \mathrm{j}}+\rho f_{\mathrm{i}}=\rho \ddot{x}_{\mathrm{i}}
$$

satisfying the traction boundary conditions

$$
\sigma_{\mathrm{ij}} n_{\mathrm{i}}=t_{\mathrm{i}}(t)
$$

on boundary $\delta b_{1}$, the displacement boundary conditions 
$x_{\mathrm{i}}\left(X_{\alpha}, t\right)=D_{\mathrm{i}}(\mathrm{t})$

\section{(3.3)}

and on boundary $\delta b_{2}$, the contact discontinuity

$$
\left(\sigma_{\mathrm{ij}}^{+}-\sigma_{\mathrm{ij}}^{-}\right) n_{\mathrm{j}}=0
$$

along and interior boundary $\delta b_{3}$ when $\mathrm{x}_{\mathrm{i}}^{+}=\mathrm{x}_{\mathrm{i}}^{-}$. Here $\sigma_{\mathrm{ij}}$ represents the Cauchy stress, $\rho$ is the density, $f_{\mathrm{i}}$ the body force, $\ddot{x}$ is the acceleration, comma denotes the covariant differentiation and $n_{\mathrm{j}}$ is the unit vector normal to the boundary $\delta b$.

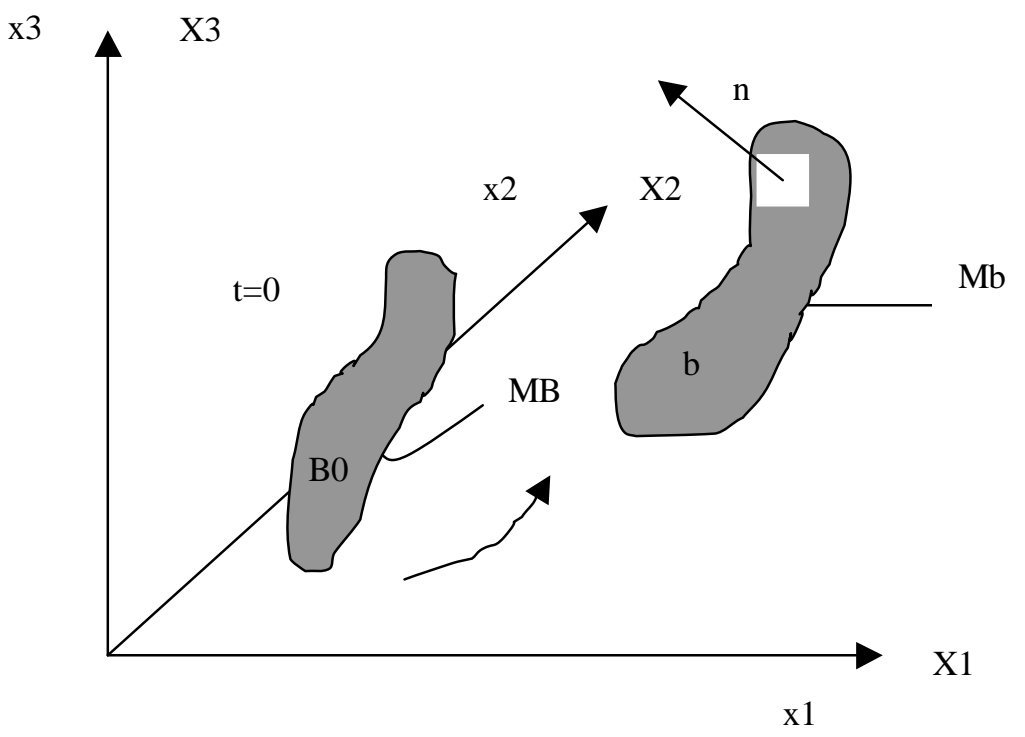

Equations of global energy balance and state evaluations can be obtained by integrating the energy equation in time. The energy equation is given as 


$$
\dot{E}=V s_{\mathrm{ij}} \dot{\varepsilon}_{\mathrm{ij}}-(p+q) \dot{V}
$$

the above equation is integrated in time and used for equation of state evaluation. $s_{\mathrm{ij}}$ is the deviatoric stresses and $p$ represents the pressure. Deviatoric stress is given by

$$
s_{\mathrm{ij}}=\sigma_{\mathrm{ij}}+(p+q) \delta_{\mathrm{ij}}
$$

$q$ is the bulk viscosity, $\delta_{\mathrm{ij}}$ is the Kronecker delta $\left(\delta_{\mathrm{ij}}=1\right.$ if $i=j$; otherwise $\delta_{\mathrm{ij}}=0$, and $\dot{\varepsilon}_{\mathrm{ij}}$ is the strain rate tensor. The weak form for the equilibrium equation when $\delta x_{\mathrm{i}}$ satisfies all boundary conditions on $\delta b_{2}$ and integration over the geometry gives

$$
\int_{V}\left(\rho \ddot{x}_{\mathrm{i}}-\sigma_{\mathrm{ij}, \mathrm{j}}-\rho f_{\mathrm{i}}\right) \delta x_{\mathrm{i}} d v+\int_{\partial b_{1}}\left(\sigma_{\mathrm{ij}} n_{\mathrm{i}}-t_{\mathrm{i}}\right) \delta x_{\mathrm{i}} d s+\int_{\partial b_{3}}\left(\sigma_{\mathrm{ij}}^{+}-\sigma_{\mathrm{ij}}^{-}\right) n_{\mathrm{j}} \delta x_{\mathrm{i}} d s=0
$$

(3.7) and $\left(\sigma_{\mathrm{ij}} \delta x_{\mathrm{i}}\right), j-\sigma_{\mathrm{ij}, \mathrm{j}} \delta x_{\mathrm{i}}=\sigma_{\mathrm{ij}} \delta x_{\mathrm{i}, \mathrm{j}}$ leads to the divergence theorem giving rise to the statement of principle of virtual work

$$
\delta \Pi=\int_{v} \rho \ddot{x}_{\mathrm{i}} \delta x_{\mathrm{i}} d v+\int_{v} \sigma_{\mathrm{ij}, \mathrm{j}} \delta x_{\mathrm{i}} d v-\int_{v} \rho f_{\mathrm{i}} \delta x_{\mathrm{i}} d v-\int_{\partial b_{1}} t_{\mathrm{i}} \delta x_{\mathrm{i}} d s=0
$$

By superimpose a mesh of finite elements interconnected at nodal points on a reference configuration and track particles through time, i.e.,

$$
x_{\mathrm{i}}\left(X_{\alpha}, t\right)=x_{\mathrm{i}}\left(X_{\alpha}(\xi, \eta, \zeta), t\right)=\sum_{j=1}^{k} \phi_{\mathrm{j}}(\xi, \eta, \zeta) x_{i}^{j}(t)
$$

(3.9) where $\phi_{\mathrm{j}}$ are shape (interpolation) functions of the parametric coordinates $(\xi, \eta, \zeta), k$ is the number of nodal points defining the element, and $x_{i}^{j}$ is the nodal coordinate of the $j^{\text {th }}$ node in the $i^{\text {th }}$ direction. 
Summing over the $\mathrm{n}$ elements it is approximated to

$$
\delta \Pi=\sum \delta \Pi \mathrm{m}=0
$$

The matrix notation of the above equation, using 3.8 , is

$$
\sum_{m=1}^{n}\left\{\int_{V_{m}} \rho \mathrm{N}^{\mathrm{t}} \mathrm{N} a d v+\int_{V_{m}} \mathrm{~B}^{\mathrm{t}} \sigma d v-\int_{V_{m}} \rho \mathrm{N}^{\mathrm{t}} b d v-\int_{\partial b_{1}} \mathrm{~N}^{\mathrm{t}} t d s \quad\right\}=0
$$

using the interpolation matrix $\mathrm{N}$, strain-displacement matrix $\mathrm{B}$, nodal acceleration vector a, and displacements in matrix notation becomes,

$$
\left[\begin{array}{c}
\ddot{x}_{1} \\
\ddot{x}_{2} \\
\ddot{x}_{3}
\end{array}\right]=\mathrm{N}\left[\begin{array}{c}
a_{x 1} \\
a_{y 1} \\
\vdots \\
a_{y k} \\
a_{z k}
\end{array}\right]=\mathrm{N} a
$$

and

$b=\left[\begin{array}{l}f_{x} \\ f_{y} \\ f_{z}\end{array}\right]$, and $t=\left[\begin{array}{c}t_{x} \\ t_{y} \\ t_{z}\end{array}\right]$

where $b$ is the body force load vector and $t$ is the applied traction loads.

\subsection{Solid Element}


In the present study a mesh of 8-node hexahedron solid element is used. A typical eight-node solid hexahedron element is shown below

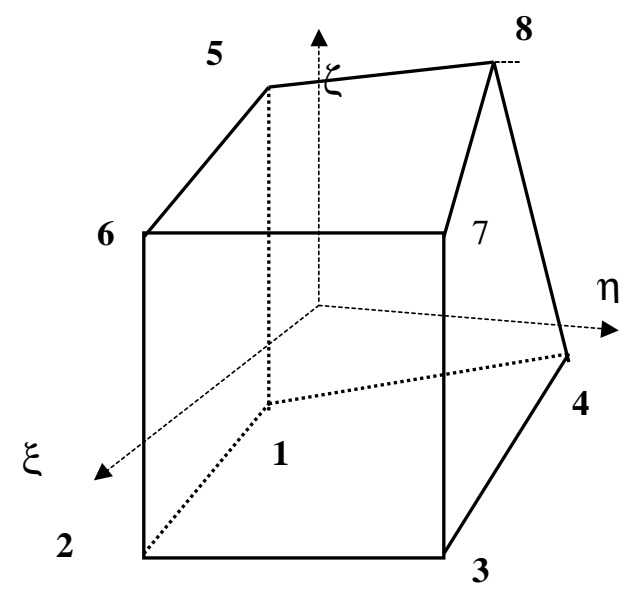

and the node definition for the above eight-node hexahedron element is as follows

$\begin{array}{lrrr}\text { Node } & \xi & \eta & \zeta \\ 1 & -1 & -1 & -1 \\ 2 & 1 & -1 & -1 \\ 3 & 1 & 1 & -1 \\ 4 & -1 & 1 & -1 \\ 5 & -1 & -1 & 1 \\ 6 & 1 & -1 & 1 \\ 7 & 1 & 1 & 1 \\ 8 & -1 & 1 & 1\end{array}$

For a mesh with an 8-node hexahedron solid element, equation (3.2.10) becomes

$$
x_{\mathrm{i}}\left(X_{\alpha}, t\right)=x_{\mathrm{i}}\left(X_{\alpha}(\xi, \eta, \zeta), t\right)=\sum_{j=1}^{8} \phi_{\mathrm{j}}(\xi, \eta, \zeta) x_{i}^{j}(t)
$$

and the shape function $\phi_{\mathrm{j}}$ can be defined as 


$$
\phi_{\mathrm{j}}=\frac{1}{8}\left(1+\xi \xi_{\mathrm{j}}\right)\left(1+\eta \eta_{\mathrm{j}}\right)\left(1+\zeta \zeta_{\mathrm{j}}\right)
$$

where $\xi_{\mathrm{j}}, \eta_{\mathrm{j}}, \zeta_{\mathrm{j}}$ take their nodal values of $( \pm 1, \pm 1, \pm 1)$ as shown above in the figure.

Summing over the $n$ elements $\delta \pi$ may be approximated to $\delta \pi=\sum_{m=1}^{n} \delta \pi_{\mathrm{m}}$

For an 8-node hexahedron solid element B is the $6 \times 24$ strain-displacement matrix and $\mathrm{N}$ is the $3 \times 24$ rectangular interpolation matrix and are given by

$\mathrm{B}=\mathrm{N}\left[\begin{array}{ccc}\frac{\partial}{\partial x} & 0 & 0 \\ 0 & \frac{\partial}{\partial y} & 0 \\ 0 & 0 & \frac{\partial}{\partial z} \\ \frac{\partial}{\partial y} & \frac{\partial}{\partial x} & 0 \\ 0 & \frac{\partial}{\partial z} & \frac{\partial}{\partial y} \\ \frac{\partial}{\partial z} & 0 & \frac{\partial}{\partial x}\end{array}\right]$

and

$$
\mathrm{N}(\xi, \eta, \zeta)=\left[\begin{array}{cccccccc}
\phi_{1} & 0 & 0 & \phi_{2} & 0 & \cdots & 0 & 0 \\
0 & \phi_{1} & 0 & 0 & \phi_{2} & \cdots & \phi_{8} & 0 \\
0 & 0 & \phi_{1} & 0 & 0 & \cdots & 0 & \phi_{8}
\end{array}\right]
$$

Terms in the strain-displacement matrix are 


$$
\begin{aligned}
& \frac{\partial \phi_{i}}{\partial \xi_{i}}=\frac{\partial \phi_{i}}{\partial x} \frac{\overline{\partial x}}{\partial \xi}+\frac{\partial \phi_{i}}{\partial y} \frac{\partial y}{\partial \xi}+\frac{\partial \phi_{i}}{\partial z} \frac{\bar{o} z}{\partial \xi} \\
& \frac{\partial \phi_{i}}{\partial \eta_{i}}=\frac{\partial \phi_{i}}{\partial x_{i}} \frac{\partial x}{\partial \eta}+\frac{\partial \phi_{i}}{\partial y} \frac{\partial y}{\partial \eta}+\frac{\partial \phi_{i}}{\partial z} \frac{\partial z}{\partial \eta} \\
& \frac{\partial \phi_{i}}{\partial \zeta}=\frac{\partial \phi_{i}}{\partial x} \frac{\partial x}{\partial \zeta}+\frac{\partial \phi_{i}}{\partial y} \frac{\partial y}{\partial \zeta}+\frac{\partial \phi_{i}}{\partial z} \frac{\partial z}{\partial \zeta}
\end{aligned}
$$

which can be rewritten as

$$
\left[\begin{array}{l}
\frac{\partial \phi_{i}}{\partial \xi} \\
\frac{\partial \phi_{i}}{\partial \eta} \\
\frac{\partial \phi_{i}}{\partial \zeta}
\end{array}\right]=\left[\begin{array}{lll}
\frac{\partial x}{\partial \xi} & \frac{\partial y}{\partial \xi} & \frac{\partial z}{\partial \xi} \\
\frac{\partial x}{\partial \eta} & \frac{\partial y}{\partial \eta} & \frac{\partial z}{\partial \eta} \\
\frac{\partial x}{\partial \zeta} & \frac{\partial y}{\partial \zeta} & \frac{\partial z}{\partial \zeta}
\end{array}\right]\left[\begin{array}{c}
\frac{\partial \phi_{i}}{\partial x} \\
\frac{\partial \phi_{i}}{\partial y} \\
\frac{\partial \phi_{i}}{\partial z}
\end{array}\right]=J\left[\begin{array}{l}
\frac{\partial \phi_{i}}{\partial x} \\
\frac{\partial \phi_{i}}{\partial y} \\
\frac{\partial \phi_{i}}{\partial z}
\end{array}\right]
$$

Hence, inverting the Jacobian Matrix $\mathrm{J}$ as follows can solve the desired terms

$$
\left[\begin{array}{l}
\frac{\partial \phi_{i}}{\partial x} \\
\frac{\partial \phi_{i}}{\partial y} \\
\frac{\partial \phi_{i}}{\partial z}
\end{array}\right]=J^{-1}\left[\begin{array}{l}
\frac{\partial \phi_{i}}{\partial \xi} \\
\frac{\partial \phi_{i}}{\partial \eta} \\
\frac{\partial \phi_{i}}{\partial \zeta}
\end{array}\right]
$$

\subsection{Volume Integration}


Volume integration is carried out with Gaussian quadrature. If $g$ is some function defined over volume, and $n$ the number of integration points then

$$
\int_{\nu} g d v=\int_{-1}^{1} \int_{-1}^{1} \int_{-1}^{1} g|J| d \xi d \eta d \zeta
$$

equation (3.20) may be approximated by

$$
\sum_{j=1}^{n} \sum_{k=1}^{n} \sum_{l=1}^{n} g_{\mathrm{jkl}}\left|J_{\mathrm{jkl}}\right| w_{\mathrm{j}} w_{\mathrm{k}} w_{\mathrm{l}}
$$

where $w_{\mathrm{j}}, w_{\mathrm{k}}, w_{\mathrm{l}}$ are weighting factors and $g_{\mathrm{jkl}}=\mathrm{g}\left(\xi_{\mathrm{j}}, \eta_{\mathrm{k}}, \zeta_{\mathrm{l}}\right)$ and $|J|$ is the determinant of the Jacobian matrix. For one point quadrature $n=1, w_{\mathrm{j}}=w_{\mathrm{k}}=w_{\mathrm{i}}=2$ and $\xi_{1}=\eta_{1}=\zeta_{1}=0$ from which we can write

$$
\int g d v=8 g(0,0,0)|J(0,0,0)|
$$

(3.22) note that $8|J(0,0,0)|$ gives an approximation to the element volume.

The biggest advantage of one-point integration is a substantial saving in the computer time and the disadvantage is that a fine mesh may be needed. An antisymmetry property of the strain matrix

$$
\begin{aligned}
& \frac{\partial \phi_{1}}{\partial x_{i}}=\frac{-\bar{\partial} \phi_{7}}{\partial x_{i}} \frac{\partial \phi_{3}}{\partial x_{i}}=\frac{-\partial \phi_{5}}{\partial x_{i}} \\
& \frac{\partial \phi_{2}}{\partial x_{i}}=\frac{\partial \phi_{8}}{\partial x_{i}} \frac{\partial \phi_{4}}{\partial x_{i}}=\frac{-\partial \phi_{6}}{\partial x_{i}}
\end{aligned}
$$

When $\xi=\eta=\zeta=0$, the amount of effort to compute strain matrix given in equation (3.4.4) is reduced to more than 25 times over an 8-point integration. These cost savings can be extended for the strain and nodal force evaluations where the number 
of multiples is reduced by a factor of 16 . Since only one constitutive evaluation is required, the time spent on determining stresses is reduced by a factor of 8 . However, 8-point integration has another disadvantage in addition to cost. When fully integrated elements used in the solution of plasticity problems and other problems where Poisson's ratio approaches 0.5 results in the constant volume bending modes. An average pressure must be applied to all the elements to avoid the elements becoming locked in the constant volume bending modes, consequently, the hourglassing modes are resisted by the deviatoric stresses. If these deviatoric stresses become negligible when compared to the pressure or if the material failure causes loss of this stress state component, then hourglassing will still occur without any means to resist it. Most of the times the cost of fully integrated element may be justified by increased reliability.

\subsection{Hourglass Control}

Hour glassing modes are zero energy modes. At this situation, the sum of internal and kinetic energies is not equal to the total energy. These undesirable hourglass modes are often observed to be oscillatory and they tend to have periods that are typically much shorter than the periods of the structural response. If these hourglass modes tend to have periods that are comparable to the structural response periods then it forms a stable kinematic component of the global deformation and is admissible. One way of resisting zero energy modes is with a viscous damping or small elastic stiffness capable of stopping the anomalous modes while having a negligible affect on the state global deformation modes. The work done by the hour 
glass resistance are neglected because the zero energy modes are made orthogonal to the real deformation which may lead to the slight loss of energy. However, hourglass control is always recommended for the underintegrated solid elements.

\subsection{Contact-Impact Algorithm}

DYNA3D uses three approaches for dealing with the impact contact and sliding interfaces of the models. The methods are known as the "kinematic constraint method", the "penalty method", and the "distributed parameter method". Interfaces are defined in three dimensions by listing in arbitrary order all triangular and quadrilateral segments that comprise each side of the interface. One side of the interface is designated as the slave side and the other as the master side. The nodes are classified as slave and master nodes respectively. The slave nodes are constrained to move over the master surface after impact and must remain on master surface until a tensile force develops between the node and the surface.

\subsubsection{Kinematic Constraint Method}

The kinematic constraint method is used only for tying surfaces. In this method, constraints are imposed in the global equations by a transformation of the nodal displacement components of the "slave" nodes along the contact interfaces. This way only the global degrees of freedom of each master node are coupled. Impact and release conditions are imposed to ensure momentum conservation. Problems arises when the meshing of master surface is finer than the slave surface where the master nodes can penetrate through the slave surface meshing. A better zoning would minimize such problems. This method requires "consistent" zoning of the interfaces. 


\subsubsection{Penalty Method}

In the penalty method, artificial interface springs are placed normal to the contacting surfaces on all the penetrating nodes. These artificial spring elements are assembled in the global stiffness matrix and their modulus is determined based on the elements in which the nodes reside. This method seems to be very stable and produces less noise for hourglassing modes. Momentum is exactly conserved without the necessity of imposing impact and release conditions. However, for relatively large interface pressures, the stiffnesses have to be scaled up and the time step reduced. In such cases the third method "distributed parameter" is more appropriate.

\subsubsection{Distributed Parameter Method}

This last method is mainly used for "sliding interfaces" in which the internal stress in each element in contact determines the pressure distribution for the corresponding master surface. One half of the slave element mass of each element in contact is distributed to the covered master surface area. Accelerations are updated after mass and pressure distributions on the master surface are completed. Constraints are then imposed on the slave node accelerations and velocities to ensure their movement along the master surface

With these three algorithms, an array of contacting interfaces is available in DYNA3D, which allow the simulation of most contact conditions. 


\subsection{Time Step Control}

A new time step size is determined by taking the minimum value over all elements as follows

$$
\Delta t^{n+1}=\alpha \min \left\{\Delta t_{1}, \Delta t_{2}, \cdots, \Delta t_{N}\right\}
$$

where $N$ is the number of elements. For stability reasons the scale factor $\alpha$ is typically set to a value of 0.9 (default) or smaller value.

For a solid element, a critical time step size $\Delta t_{e}$, is computed as follows:

$$
\Delta t_{e}=\frac{L_{e}}{\left\{\left[Q+\left(Q^{2}+c^{2}\right)^{1 / 2}\right]\right\}}
$$

where $L_{e}=\frac{V_{e}}{A_{e \max }}$ for 8-node solid element and $Q\left(C_{0}, C_{1}\right)$ and $C_{0}, C_{1}$ are the bulk viscosity coefficients and $Q$ is given by

$$
Q=C_{1} C+C_{0} \frac{v_{e}}{A e_{\text {max }}}\left|\dot{\varepsilon}_{k h}\right| \text { for } \dot{\mathcal{E}}_{k k}<0
$$

$$
Q=0 \text { for } \dot{\mathcal{E}}_{k k} \geq 0
$$

where $v_{\mathrm{e}}$ is the element volume, $A_{e_{\max }}$ is the area of the largest side, and $c$ is the adiabatic sound speed given by

$$
\left.c=\left[\frac{4 G}{3 \rho_{0}}+\frac{\partial p}{\partial \rho}\right)_{s}\right]^{\frac{1}{2}}
$$


and $\rho$ is the specific mass density.

For an isentrope sound speed, $c$ is given by

$$
\left.\left.c=\left[\frac{4 G}{3 \rho_{0}}+\frac{\partial p}{\partial \rho}\right)_{E}+\frac{p V^{2}}{\rho_{0}} \frac{\partial \rho}{\partial E}\right)\right]
$$

for the incremental energy, $E$, in the units of pressure is the product of pressure, $p$, and the incremental relative volume, $d \mathrm{~V}$ :

$$
\left.\left.\left.\left.\frac{\partial p}{\partial \rho}\right)_{s}=\frac{\partial p}{\partial \rho}\right)_{E}+\frac{\partial p}{\partial E}\right)_{\rho} \frac{\partial E}{\partial \rho}\right)_{s} \text { and } d E=-p d V
$$

Sound speed for elastic materials with constant bulk modulus is given by

$$
c=\sqrt{\frac{E(1-v)}{(1+v)(1-2 v) \rho}}
$$

where $E$ is the Young's modulus and $v$ is the Poisson's ratio.

\subsection{Time Integration}

Consider the single degree of freedom damped system as shown below

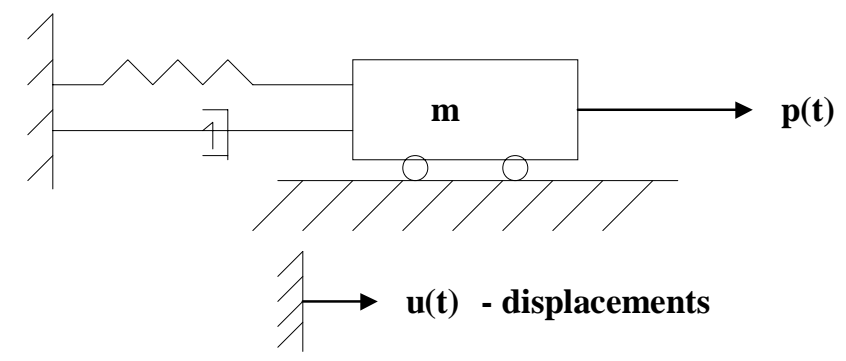

Forces acting on mass $\mathbf{m}$ are shown below

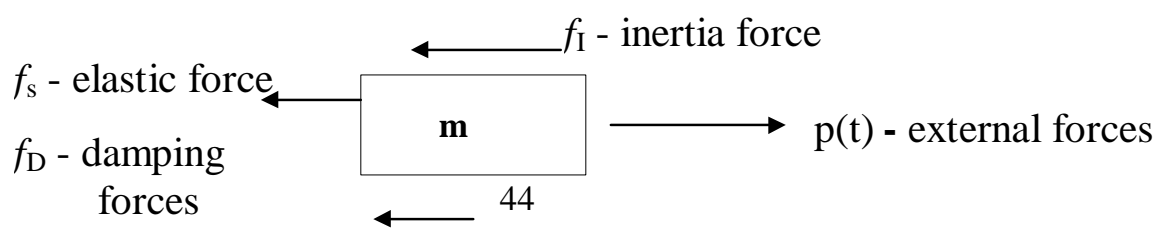


The equilibrium equations for the given system are obtained from d'Alembert's principle

$$
f_{\mathrm{I}}+f_{\mathrm{D}}+f_{\text {int }}=p(t) f_{\mathrm{I}}+f_{\mathrm{D}}+f_{\text {int }}=p(t)
$$

$$
\begin{aligned}
& f_{\mathrm{I}}=m \ddot{u} ; \ddot{u}=\frac{d^{2} u}{d t^{2}} \text { acceleration } \\
& f_{\mathrm{D}}=c \dot{u} ; \dot{u}=\frac{d u}{d t} \text { velocity, and } c \text { is the damping coefficient } \\
& f_{\text {int }}=k \cdot u ; u \text { displacement, and } k \text { is the linear stiffness }
\end{aligned}
$$

For a linear system the equations of motion lead to linear ordinary differential equation given by $m \ddot{u}+c \dot{u}+k \cdot u=p(t)$ and for a nonlinear case the inertial force varies as a nonlinear function of the displacement which leads to a nonlinear ordinary differential equation given by $m \ddot{u}+c \dot{u}+f_{\text {int }}(u)=p(t)$. Let us consider the dynamic response of linear system subjected to a harmonic loading

$$
p(t)=p_{0} \sin \bar{\omega} t
$$

The closed form solution with initial conditions $u_{0}=$ initial displacement, $\dot{u}_{0}=$ initial velocity and $\frac{p_{0}}{k}=$ static displacement is given by

$$
u(t)=\underbrace{u_{0} \cos \omega t+\frac{\dot{u}_{0}}{\omega} \sin \omega t}_{\text {homogeneous solution }}+\frac{\frac{p_{0}}{k} \frac{1}{1-\beta^{2}}(\sin \bar{\omega} t}{\text { steady state }}-\frac{\beta \sin \omega t)}{\text { transient }}
$$

particular solution 
For nonlinear problems, only numerical solutions are possible. LS-DYNA3D uses the explicit central difference method to integrate the equations of motion.

The semi-discrete equations of motion at time $\mathrm{n}$ are :

$$
\mathrm{Ma}^{\mathrm{n}}=\mathrm{P}^{\mathrm{n}}-\mathrm{F}^{\mathrm{n}}+\mathrm{H}^{\mathrm{n}}
$$

where $\mathrm{M}$ is the diagonal mass matrix, $\mathrm{P}^{\mathrm{n}}$ is the external and body force loads, $\mathrm{F}^{\mathrm{n}}$ is the stress divergence vector, and $\mathrm{H}^{\mathrm{n}}$ is the hourglass resistance. Central difference time integration method to advance time $\mathrm{t}^{\mathrm{n}+1}$ is as follows:

$$
a^{n}=M^{-1}\left(P^{n}-F^{n}+H^{n}\right)
$$

$$
\begin{aligned}
& v^{n+\frac{1}{2}}=v^{n-\frac{1}{2}}+a^{n} \Delta t^{n} \\
& \text { (3.35) } u^{n+1}=u^{n}+v^{n+\frac{1}{2}} \Delta t^{n+\frac{1}{2}}
\end{aligned}
$$

where $\Delta t^{n+\frac{1}{2}}=\frac{\left(\Delta t^{n}+\Delta t^{n+1}\right)}{2}$

and $\mathbf{v}$ and $\mathbf{u}$ are the global nodal velocity and displacement vectors, respectively. Initial geometry can be updated by adding the displacement increments

$$
x^{n+1}=x^{0}+u^{n+1}
$$

The stability of the central difference method is determined by looking at the stability of the linear system. The equations of a linear system is uncoupled into the modal equations where the modal matrix of eigen vectors, $\phi$, are normalized with respect to 
the mass matrix $M$, and linear stiffness matrix $K$. The decoupling of damping matrix, $C$ for viscous proportional damping is obtained from the normalization as

$$
\phi^{\mathrm{T}} C \phi=2 \xi \omega
$$

The equations of motion in the modal coordinates $x$ are

$$
\ddot{x}+2 \xi \omega \dot{x}+\omega^{2} x=\underbrace{\phi^{T} p}_{=Y}
$$

with central differences we obtain for the velocity and acceleration

$$
\dot{x}_{n}=\frac{x_{n+1}-x_{n-1}}{2 \Delta t} \text { and } \ddot{x}_{n}=\frac{x_{n+1}-2 x_{n}+x_{n-1}}{\Delta t^{2}}
$$

substituting equation (4.7.9) into equation of motion at time $t^{n}$ leads to

$$
x_{n+1}=\frac{2-\omega^{2} \Delta t^{2}}{1+2 \xi \omega \Delta t^{2}} x_{n}-\frac{1-2 \xi \omega \Delta t}{1+2 \xi \omega \Delta t} x_{n-1}+\frac{\Delta t^{2}}{1+2 \xi \omega \Delta t^{2}} Y_{n}
$$

and equation (4.7.10) in the matrix form is given by

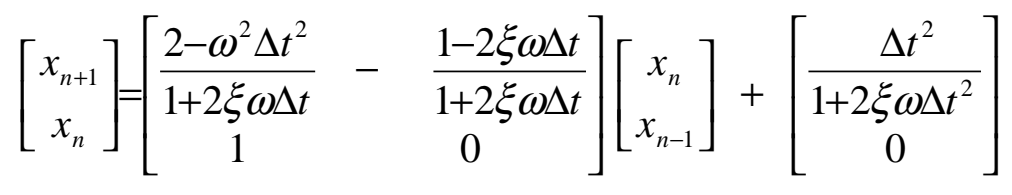

or

$$
\left[\mathrm{x}_{\mathrm{n}+1}\right]=[\mathrm{A}]\left[\mathrm{x}_{\mathrm{n}}\right]+[\mathrm{L}] \mathrm{Y}_{\mathrm{n}}
$$

where, $\mathrm{A}$ is the time integration operator for discrete equations of motion. After $\mathrm{m}$ time steps with $\mathrm{L}=0$

$\left[\mathrm{x}_{\mathrm{m}}\right]=\left[\mathrm{A}_{\mathrm{m}}\right]\left[\mathrm{x}_{0}\right]$ 
The spectral radius $\rho(A)$ is the largest eigenvalue of $A$. The solution will be stable if and only if $|\rho(\mathrm{A}) \leq 1|$. The condition that $|\rho(\mathrm{A}) \leq 1|$ for an undamped equation of motion gives the value of time step $\Delta \mathrm{t}$ as

$$
\Delta t \leq \frac{2}{\omega_{\max }}
$$

Thus the time step size is bound by the largest natural frequency in the model which, in turn is bound by the highest natural frequency of any element in the model.

The time step size is always limited by the single element in the model. The disadvantage of this method is that even if only one element has a time step very less, then all other elements should also be calculated for the same step size. So, 'subcycling' called as mixed time integration was introduced. This method employs in grouping the elements based on their step size and individual time integration is carried out for each group. This method is helpful as it reduces the time for solving.

\subsection{Numerical Analysis}

The numerical analysis attempts to solve the differential equations by numerical procedures, which can be easily programmed using a standard programming language. The higher time step values from the initial boundary values can be programmed by the differential equations. This is done by splitting the differential equation into numerical components in the time axis using the forward, central or the backward differentiation methods. The numerical method can be broadly classified as the explicit and implicit methods. In the explicit method, previous time step method is used to calculate the next time step method. On the otherhand, implicit method calculates the next time step values by solving a matrix of 
the present and the previous time step values. The explicit method gives an accurate solution for a shorter time step and is conditionally stable that is underlying principle used in LS-DYNA3D. 


\section{CHAPTER 4 \\ MODEL DEVELOPMENT: PRELIMINARY CONDITION}

\subsection{Introduction}

Many experiments were conducted in the past to come to a comprehensive understanding of how and why small solid particles entrained in the gas or liquid media can cause material degradation. Based on these experiments many theories have been proposed. Erosion material wastage is dependent on many inter related factors that include the properties and structures of the target material, the micro and macro exposures, the metal/metal oxide interface properties, strength of the interface and the physical and the chemical characteristics of the impacting particle. Each experimental work covers a single or a set of metals, alloys or coatings, leaving behind a large number of substances not experimented. There are several new materials that are used for different applications, many of them working at high temperatures and it is difficult to conduct experiments for each of them. A numerical model is proposed that takes into account all the available parameters and estimates the volume loss due to particle impact.

IDEAS, a powerful pre-processor, was used to model the metal, metal oxide and the rigid spherical particle. The dynamic analysis was done using LS-DYNA3D. Referring to Levy's [52] experimental work on effect of the size of impacting particle on the aluminum model, the procedure was validated comparing the erosion loss trend lines. Later the model was extended to Iron/Iron Oxide, changing several 
parameters like size of the particle, velocity, temperature and the angle of attack of the impacting particle and the erosion loss was calculated.

The present work can be extended to several materials and the erosion procedure can be adopted in calculating erosion loss. By changing the material properties, new models can be created and trend lines (effect of size, velocity, and angle of attack of particles on volume loss) can be observed. Once the pre-model is ready, the material properties of the particle and the target surface are very important for dynamic solutions.

\subsection{Material Properties}

The control of test conditions in numerical analysis of mechanical materials has limits. Variations beyond the control of the tester can have significant effects on the behavior of the material. Similarly, unknown or uncontrolled aspects of the operating conditions of an computational model compounds the problem of being able to precisely calculate the desirable quantities. The material properties of the model play an important role in avoiding numerical errors. In the present work the material properties of the metal, metal-Oxide and the bombarding particle are key factors. The mechanical properties of the metal (elastic) and that of the spherical particle (rigid) are directly obtained from mechanical handbooks. But properties of

the oxide scales at different temperatures are complex and need a clear understanding of the physical nature. 


\subsubsection{Metal Oxide Scales}

Successful simulation of the in service operating conditions at the surface of a component such as a tube or tubing blade that is being degraded by erosion or erosion-corrosion requires both the depth of oxide scale at a particular temperature and the mechanical properties. Because the exact conditions at the target surface are not precisely known, the accuracy of the numerical simulation relies on the material property, Yalamanchilli [39].

Oxide scales that act like protective scale on metallic components may experience stresses having various origins. Stress in the oxide-metal system either arises from external mechanical or thermal loading or from the oxidation processes itself. When these stresses exceed critical values various types of scale damage may occur, such as microcrack formation, through scale cracking, formation of cracks at the interfaces, between oxide partial layers, stable growth of delaminations at the scale/metal interface, and or spalling of parts or of the entire scale [45]. According to Schutze, separation at the scale/metal interface occurs either when the tensile stresses perpendicular to the interface exceed a critical value $\sigma$ or the interfacial shear stresses exceed a critical value $\tau$. Also the superposition of both type of loading is possible.

The loading is referred to mode I, mode II and the combination as mixed mode I and II. Assuming linear elastic behavior of the oxide-metal system, the tensile stress necessary to increase a separation of length $\mathrm{C}$ was given by

$$
\sigma=\left[\frac{E^{*} G}{\prod C}\right]^{1 / 2},
$$


where $E^{*}$ is the effective young's modulus of the scale metal system and $G$ is the critical crack extension force which corresponds to the energy necessary to extend the separation. He also observed that decohesion slows down the oxidation process as a result of the interruption of the diffusion paths at the interface when no scale cracks are present. Such unsupported scales are very sensitive to cracking by external forces and no reliable protection is expected.

Measuring the natural frequency of the freely suspended specimen was the technique used by Bruce et al. [46] for studying the high-temperature oxidation of metals. They investigated the oxidation characteristics of iron and nickel by this technique and compared the results with the conventional thermobalance. They showed that oxide cracking during scale growth can be detected by vibrational technique and found that nickel produces crackfree oxide scale at $800-900{ }^{\circ} \mathrm{C}$, and appreciable cracking of iron oxide layer at $500-1000{ }^{\circ} \mathrm{C}$.

Bruce and Hancock [46] derived the relationship between the frequency change of a freely supported specimen and the mass increase due to oxidation. They worked with a long thin cylindrical rod subjected to flexural vibration in a freely supported position. The characteristic frequency of the firstmode of vibration $\mathrm{f}_{0}$ is related to the dimensions and young modulus (E) of the rod, given by,

$$
f_{o}^{2}=\frac{(4.73)^{4} E a^{4}}{16 \prod l^{3} m_{o}},
$$

where $\mathrm{a}, \mathrm{l}$, and $\mathrm{m}_{0}$ are the radius, length, and mass of the rod, respectively. 
If the rod carries a surface oxide film then the system approximates a composite cylinder, and if the radius of the metal and composite is $b$ and the radius of the inner metal core is c, then again following Rayleigh, the frequency of the first mode of vibration of the composite is given by

$$
f^{2}=\frac{(4.73)^{4}}{16 \prod l^{3} m}\left[E_{1} c^{4}+E_{2}\left(b^{4}-c^{4}\right)\right],
$$

where $\mathrm{m}$ is the total mass of the composite rod and E1 and E2 are the moduli of the metal and the oxide respectively.

During oxidation the increase in the weight of the specimen can be determined by the thermobalance and most of the kinetic data available are based on such measurements. Using the above equations they derived the relationship between the natural frequency $f$ and the weight increase by the oxidation.

$$
\frac{f^{2}-f_{0}^{2}}{f_{0}^{2}}=\Delta\left[\frac{2 \beta M_{1}}{M_{2}-M_{1}}-\frac{M_{2}+M_{1}}{M_{2}-M_{1}}\right]+\frac{\Delta^{2}}{1+\Delta}\left[\frac{M_{2} \rho_{1}}{M_{1} \rho_{2}} \beta+\frac{M_{2}{ }^{2}}{M_{1}{ }^{2}}-2 \beta \frac{M_{2}}{M_{1}}\right]\left(\frac{M_{1}}{M_{2}-M_{1}}\right)^{2}
$$

Where $\Delta$ is defined by $\mathrm{m}=\mathrm{m}_{0}(1+\Delta)$

$f$ is the natural frequency of the oxidized rod $f_{0}$ is the natural frequency of the original rod before oxidation 
$\mathrm{M}_{1}, \rho_{1}$ and $\mathrm{E}_{1}$ are the atomic weight, density and young's modulus of the oxide and

$$
\beta=\frac{E_{2} \rho_{1} M_{2}}{E_{1} \rho_{2} M_{1}},
$$

The above equation can be simplified to

$$
\frac{f^{2}-f_{0}^{2}}{f_{0}^{2}}=\Delta\left[\frac{2 \beta M_{1}}{M_{2}-M_{1}}-\frac{M_{2}+M_{1}}{M_{2}-M_{1}}\right]
$$

And for most oxidation conditions the error involved by using the simplified equation is $2 \%$.

In the present work, the volume loss of the oxide scales of the Armco iron was calculated. As explained above, the oxide layer formed at different temperatures on the iron substrate has a lot of imperfections and because of this there are lot of variations in the physical properties.

\subsubsection{Metal-Metal Oxide Interface}

To assess the tendency of an oxide scale to decohesion under the presence of stresses, appropriate methods for adhesion strength measurements are necessary. The properties of the metal/metal-oxide interface are very important for numerical simulation to estimate the erosion loss accurately. Good adherence requires a high 
fracture toughness of the oxide and the metal, few flaws, zero voids at the interface and non-planar defects. Several testing methods have been developed for this purpose. By fixing a brass cone to the oxide surface, scale adhesion has been measured by Gulyaev et al. [47]. The brass cone was connected to a steel wire and the interface adhesion strength was determined by performance of the tensile test. In another method [48] the concept of forming a metal/scale joint, similar in a shape to a fillet weld was used. The metal/scale joint was produced when oxide formed around the periphery of the small diameter $(10 \mathrm{~mm})$ cylinder and the large diameter $(20 \mathrm{~mm})$ cylinder. The specimen configuration was subjected to the tensile test in which the decohesion forces are measured. In each of the above methods problems may arise with the exact determination of the geometrical values necessary for stress calculations.

Bruce et al. [46] developed a vibration technique to detect the onset of cracking in the scale, measuring adhesion of a growing oxide scale by subjecting it to thermal stresses without attaching any device to the specimen and measuring the thermal stresses necessary to cause cracking and breakdown of the adhesion. The data obtained from this technique was used in the present work.

\subsubsection{Particle}

In order to understand the nature of erosivity of various kinds of particles that can occur singularly or together in a group, series of experiments have been conducted in the past. The geometry of the deformation due to solid particle impact 
depends on the shape, velocity and the orientation of the impacting particle. Researchers classify the particles into two categories, spherical and angular. The spherical particle is a point contact bombardment and angular is subdivided to sharp point contact, line contact and the surface contact. Spherical particle deforms the target surface by ploughing, displacing material to the side and in front of the impacting particle as shown in Figure 4.1a. Angular particle deformation depends on the orientation of the particle during bombardment and on whether the particle is rolling forward or backwards during contact.

If the particle rolls forward, it is termed as a type I cutting as in Figure 4.1b, intending towards surface degradation by raising the material onto prominent lip which can be removed by subsequent impacts by erodents. True machining action occurs when the impacting particle rolls back after impacting the target surface, shown in the Figure 4.1c. Effects of the particle shape, orientation and the velocity (flow rate) was explained clearly in chapter 2 .

In the present work spherical silicon carbide particles were considered. Different particle sizes ranging from $100 \mu \mathrm{m}$ to $300 \mu \mathrm{m}$ with a gradual increase in diameters were taken into account for size effects. Since the silicon carbide particles are very hard compared to the target surface, they were treated as rigid particles in analysis. 
(a) Ploughing

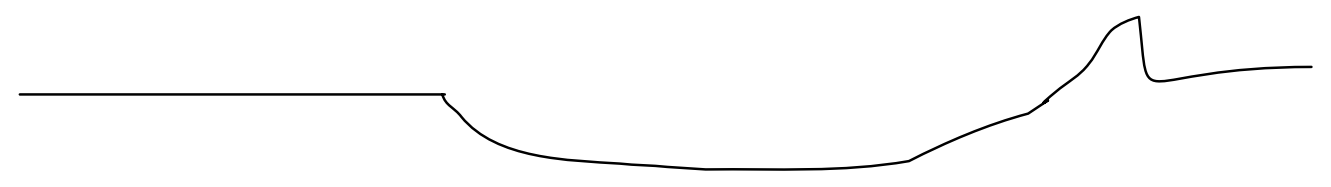

(b) Type I Cutting

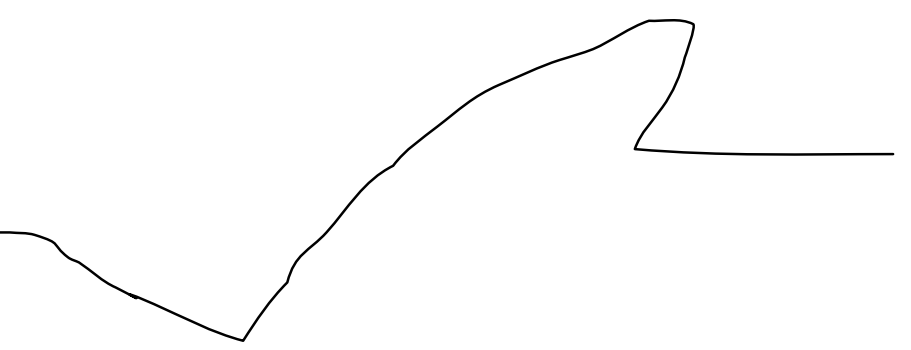

(c) Type II Cutting

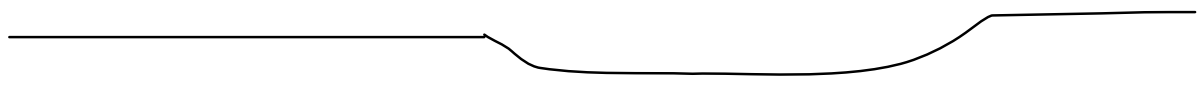

Fig. 4.1 Different Types of Impact Damages. 


\subsection{Assumptions}

- Single particle erosion was considered.

- The impacting particles were spherical in shape indicating a point contact.

- The metal was assumed to be ductile.

- The metal oxide was assumed to be brittle.

- The target surface was assumed to be flat without the influence of previous failure effects.

- Tied nodes with failure constraints were used to simulate the metal/metal-oxide interface.

- Vibrational effects during particle impact were neglected.

- Damping effects were not included in the model.

- Axis-symmetric model was used in order to save computational time.

- Temperature effects were not actually simulated in the model but were included in the material properties.

- Silicon carbide particle was assumed to be rigid in solutions. 


\section{CHAPTER 5}

\section{MODEL DEVELOPMENT: FINITE ELEMENT ANALYSIS}

\subsection{Introduction}

The purpose of this thesis is to develop a numerical model simulating solid particle erosion and to account for all of the available parameters and boundary conditions. The knowledge of volume loss of an oxide scale by solid particle impact is necessary in selecting the most economical materials of construction and operating conditions in the design of equipment. In this thesis, effort has been made to model it and thereby be able to predict accurately the volume loss at particular set of conditions. The first model simulates the impact of silicon carbide particle onto the aluminum oxide scale and the second one simulates that of iron/iron-oxide system. Both the models were developed in IDEAS MS 4.0 and solved in sequential LSDYNA3D. IDEADYN, software developed at Mechanical and Aerospace Engineering Department, WVU was used to transfer the IDEAS output file to LSDYNA3D input format.

\subsection{Mesh Generation}

The initial step in finite element modeling is to develop a two-dimensional mesh. Effort was made to see that the fine mesh was generated near the contact area and a coarse mesh away from the point of contact, for which the wire frame was 
divided into surfaces accordingly. The $2 \mathrm{D}$ model was map meshed and extruded in $\mathrm{z}$ direction. As LS-DYNA3D software cannot understand the definition of the wedge elements enough care was taken in modeling the spherical particle. All the above mentioned modeling details were done using a powerful software called IDEAS. IDEAS provides the capability to generate complex geometry's, meshing and specify boundary conditions with minimum user input. It is a user-friendly interactive graphics with the ability to identify irregularities in the mesh like warpage and the stretch of the element. Once the model is ready other definitions like initial and boundary conditions can be added and modified interactively.

The current model was developed with user defined unit system of millinewton, millimeter and millisecond. The types of elements used were three dimensional hexahedral brick elements. The first model was to simulate the impact of silicon carbide particle onto the aluminum oxide scale. The second model was of silicon carbide particle bombarding with the iron/iron-oxide system. The finite element model consisting of spherical particle, metal and metal oxide is shown in the Figure 5.1.

\subsection{Material models}

The second step of finite element modeling is defining the material models for the metal, metal oxide and the rigid spherical particle. The materials should be defined properly according to the specified units in order to get accurate results from analysis. LS-DYNA3D has several inbuilt material models defining various 
materials. IDEADYN, a translator used to transfer the IDEAS universal file to LSDYNA3D input format, does not allow the definition of material properties in IDEAS itself. The material

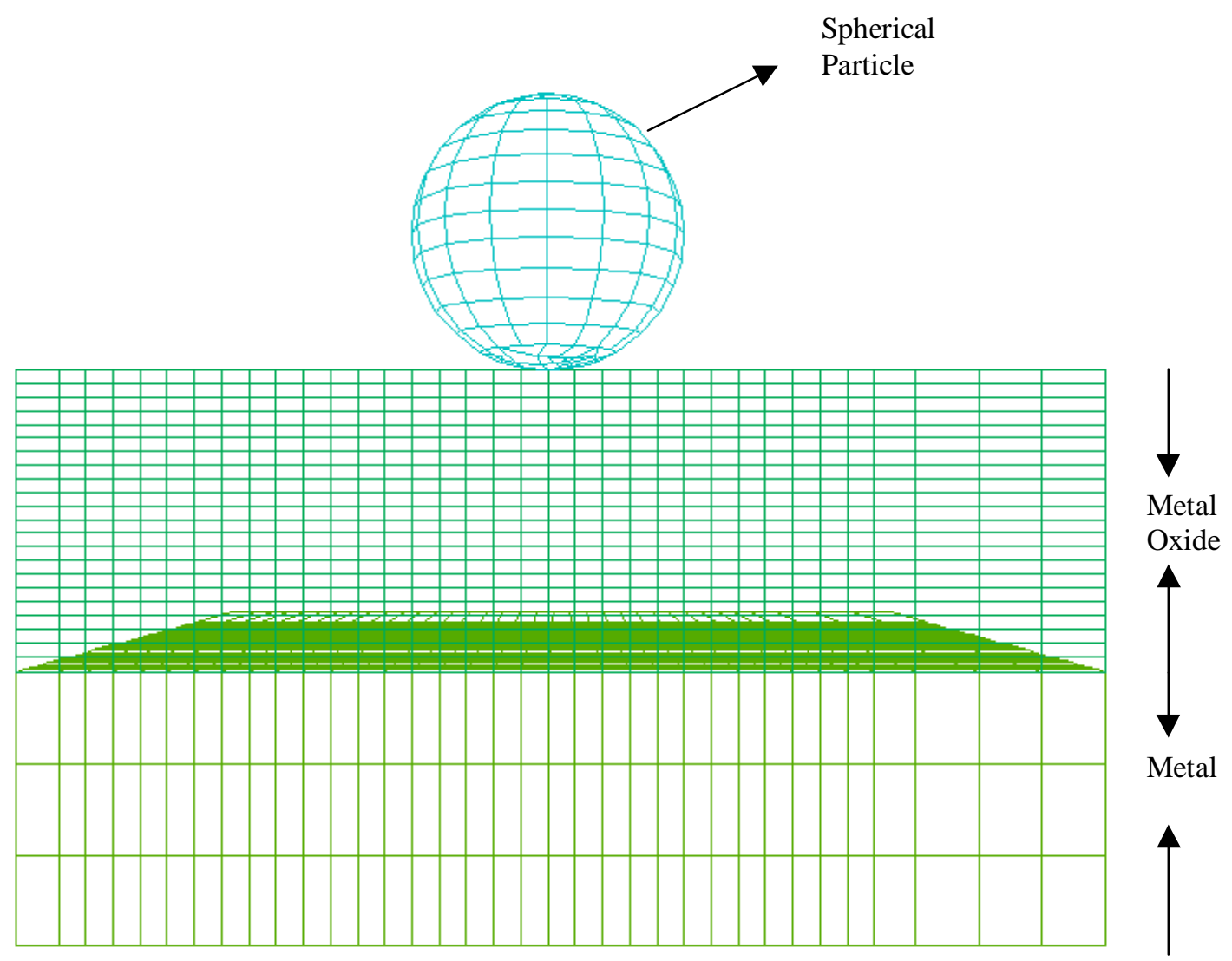

Fig 5.1 Iron/Iron Oxide System 
properties were to be given in the LS-DYNA3D file only. In the present work the effects of impact on the particle were neglected, as the work is focussed only on the erosion loss of the oxide layer. The particle is assumed to be rigid and was assigned rigid material properties. The rigid material model takes into account all the material properties of the silicon carbide particles, but doesn't show the deformations and other results of the particle. The following are the properties of the rigid material required by the LS-DYNA3D input file to solve.

\section{Mass Density}

Modulus of Elasticity

Poisson's Ratio

Rigid body constraints (rotational and translational)

The metal substrate was assumed to be ductile and was assigned elastic material type. The properties of the metal substrate are needed for dynamic solution

Mass density

Modulus of Elasticity

Poisson's Ratio

The metal oxide scale is assumed to be brittle and was assigned the properties of the elastic-plastic material model. The metal oxides behave linearly elastic until fracture. The oxide scales are treated as elastic-plastic material model with kinematic hardening in the mode. The stress strain curve of the metal oxide is shown in figure

\section{2.}

The elastic-plastic material type requires the following properties.

Mass Density 
Modulus of Elasticity

Poisson's Ratio

Yield stress

Tangent Modulus or Hardening Modulus

Hardening Parameter

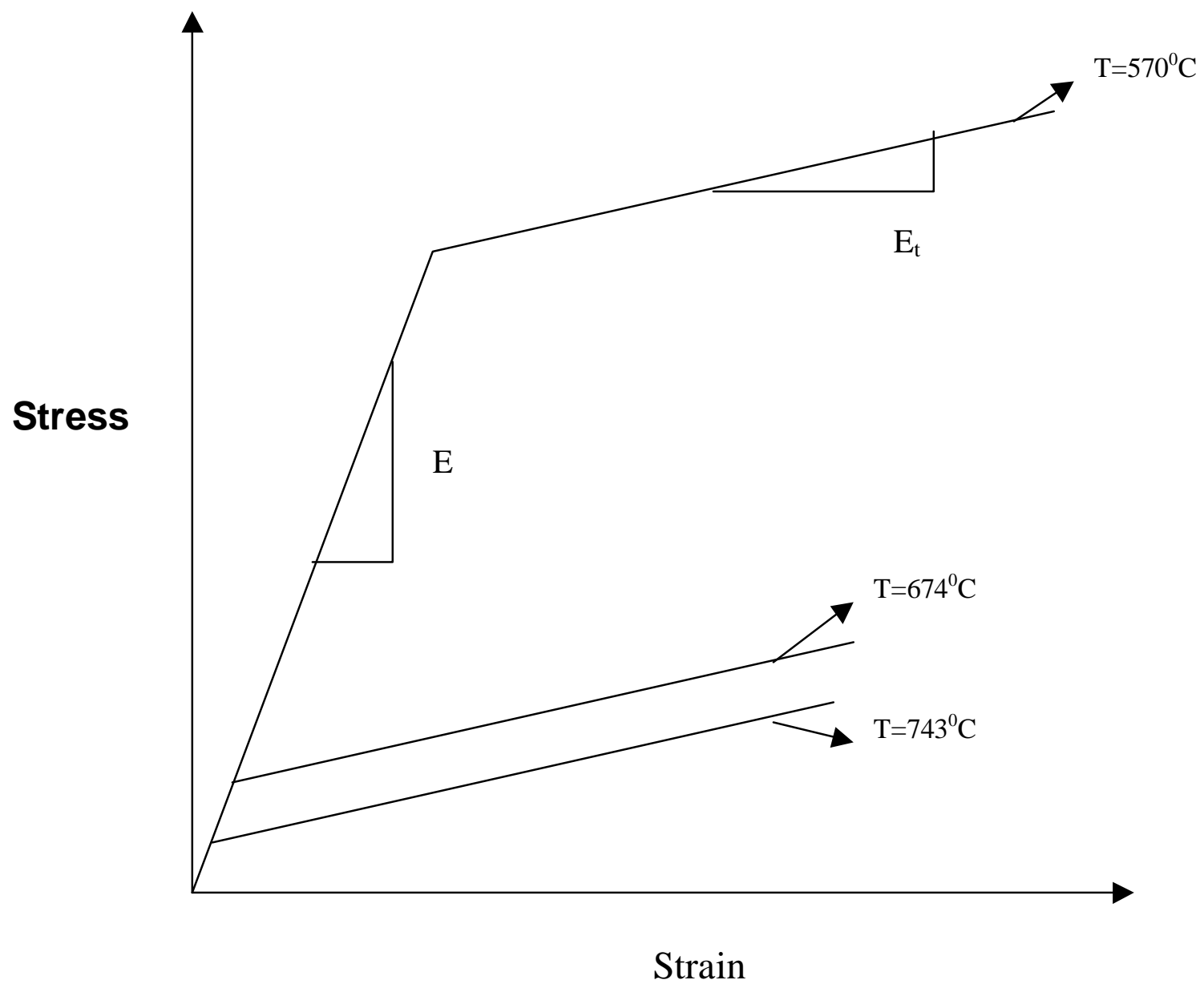

Fig. 5.2 Stress-Strain Plot of Elastic-Plastic Material Type (T=Temperature) 


\subsection{Initial and Boundary Conditions}

In order to save the computational time only half of the model was considered. Axi-symmetric boundary conditions were applied to take care of the other half. The metal and the metal-oxide were restrained at the bottom and on the sides in order to avoid rigid body motion of the whole model. Sliding with friction definition was used to define the sliding contact of the impacting particle and the target surface. This particular sliding interface was designated as a type III algorithm. The spherical particle nodes were taken as master nodes and those of the oxide scale as slave nodes. Tied nodes with failure constraint were used to define the metal/metal-oxide interface. This particular constraint takes into account the failure strain, which when exceeded, the nodes at the interface become detached. The lower failure strain can be used to define the spallation phenomenon.

The impacting particle was given an initial velocity (condition) in negative direction onto the target surface. The velocity and the direction of the impacting particle can be easily modified with minimal user input in LS-DYNA3D input file. The output of IDEAS file is then translated to LS-DYNA3D format using IDEADYN. 


\subsection{Model Solution}

The third step of the analysis is solving the LS-DYNA3D file. LS-DYNA3D is an explicit finite element code for analyzing the transient dynamic response of three dimensional solids and structure. It takes the results from the previous time step and calculates the present time step values. Once the required material properties were given
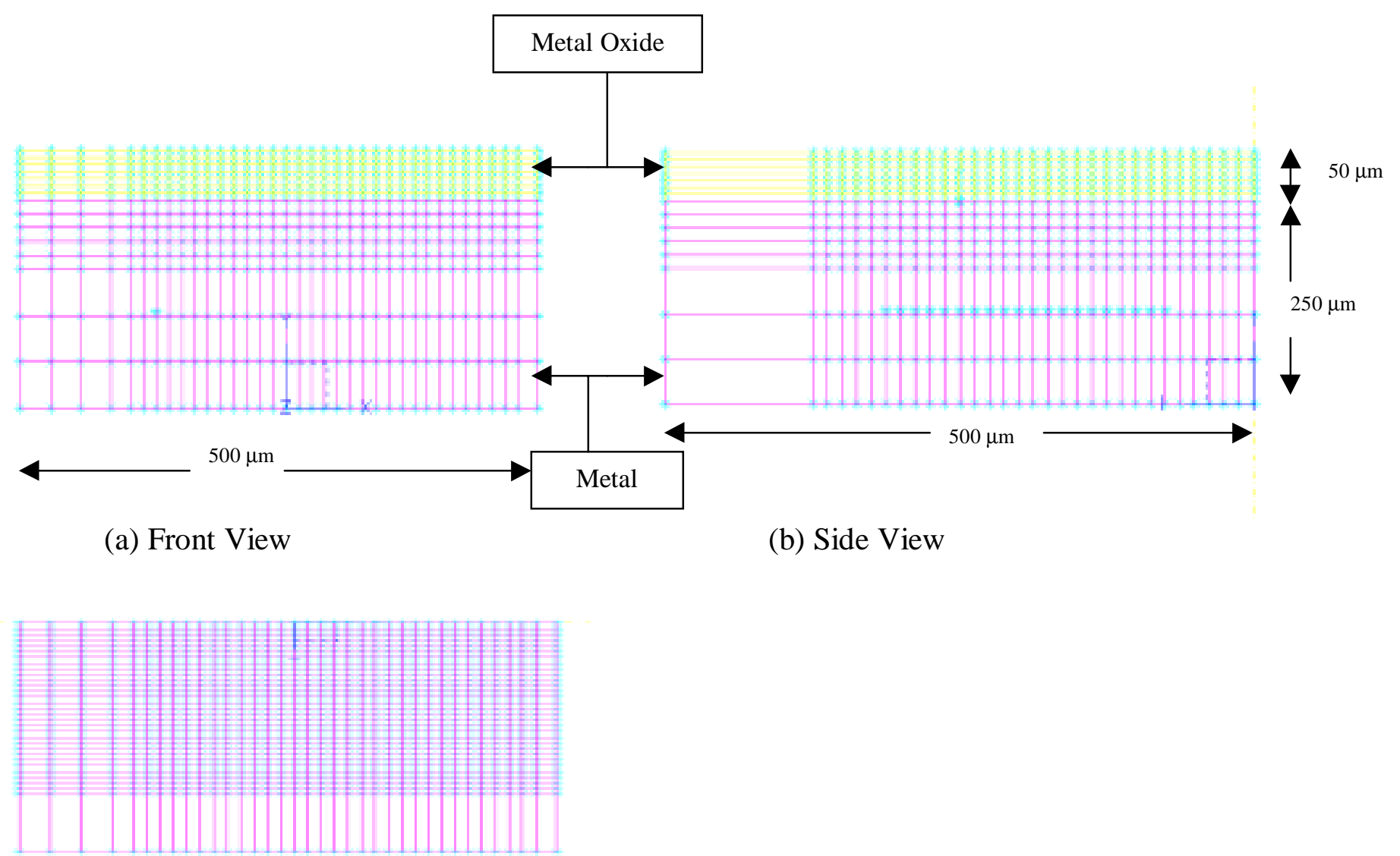

(c) Top View

Fig. 5.3 Views of Iron/Iron Oxide System 
in the LS-DYNA3D input file and checked for accuracy in coding and default hour glassing was added the file would be ready for the solution. The results can be viewed in the post processor called LS-TAURUS.

The total energy of the system is equal to the sum of the kinetic and internal energy. In the present work the system consists of metal/metal-oxide and the impacting particle. When the particle bombards with the target surface, it loses its kinetic energy and the target surface gains the internal energy. The kinetic and internal energies with respect to the total energy are shown in the Figure 5.4. It was assumed that the damage was caused to the oxide scale at the time step where the internal energy of the whole system reaches maximum value. The effective stresses in all the elements were calculated and compared to the failure stress of the oxide scale at that particular temperature.

\subsection{Post Processing}

The output file from the LS-DYNA3D had to be post processed in order to get the solutions in the designed fashion. The LS-TAURUS was used as post processor in the analysis. LS-TAURUS is a powerful, interactive and user-friendly software that can read binary and time history files generated by LS-DYNA3D. Also the software has the feature of displaying the results in various forms, like line plots, contour plots, arrow plots, data reports and XY graph plots.

In the present work the required results for the failure analysis are stresses and the displacements. The displacement results provide the qualitative estimate of the 
deformation and that of stresses provides the quantitative estimation of the erosion loss.

The binary plot files GLSTAT and MATSUM were used for the energy plots that give the kinetic and internal energies with respect to the total energy. The phase I of the TAURUS commands gives a plot of effective stresses (Von Mises stresses) against the element numbers at a particular time step during analysis and prints the data in HSPBULL file. These graphs and data are used in the estimation of volume loss of the system.

\subsection{Erosion Loss Estimation}

The maximum internal energy point was taken as the time step where the target experiences damage. At that particular time interval the plot between effective stress profiles and the elements were obtained and the data reports printed in HSPBULL file. A program was written in C language to estimate the erosion loss for particular conditions. The first program scans the HSPBULL file for the elements whose stress values were more than that of the failure stress for that particular temperature giving the output file as a count of failed elements. The second program which was also written in $\mathrm{C}$ language reads the output of the first program and takes into account the volume of a single element giving the volume loss for the half model in $\mathrm{mm}^{3}$ units. The output of each solution was used as a point in the graph for the erosion loss in micrometer to size of the impacting particle, velocity, temperature or 
the angle of attack and comparing the trend lines with the previous experimental results. 


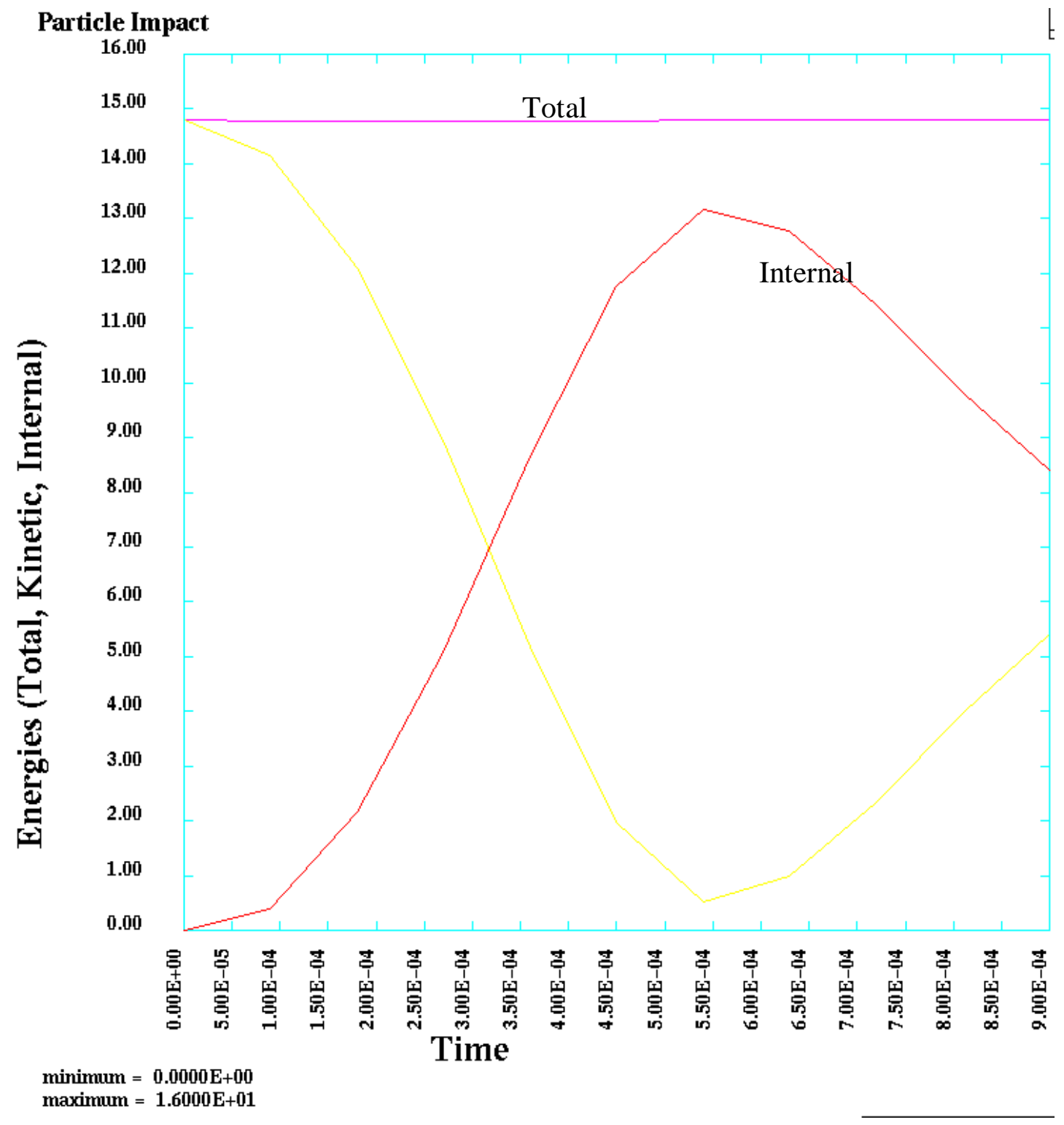

Fig. 5.4 A Graph from GLSTAT file, Energies (N/mm²) Vs Time (ms). 


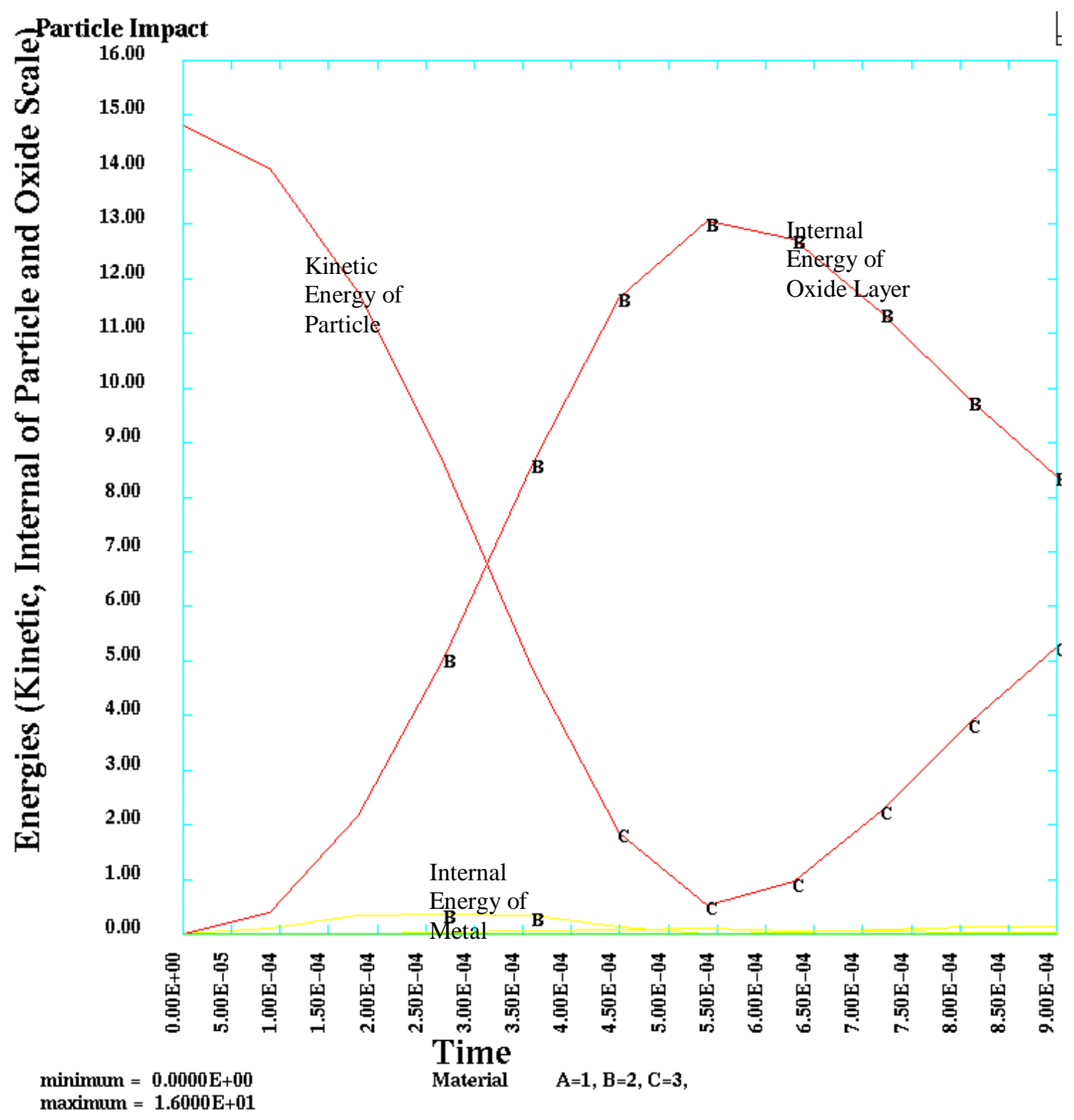

Fig. 5.5 Graph from MATSUM file, Energies $\left(\mathrm{N} / \mathrm{mm}^{2}\right)$ of Particle and Oxide Scale Vs Time (ms) 


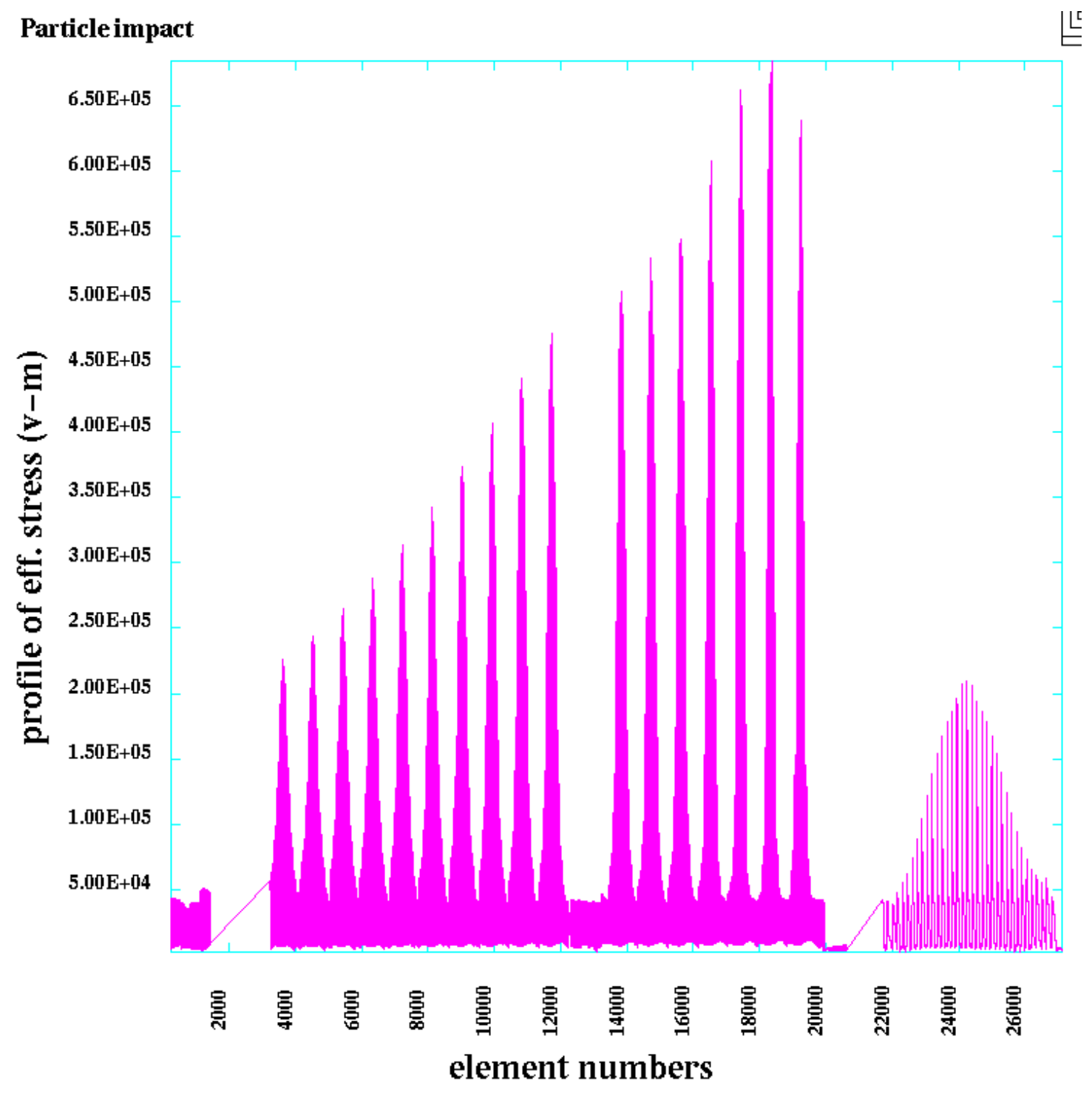

minimum $=2.0021 \mathrm{E}+03$ at element 22234 maximum $=6.8411 \mathrm{E}+05$ at element 18362

Fig. 5.6 Effective Stress $\left(\mathrm{N} / \mathrm{mm}^{2}\right)$ Vs Element Number. 


\section{CHAPTER 6}

\section{RESULTS AND DISCUSSIONS}

\subsection{Introduction}

The main objective of this chapter revolves around the results and conclusions of the comparison between in service wear rates with the developed numerical model to assess the value of the computational model in depicting the behavior of in service material. The first step that included in this study is the volume loss estimation of the aluminum oxide model and comparing the results with that of Levy's [52] work. The core of this study based on the Levy's statement "the effect of the particle sizes above $200 \mu \mathrm{m}$ and up to $500 \mu \mathrm{m}$ remains essentially constant." He worked with the aluminum oxide models at different temperatures comparing in service and the threebody abrasion testing conditions. As the results given by Levy in this paper are based on different parameters of the three body wear which were not clearly mentioned, the present comparison had been done with the statement rather than with the numerical data of the erosion loss. The results showed a good correlation with the Levy's statement. The same procedure was then extended to the iron/iron-oxide system to study the effect of the various parameters such as

- Size of the Impacting Particle.

- Velocity of the Impacting Particle.

- Angle of Incidence of the Impacting Particle.

- Temperature Effects. 
The size effects were tested for diameters ranging from $100 \mu \mathrm{m}$ to $300 \mu \mathrm{m}$, with a gradual increase in diameter length at different temperatures. The study focuses the effect of particle velocity and the angle of incidence on the $100 \mu \mathrm{m}$ particle. The results were presented as graphs and plots between the volume loss $(\mu \mathrm{m})^{3}$ and the parameters effecting the erosion loss.

\subsection{Aluminum Oxide System}

The initial step to validate the computational model with the experimental work and to extend the procedure to the iron/iron oxide system. The aluminum model was used for validation. The system consists of the silicon carbide particle and aluminum oxide. The depth of the oxide scale was taken as $50 \mu \mathrm{m}$ as given by Levy [52], the oxide scale formed for temperature range $450-500{ }^{0} \mathrm{C}$. The material properties of the Silicon particle were taken from a material handbook [53] and those of the aluminum oxide were from Coors ceramics. Material properties of the Aluminum Oxide Scale as given by Coors ceramics are given in the table 6.1 .

The model developed was exactly based on the experimental work of Levy [52]. The depth of the oxide scale and the particle diameters were taken from his work for a better comparison. The dimensions of the aluminum model was 500 X $450 \times 250 \mu \mathrm{m}^{3}$. In which $50 \mu \mathrm{m}$ was the oxide scale thickness and $200 \mu \mathrm{m}$ was the thickness of the aluminum. The particle was spherical and the size ranges from 100 to $300 \mu \mathrm{m}$. The velocity of the particle was $50 \mathrm{~m} / \mathrm{s}$ and 
impacted to the aluminum oxide scale at normal incidence. The volume loss was calculated by impacting particles to the target surface and the results were shown in the figures 6.1 to 6.3 .

\begin{tabular}{|l|l|}
\hline \multicolumn{2}{|l|}{ Properties of the Aluminum Oxide Model } \\
\hline Modulus Of Elasticity (Gpa) & 372.3 \\
\hline Mass Density $\left(\mathrm{kg} / \mathrm{m}^{3}\right)$ & 3890 \\
\hline Poison's Ratio & 0.22 \\
\hline Fracture Stress $(\mathrm{MPa})$ & 26.10 \\
\hline
\end{tabular}

6.1 Material properties of the Aluminum Oxide model as given in Coors ceramics.

\begin{tabular}{|l|l|}
\hline \multicolumn{2}{|c|}{ Properties of the Silicon Carbide Particles } \\
\hline Modulus Of Elasticity (Gpa) & 37.49 \\
\hline Mass Density $\left(\mathrm{kg} / \mathrm{m}^{3}\right)$ & 71.28 \\
\hline Poisson's Ratio & 0.192 \\
\hline
\end{tabular}

Table 6.2. Material Properties of Silicon Carbide Particles required for the LSDYNA3D input format. 
The assumption that the aluminum oxide and iron oxide behaves as brittle materials was taken from the conclusions of the Yalamanchilli et al., [39] work. Levy [52] conducted experiments on erosion wear of different particle sizes to compare the three body wear methods with that of in service materials. He concluded that the effect of size is significant to that of particle hardness or its strength. According to him the particle size above $200 \mu \mathrm{m}$ and up to $500 \mu \mathrm{m}$ had same effect on the erosion of target surface.

In the present work numerical model was used to simulate the experimental work of Levy [52]. The analysis was performed using the IDEAS and LS -DYNA3D. The details of the procedure adopted for the estimation of volume loss was given in the Chapter 5. The erosion loss was estimated to $\mu \mathrm{m}^{3}$.

The results show that the volume loss increases steadily with increase in diameter of the particle. The kinetic energy of the particle increases with the size, increasing its capability to penetrate into the target surface developing cracks resulting in more volume loss. Until $200 \mu \mathrm{m}$ the dominating factor is the size of the particle. But as the size increases further than $200 \mu \mathrm{m}$, the diameter becomes dominating factor comparing to its mass and the kinetic energy, decreasing its ability to penetrate the target surface. Hence, the erosion loss remains same or decreases as predicted by Levy. In the present work the volume loss remained more or less the same as that at $200 \mu \mathrm{m}$. The graph between the volume loss $\left(\mu \mathrm{m}^{3}\right)$ Vs the size of the 
impacting particle $(\mu \mathrm{m})$ is shown in the figure 6.2. The stress contours for the impacting particle range 200 to $300 \mu \mathrm{m}$ is shown in the figure 6.3 .

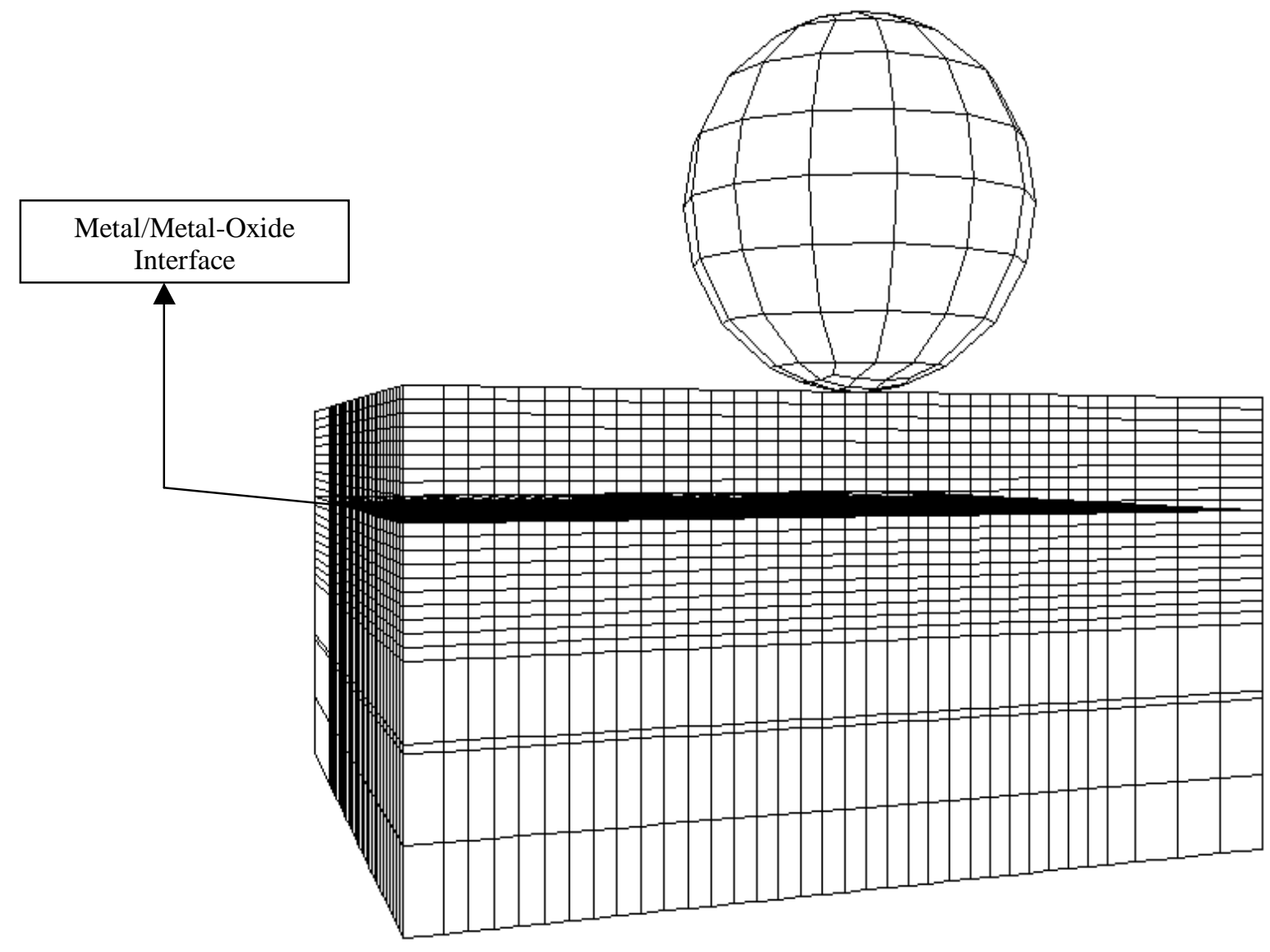

Fig 6.1 Aluminum/Aluminum-Oxide System 


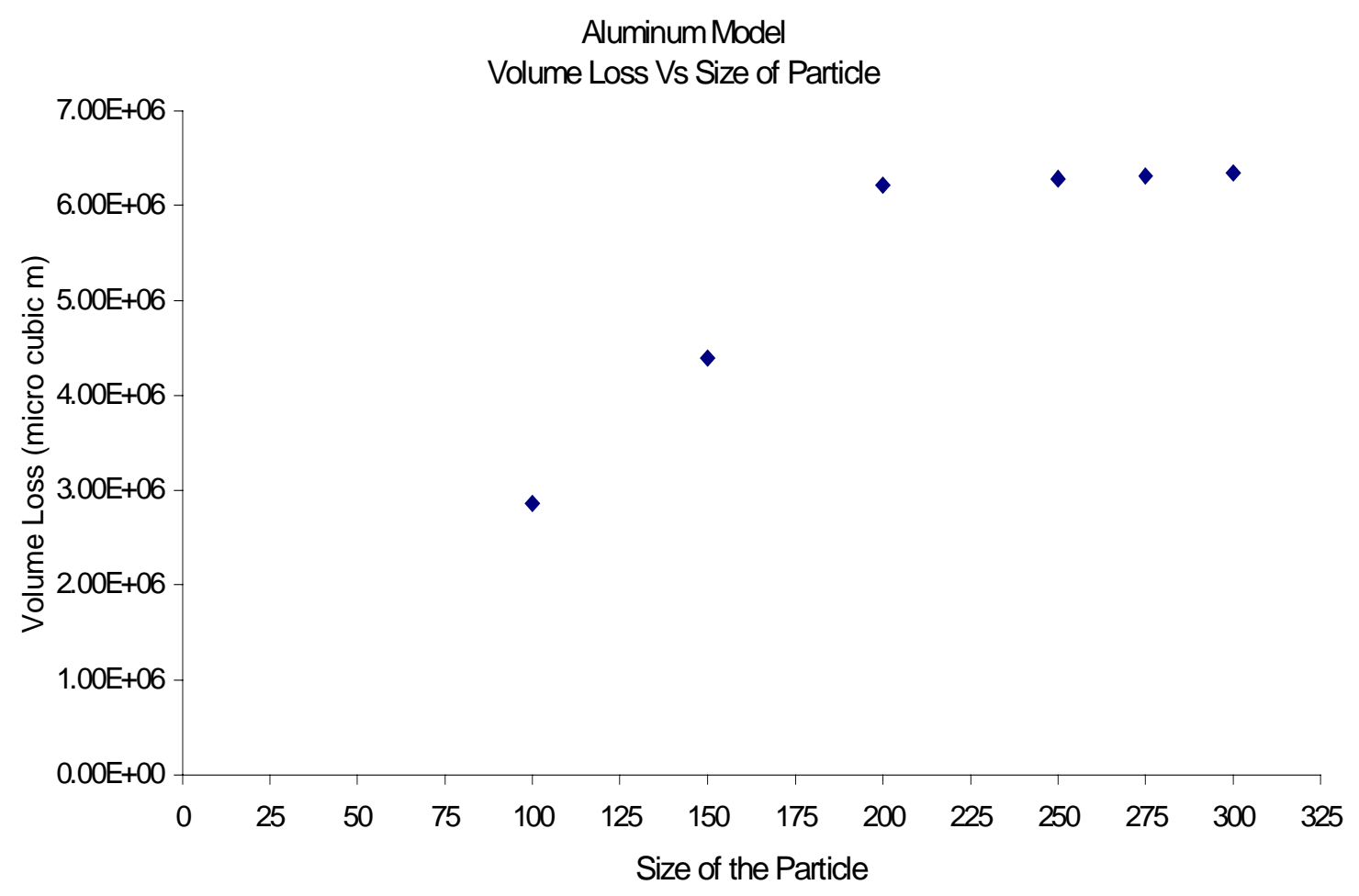

Fig 6.2 Volume loss Vs size of the particle impacting at normal incidence with $50 \mathrm{~m} / \mathrm{s}$ velocity at temperature $570^{\circ} \mathrm{C}$, Oxide layer thickness is $50 \mu \mathrm{m}$ 
$\mathrm{N} / \mathrm{mm}^{2}$

time $=1.00000 \mathrm{E}-03$

fringes of eff. stress ( $v-m)$

$\min =0.000 \mathrm{E}+00 \mathrm{in}$ element 26520

$\max =4.946 \mathrm{E}+05$ in element 22563

fringe levels

0.000E $+00=$

$1.978 E+04>$

$3.956 \mathrm{E}+04=$

$5.935 E+04>$

$7.913 E+04=$

$9.891 \mathrm{E}+04$ ?

1.187E+05 >

1.385E +05 =

1.5S3E+05 ?

1.7S0E +05 >

$1.978 E+05>$

2.176E+05 ? $2.374 \mathrm{E}+05$ > $2.572 E+05=$

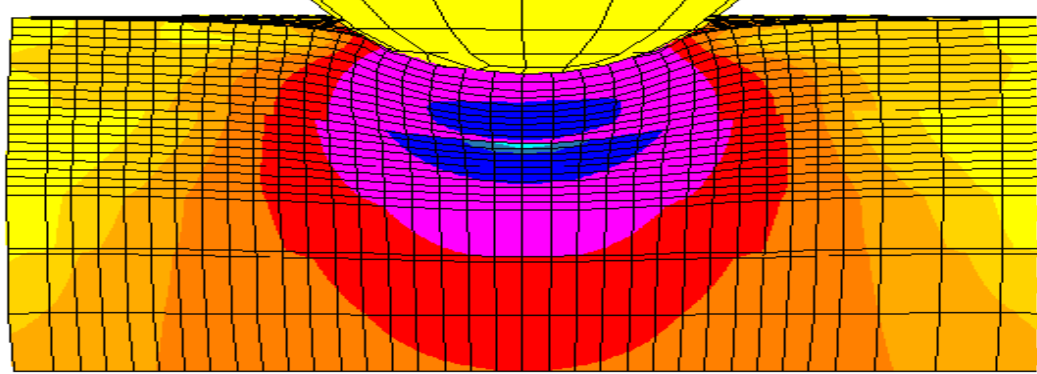

$7705+05$ $2.967 E+05$ > .165E $+05=$ $363 \mathrm{E}+05$ $3.561 \mathrm{E}+05$ > $3.759 \mathrm{E}+05$ $3.956 \mathrm{E}+05=$ 4.154E+05 $4.352 \mathrm{E}+05$. $4.550 \mathrm{E}+05$ ? $4.748 E+05=$ $4.946 \mathrm{E}+05$ ?

\section{Fig 6.3 The stress contour of aluminum oxide model}

time $=1.20000 \mathrm{E}-03$

fringes of eff. stress ( $v-m$ )

$\min =0.000 \mathrm{E}+00$ in element 26520
$\max =4.920 \mathrm{E}+05$ in element 21693

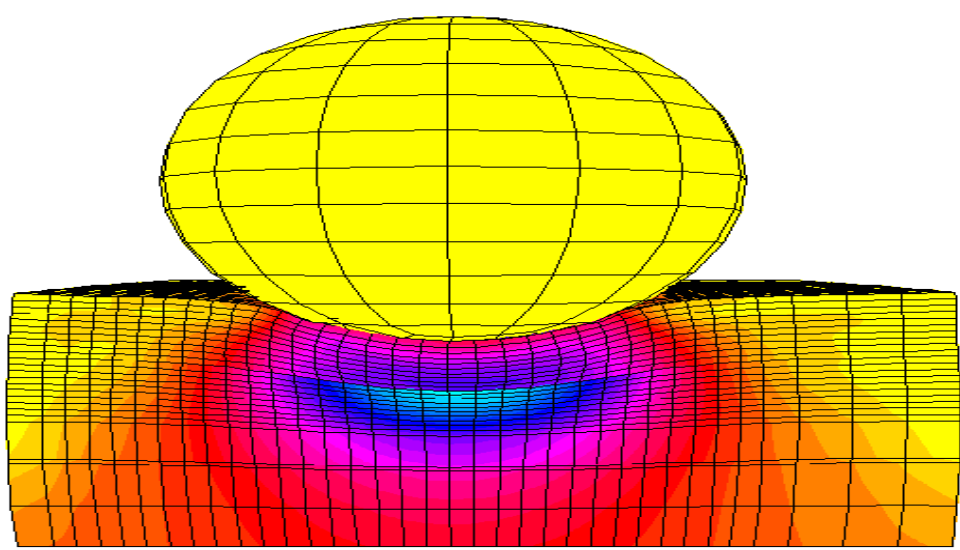

fringe level $1.968 \mathrm{E}+04$

$3.936 \mathrm{E}+04>$

$5.904 E+04>$

$7.872 E+04>$

$9.840 E+04>$

$1.181 E+05>$

$1.378 E+05>$

$1.574 \mathrm{E}+05=$

$1.771 E+05>$

$.968 \mathrm{E}+05>$

$2.165 E+05=$

$2.361 \mathrm{E}+05>$

$2.558+05=$

$2.755 E+05=$

$2.952 \mathrm{E}+05=$

3.149E+05 >

$3.345 E+05=$

$3.542 \mathrm{E}+05$ ?

$3.739 \mathrm{E}+05>$

$3.936 \mathrm{E}+05$ >

$4.133 E+05$ ?

$4.329 \mathrm{E}+05$ ?

$4.526 \mathrm{E}+\mathrm{0S}$ >

4.723E+05 ?

$\mathbf{x} \uparrow_{\mathbf{z}}^{\mathbf{y}}$

$4.920 \mathrm{E}+05=$ 
time $=1.30000 \mathrm{E}-03$

$\min =0.000 E+00$ in element 26488
$\max =5.337 \mathrm{E}+05$ in element 22565

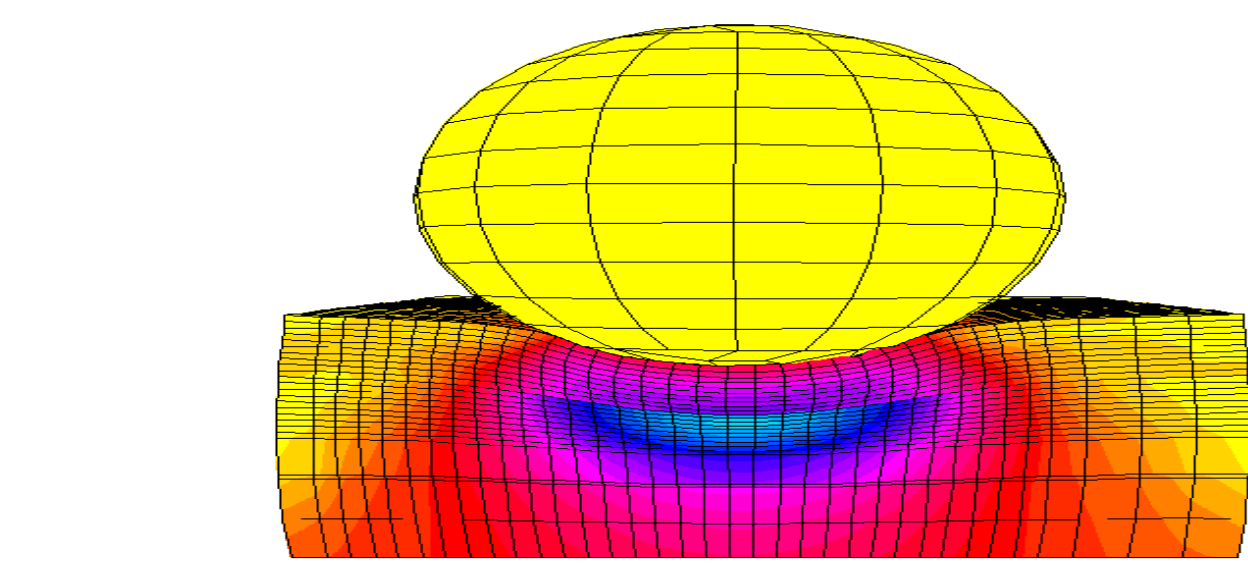

fringe level

$2.135 E+04=$

$4.269 \mathrm{E}+04>$

$6.404 \mathrm{E}+\mathrm{OC}>$

s.539E $+04>$

$1.067 E+05=$

$1.281 \mathrm{E}+0 \mathrm{05}=$

$1.494 \mathrm{E}+05$ ?

1.70sE+05 ?

$1.921 \mathrm{E}+05=$

$2.135 E+05>$

$2.348 E+05=$

$2.562 \mathrm{E}+05=$

$2.775 E+05=$

$2.989 E+05=$

$3.202 \mathrm{E}+05=$

$3.416 \mathrm{E}+05=$

$3.629 \mathrm{E}+05=$

$4.269 \mathrm{E}+05$

$4.483 \mathrm{E}+05=$

$4.696 \mathrm{E}+05$

$4.910 E+05=$

5.123E+05 $=$

$\mathbf{Y}$
$\mathbf{z}$

$5.337 E+05$

time $=1.40000 \mathrm{E}-03$

fringes of eff. stress ( $v-m$ )

$\min =0.000 \mathrm{E}+00 \mathrm{in}$ element 26520 $\max =5.603 E+05$ in element 13743

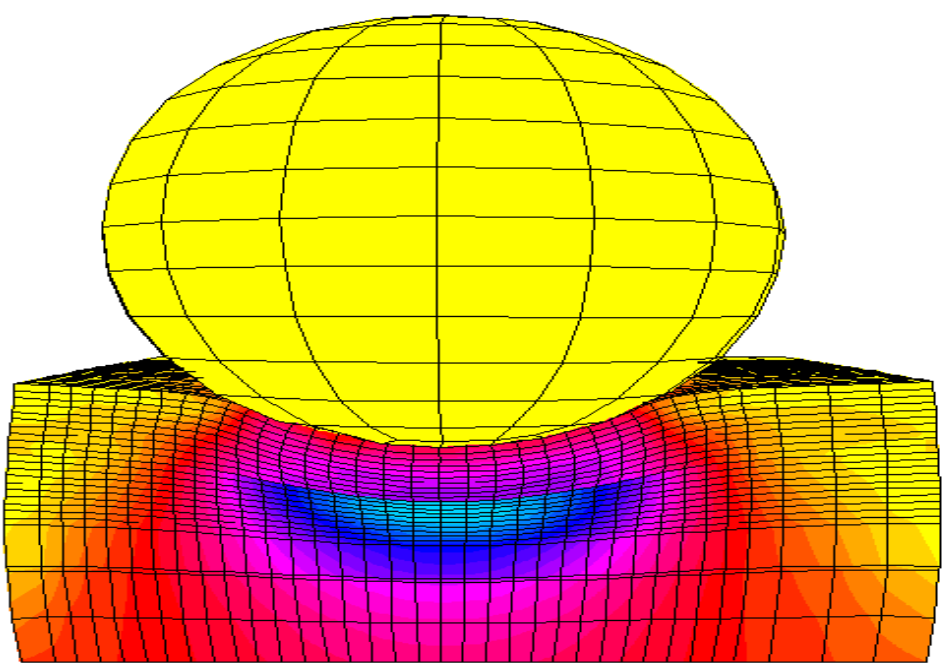

fringe levels

0.000E+00 ?

$2.241 E+04>$

$4.483 \mathrm{E}+04$ >

$6.724 E+04>$

$8.965 E+04>$

1.121E+05 >

$1.345 E+05$ ?

$1.569 \mathrm{E}+0 \mathrm{0S}$ ?

$1.793 \mathrm{E}+05$ ?

2.017E+05 >

$2.241 \mathrm{E}+05$ ?

$2.465 E+05>$

$2.690 \mathrm{E}+05$ ?

$2.914 E+05>$

$3.138 E+05$ ?

$3.362 \mathrm{E}+05$ ?

$3.586 \mathrm{E}+05$ ?

$3.810 E+05$ ?

4.034E +05 ?

$4.258 \mathrm{E}+05$ ?

$4.483 \mathrm{E}+05$ ?

$4.707 \mathrm{E}+05=$

$4.931 E+05$ ?

$5.155 E+05=$

$5.379 \mathrm{E}+05$ ?

$\mathbf{Y}$

$5.603 E+05$ ?

$\mathbf{x} \mathbf{z}$

Fig 6.4 the effect of particle sizes on volume loss through contour plots. 


\subsection{Iron/Iron Oxide System}

The above model after validating with the experimental work, has been extended to the Iron/Iron-Oxide system. The Iron/Iron-Oxide system consists of metal substrate, an oxide layer and the silicon carbide particle. The dimensions of the substrate and the oxide scale were 500 X $450 \mu \mathrm{m}$. The thickness of the oxide scale and the metal substrate depends on the temperature, namely 570, 674, 743 and 800 ${ }^{0} \mathrm{C}$. The thickness of the oxide layer depends on the oxidation process that in turn depends on the temperature. The silicon carbide particle was assumed to be rigid with astrength great enough to prevent from fracturing or shattering. The oxide surface was assumed to be flat with no effects of earlier impacts. Only half the model was considered to save the computational time and the axis-symmetric boundary conditions were applied. The particle was given a constant velocity in the negative $\mathrm{Y}$ direction.

The material properties of the silicon carbide particle was taken from the hand book [ ] as shown in the table 6.2. The properties of the iron and the oxide layer were taken from the experimental results of Bruce et al. [46] and were given in the table 6.3. The particle was spherical in shape and the solid particle erosion analysis was performed for various particle sizes, velocities, and angles of incidence and temperatures.

In both laboratory and in service equipment the particles are free to change their orientation with the target surface and can hit in any direction. Hence all angles 
of attack from 10 to $90^{0}$ was considered for analysis. The size of the particles ranges from $100 \mu \mathrm{m}$ to $300 \mu \mathrm{m}$ with velocity ranging from $10 \mathrm{~m} / \mathrm{s}$ to $100 \mathrm{~m} / \mathrm{s}$. In all these cases transient dynamic analysis was performed using LS-DYNA3D. The procedure adopted was the same as that used for aluminum model. The results were given in the form of graphs.

\begin{tabular}{|c|c|c|c|c|}
\hline $\begin{array}{ll} & \text { Temperature } \longrightarrow \\
\text { Properties } & \downarrow\end{array}$ & $570{ }^{\circ} \mathrm{C}$ & $674^{\circ} \mathrm{C}$ & $743^{\circ} \mathrm{C}$ & $800^{\circ} \mathrm{C}$ \\
\hline \multicolumn{5}{|l|}{ Iron Oxide } \\
\hline Modulus of Elasticity (Gpa) & 182 & 168 & 158 & 151 \\
\hline Mass Density $\left(\mathrm{Kg} / \mathrm{m}^{3}\right)$ & 5190 & 5188 & 5187 & 5185.5 \\
\hline Poisson's Ratio & 0.345 & 0.345 & 0.345 & 0.345 \\
\hline Scale Thickness $(\mu \mathrm{m})$ & 36 & 111 & 206 & 325 \\
\hline Fracture Stress (Mpa) & 38 & 2.4 & 1.9 & 4.9 \\
\hline \multicolumn{5}{|l|}{ Iron } \\
\hline Modulus Of Elasticity (Gpa) & 155 & 149.53 & 135.06 & 125.41 \\
\hline Mass Density $\left(\mathrm{Kg} / \mathrm{m}^{3}\right)$ & 7810 & 7802 & 7800 & 7798 \\
\hline Poisson's Ratio & 0.34 & 0.34 & 0.34 & 0.34 \\
\hline Scale Thickness $(\mu \mathrm{m})$ & 150 & 100 & 50 & 25 \\
\hline
\end{tabular}

Table. 6.3 Mechanical Properties of Iron Oxide and the Iron Substrate at Different Temperatures 


\subsubsection{Influence of Size}

The effect of size of particle on iron/iron oxide system was similar to that of aluminum oxide model. The volume loss was estimated for all the sizes of impacting particle for velocity of $50 \mathrm{~m} / \mathrm{s}$ at normal incidence. The analysis was conducting for temperatures $674{ }^{\circ} \mathrm{C}$ and $743{ }^{\circ} \mathrm{C}$. The thickness of oxide layer was 111 and $206 \mu \mathrm{m}$ respectively. The particle was impacted on to the target surface and analysis was done for 9.0E-04 ms that was obtained from initial test run.

With the increase in the size of the particle, the mass as well as kinetic energy associated with the particle increases, increasing its ability to penetrate the target surface developing cracks resulting in the more volume loss. The difference in volume loss for $100 \mu \mathrm{m}$ and $150 \mu \mathrm{m}$ was more, owing to the large kinetic energy of the particle. Thereafter the difference in the volume loss for $50 \mu \mathrm{m}$ increase in size was less, as the dominating factor was its diameter decreasing the capability of particle to penetrate the target surface. Unlike aluminum system volume loss for particle impact on iron oxide surface increased until $250 \mu \mathrm{m}$. This can be attributed to the oxide layer thickness 111 and $206 \mu \mathrm{m}$ as compared to $50 \mu \mathrm{m}$ of aluminum model.

The analysis was performed at two different temperatures $674{ }^{\circ} \mathrm{C}$ and $743{ }^{\circ} \mathrm{C}$. The volume loss at $674{ }^{\circ} \mathrm{C}$ for $250 \mu \mathrm{m}$ particle was $1.41 \mathrm{E}+07 \mu \mathrm{m}^{3}$ and that of at 743 ${ }^{\circ} \mathrm{C}$ was $3.05 \mathrm{E}+07 \mu \mathrm{m}^{3}$. This is because at lower temperature the volume loss is due to the brittle fracture and at higher temperature the plastic flow dominates, reducing the 
volume loss. The iron oxide scale formed at $570{ }^{\circ} \mathrm{C}$ has higher modulus of elasticity than that at $743{ }^{\circ} \mathrm{C}$.

The graphs for volume loss of oxide layer Vs size of particles at 674 and $743{ }^{\circ} \mathrm{C}$ was shown in figures 6.5 and 6.6 and the comparison of both temperatures in 6.7. The pie diagram shows the \%age of internal energy taken by oxide layer out of total energy for all the three particle sizes 250,275 and $300 \mu \mathrm{m}$. The internal energy of the oxide scale for all the above mentioned three particles was same, hence the same volume loss.

\subsubsection{Effect of Velocity on Erosion Mechanism}

Analysis was performed at normal incidence for $100 \mu \mathrm{m}$ particle at several velocities ranging from $10 \mathrm{~m} / \mathrm{s}$ to $100 \mathrm{~m} / \mathrm{s}$ to determine the volume loss and in order to obtain trend lines. The analysis was carried out at temperature 570, 674 and 743 ${ }^{\circ} \mathrm{C}$ respectively. The steady state erosion rates were constant and were related directly to the particle velocity. The rate of increase in volume loss was different for different velocities. The slight linear variation of volume loss for the case of temperature $570^{\circ} \mathrm{C}$ and for a velocity of $30 \mathrm{~m} / \mathrm{s}$ is attributed to the numerical error and error due to rounding off volume loss estimation which was based on each individual failed brick element. In real life the eroded material need not be in the shape of brick. For temperatures 674 and $743{ }^{\circ} \mathrm{C}$, the variation of volume loss followed the constant slope. The results are in correlation with the work of Yalamanchili et al. [39]. 


\subsubsection{Effect of Impact Angle}

In real life the particles are free to change their orientation with the target surface bombarding at different angles. In the present work the angle of attack was varied from $0^{\circ}$ to $90^{\circ}$ for $100 \mu \mathrm{m}$ spherical particle keeping the velocity constant at 50 $\mathrm{m} / \mathrm{s}$. The variation of volume loss was linear at all the temperatures considered. In all the cases the variation of volume loss was more at shallow angles and less at higher angles. In all the three cases the volume loss was maximum at normal incidence. The volume loss was $7.26 \mathrm{E}+05,2.93 \mathrm{E}+06$ and $4.02 \mathrm{E}+06 \mu \mathrm{m}^{3}$ at temperatures 570,674 and $743^{\circ} \mathrm{C}$ respectively. The variation of volume loss at the shallow angle s can be attributed to the more surface contact between the particle and the oxide layer as the erosion is due to the impact and sliding. 


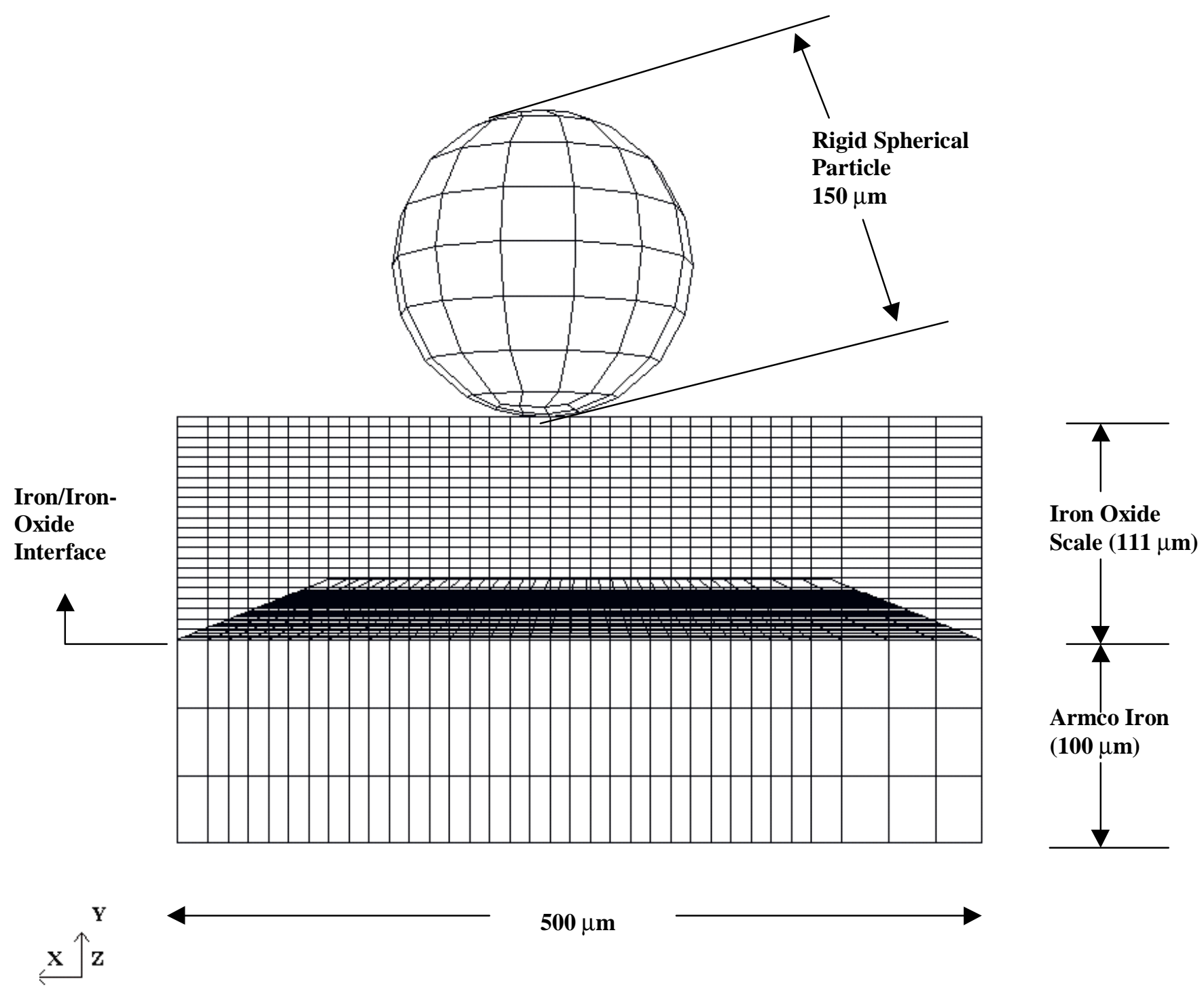

Fig 6.5 Iron/Iron-Oxide System at $674^{\circ}$ 


\section{Comparision of Size Effects}

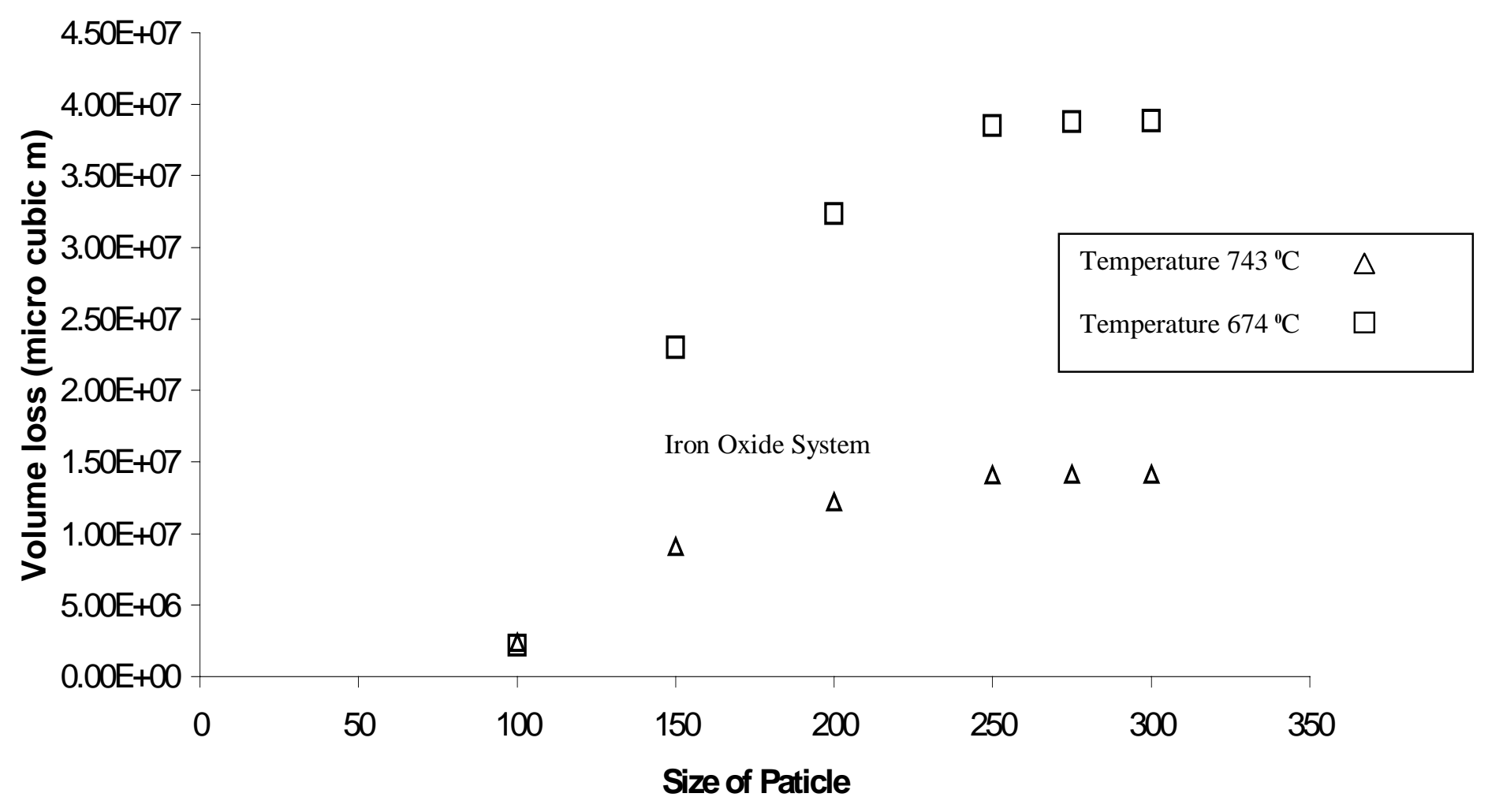

Iron Oxide System

Fig 6.6 Comparison of Size Effects at 743 and $674{ }^{\circ} \mathrm{C}$ at $50 \mathrm{~m} / \mathrm{s}$ velocity and for thickness 206 and $111 \mu \mathrm{m}$ respectively. 
$\mathrm{N} / \mathrm{mm}^{2}$

time $=$ 8.90000E-04
fringes of eff. stress $(v-m)$

$\min =0.000 \mathrm{E}+00$ in element 27573

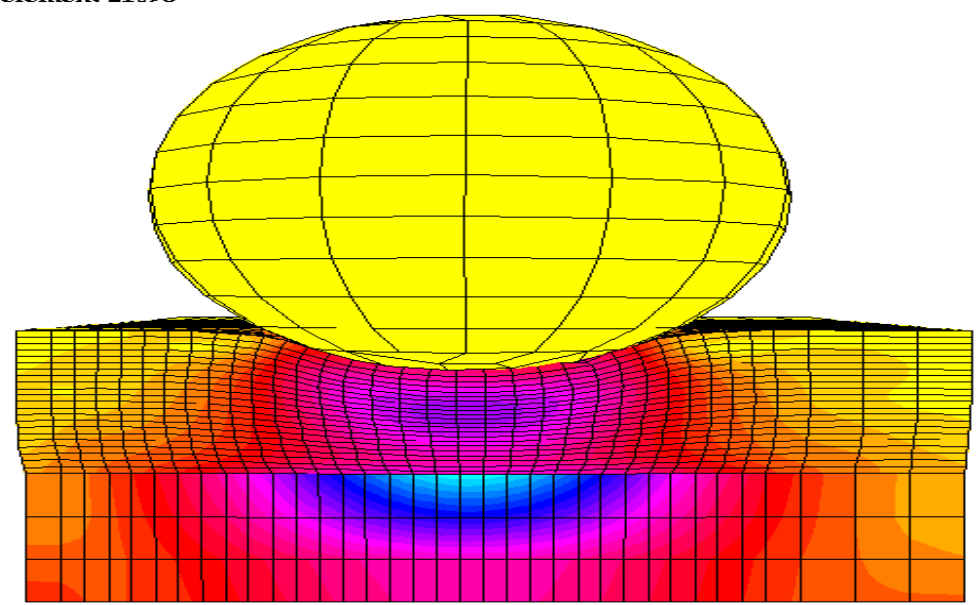

fringe levels

$4.678 E+04=$

$9.356 \mathrm{E}+04>$

$1.403 E+05$ >

1.871E+05 ?

$2.339 E+05$ ?

$2.807 E+05$ >

$3.274 \mathrm{E}+05>$

$3.742 \mathrm{E}+05$ ?

$4.210 E+05$ >

$4.678 E+05>$

$5.146 E+05$ ?

$5.613 \mathrm{E}+05$ ?

$6.081 E+05$ ?

$6.549 \mathrm{E}+05=$

$7.017 E+05$ ?

$7.484 E+05>$

$7.952 \mathrm{E}+05$ ?

S.420E+05 >

S.SSSE +05 >

$9.356 \mathrm{E}+05$ ?

$9.823 \mathrm{E}+05$ >

$1.029 E+06>$

$1.076 E+06>$

1.123E $+06>$

$\mathbf{x} \mathbf{z}$

$1.169 E+06>$

time $=8.00000 \mathrm{E}-04$

fringes of eff. stress ( $v-m$ )

fringe levels

$\min =0.000 \mathrm{E}+00$ in element 27605

$\max =9.974 \mathrm{E}+05$ in element 21096

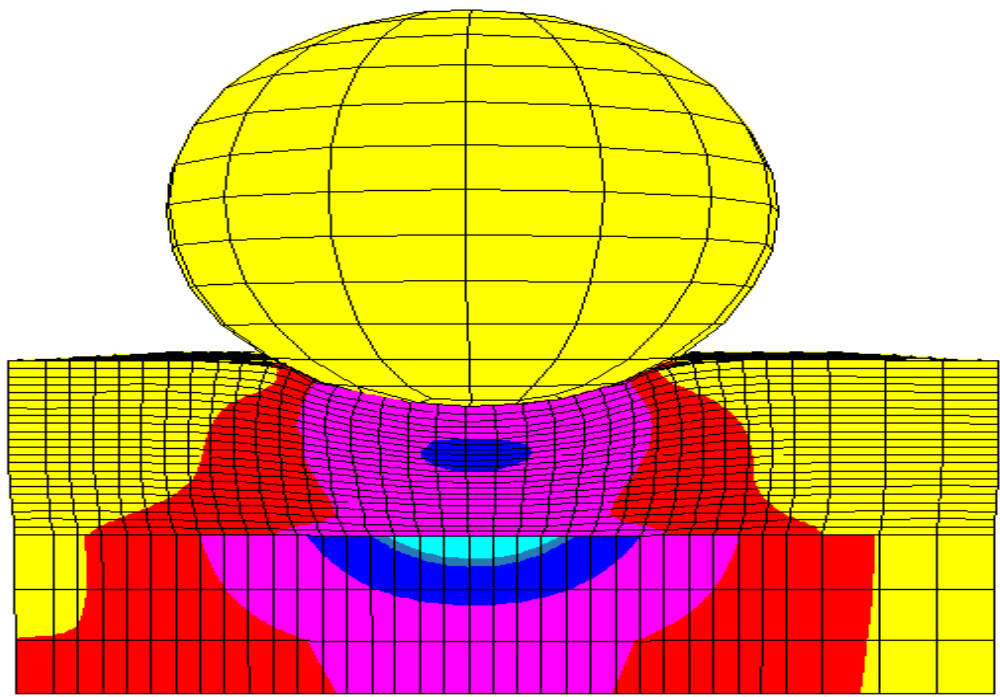

$\mathbf{Y}$

$3.990 \mathrm{E}+04>$

$7.979 E+04>$

1.197E+05 ?

$1.596 \mathrm{E}+05$ >

$1.995 \mathrm{E}+05$ ?

$2.394 E+05$ >

$2.793 \mathrm{E}+05>$

$.192 \mathrm{E}+05$ ?

$3.591 E+05$ ?

$3.990 E+05$ ?

$4.388 E+05$ ?

$4.787 E+05$ ?

$5.186 \mathrm{E}+05>$

2.585E +05 ?

$5.984 E+05$ ?

$6.383 \mathrm{E}+05$ ?

$6.782 \mathrm{E}+05>$

$7.181 E+05$ ?

$7.580 \mathrm{E}+05$ ?

$7.979 \mathrm{E}+05$ >

S.378E+05 ?

S.777E+05 >

$9.176 \mathrm{E}+05$

$9.575 \mathrm{E}+05$ >

$\mathbf{x} \mathbf{z}$

$9.974 \mathrm{E}+05=$

Fig 6.7 Stress contours for particle impact at $674{ }^{\circ} \mathrm{C}$ 
$\mathrm{N} / \mathrm{mm}^{2}$

time $=1.00000 \mathrm{E}-03$

fringes of eff. stress ( $v-m$ )

$\min =0.000 \mathrm{E}+00 \mathrm{in}$ element 27605

$\max =1.363 \mathrm{E}+06$ in element 21096

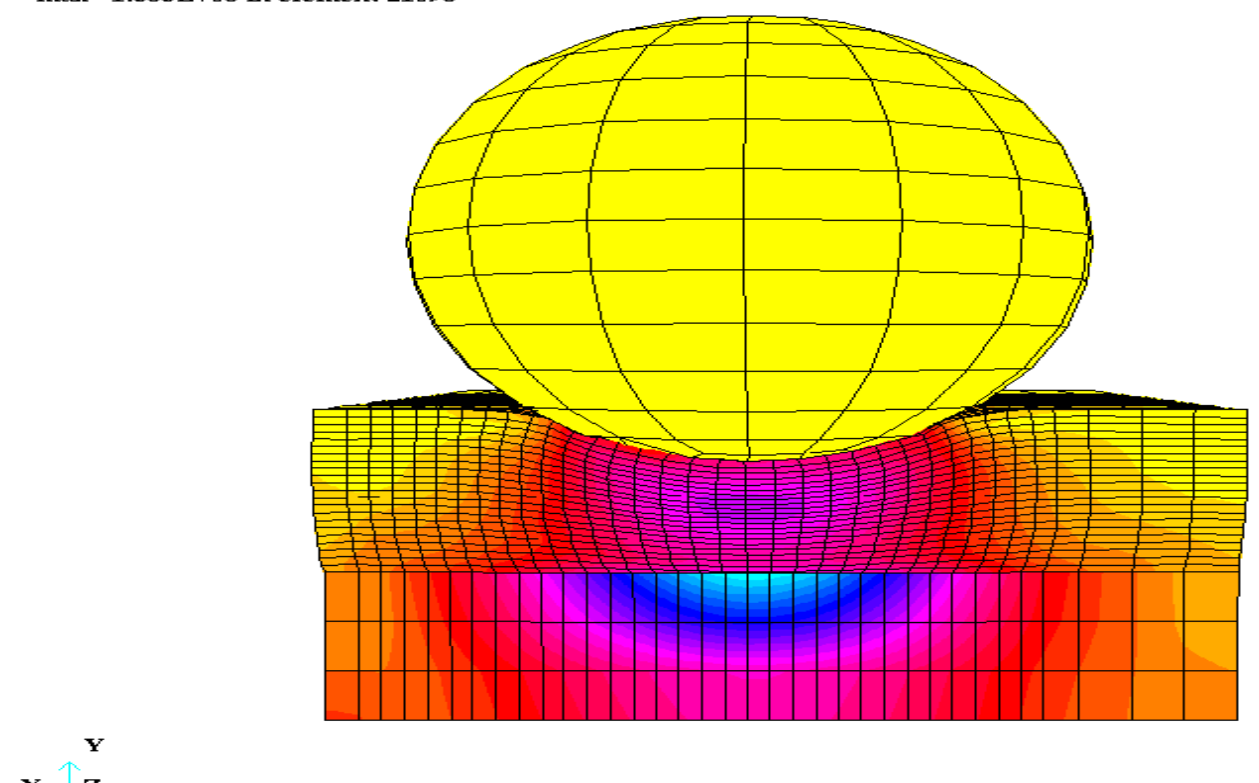

fringe levels

$0.000 E+00$ ?

$5.452 \mathrm{E}+04>$

$1.090 E+05$ ?

1.635E +05 >

2.181E+05 >

$2.726 \mathrm{E}+05$ >

$3.271 \mathrm{E}+05$ ?

$3.816 \mathrm{E}+05$ >

$4.361 \mathrm{E}+05$ >

$4.906 \mathrm{E}+05$ >

$5.452 \mathrm{E}+05$ >

$5.997 \mathrm{E}+05>$

$6.542 \mathrm{E}+05>$

7.087E+05 >

$7.632 \mathrm{E}+05$ >

S.177E+05 ?

8.723E+05 >

$9.268 \mathrm{E}+05$ >

$9.813 E+05$ ?

1.036E +06 >

1.090E +06 >

1.145E +06 >

1.199E +06 >

$1.254 \mathrm{E}+06>$

1.308E +06 >

$\mathbf{x} \mathbf{z}$

1.363E +06 >

Fig 6.8 Stress contours for particle impact at $674{ }^{\circ} \mathrm{C}$ 
$\mathrm{N} / \mathrm{mm}^{2}$

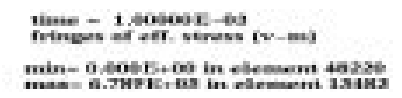

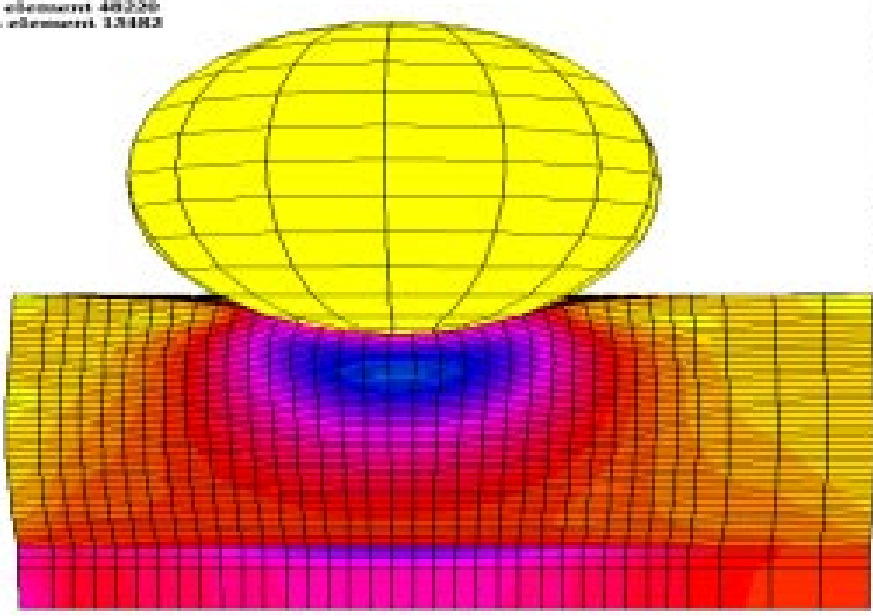

trinas level:

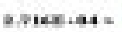

c.suxias -

c.1mseras =

inew-as :-

d. Mancras =

cease-as -

1.seristas -

cousias

m.riex as -

s.mozias -

saveras -

sometas

cerazias -

$4.3 a x+a k$ o

4.sire+as -

chascias =

actexias =

s.erseras :

crrexias :

cousens

c.sexias -

$\mathrm{v}$
$\times \quad 2$

c.raveras :

time $=9.95000 \mathrm{E}-04$

fringes of eff. stress ( $v-m$ )

$\min =0.000 \mathrm{E}+00$ in element 48188
$\max =6.971 \mathrm{E}+05$ in element 17253

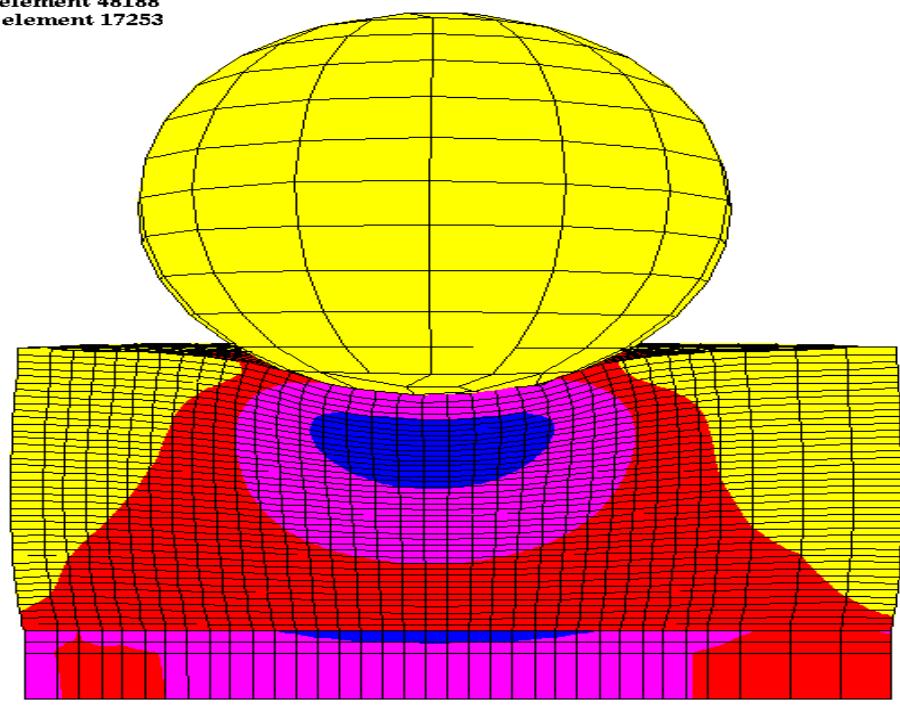

fringe levels

0.000E + 00 >

$2.788 E+04>$

$5.577 E+04$ >

8.365E +04 >

1.115E+0S ?

$1.394 \mathrm{E}+05$ >

1.673E +05 ?

$1.952 \mathrm{E}+05$ >

$2.231 E+05$ >

$2.510 E+05$ >

2.78sE+05 >

$3.067 \mathrm{E}+05$ >

$3.346 \mathrm{E}+05$ >

$3.625 \mathrm{E}+05$ >

$3.904 E+05>$

$4.183 \mathrm{E}+05$ >

$4.461 \mathrm{E}+05$ >

$4.740 E+05$ >

5.019E+05 >

5.295E $+05>$

$5.577 E+05$ >

5.856E +05 >

$6.134 \mathrm{E}+05>$

$6.413 \mathrm{E}+05$ ?

$6.692 \mathrm{E}+05$ >

$\mathbf{Y}$
$\mathbf{z}$

$6.971 \mathrm{E}+05$ >

Fig 6.9 Stress contours for particle impact at $743{ }^{\circ} \mathrm{C}$ 
$\mathrm{N} / \mathrm{mm}^{2}$

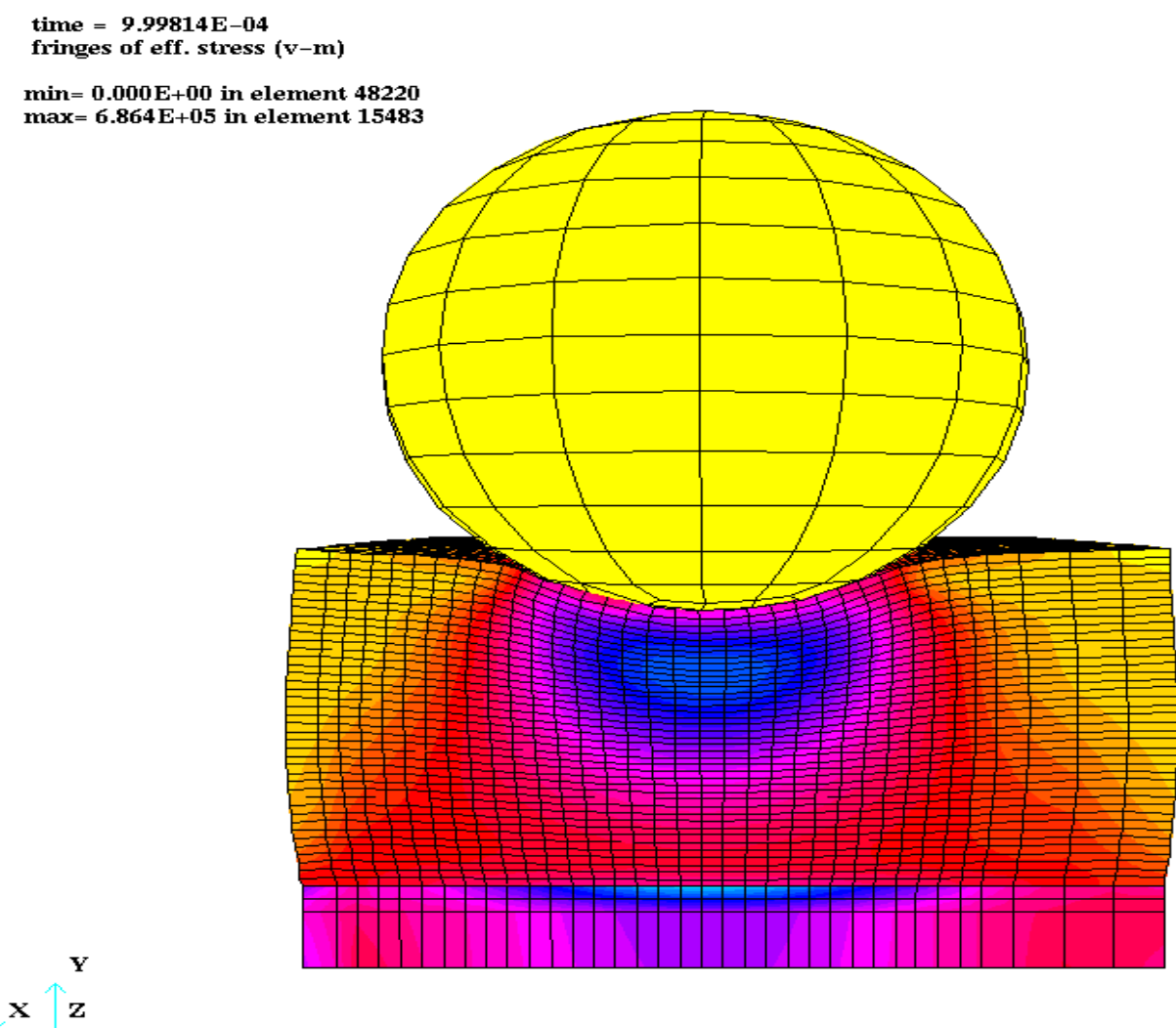

fringe levels 0.000E +00 >

$2.746 \mathrm{E}+04$

$5.491 \mathrm{E}+04$ ?

s.236E +04 >

1.09SE +05 >

1.373E +05 >

$1.647 \mathrm{E}+05$ =

$1.922 \mathrm{E}+05$ >

2.196E +05 =

2.471E+05 =

2.745E +05 =

3.020E +05 3

$3.295 \mathrm{E}+05$ ?

$3.569 \mathrm{E}+05$ ?

$3.844 \mathrm{E}+05$ ?

4.118E +05 >

4.393E +05 ?

$4.667 \mathrm{E}+05$ ?

$4.942 \mathrm{E}+05$ ?

5.216E +05 =

$5.491 \mathrm{E}+05$ =

$5.766 \mathrm{E}+05$ >

6.040E+05

6.315E+05

$6.589 \mathrm{E}+05$ =

$6.864 \mathrm{E}+05$ ?

Fig 6.10 Stress contours for particle impact at $743{ }^{\circ} \mathrm{C}$ 
Iron Oxide System

Temperature $570{ }^{\circ} \mathrm{C}$

\section{Volume Loss vs Velocity}

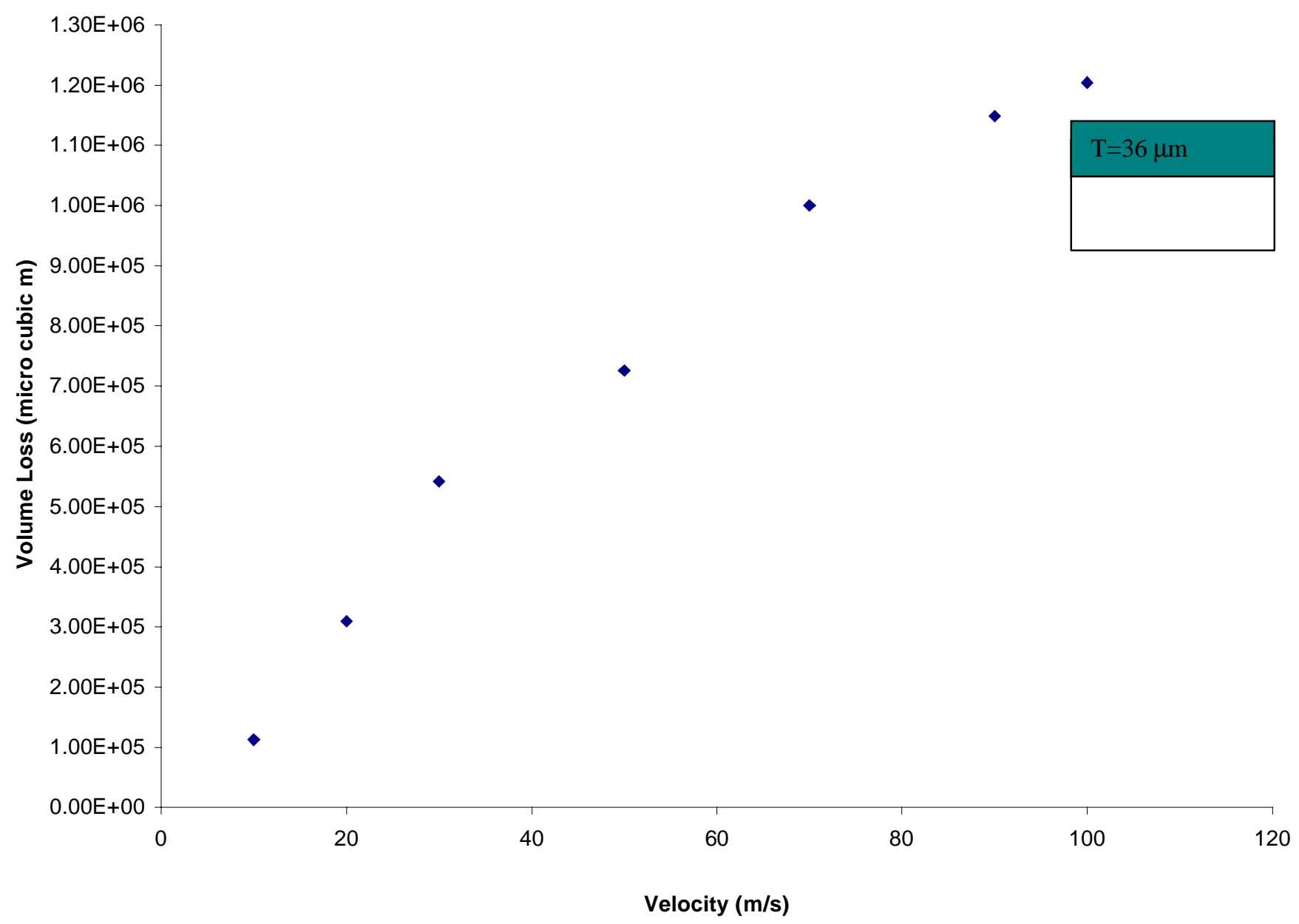

Fig. 6.11 Volume loss Vs Velocity for $100 \mu \mathrm{m}$ impacting Particle

$\mathrm{T}$ is the thickness of oxide scale 
Volume loss vs Angle of Attack

Velocity $=50 \mathrm{~m} / \mathrm{s}$

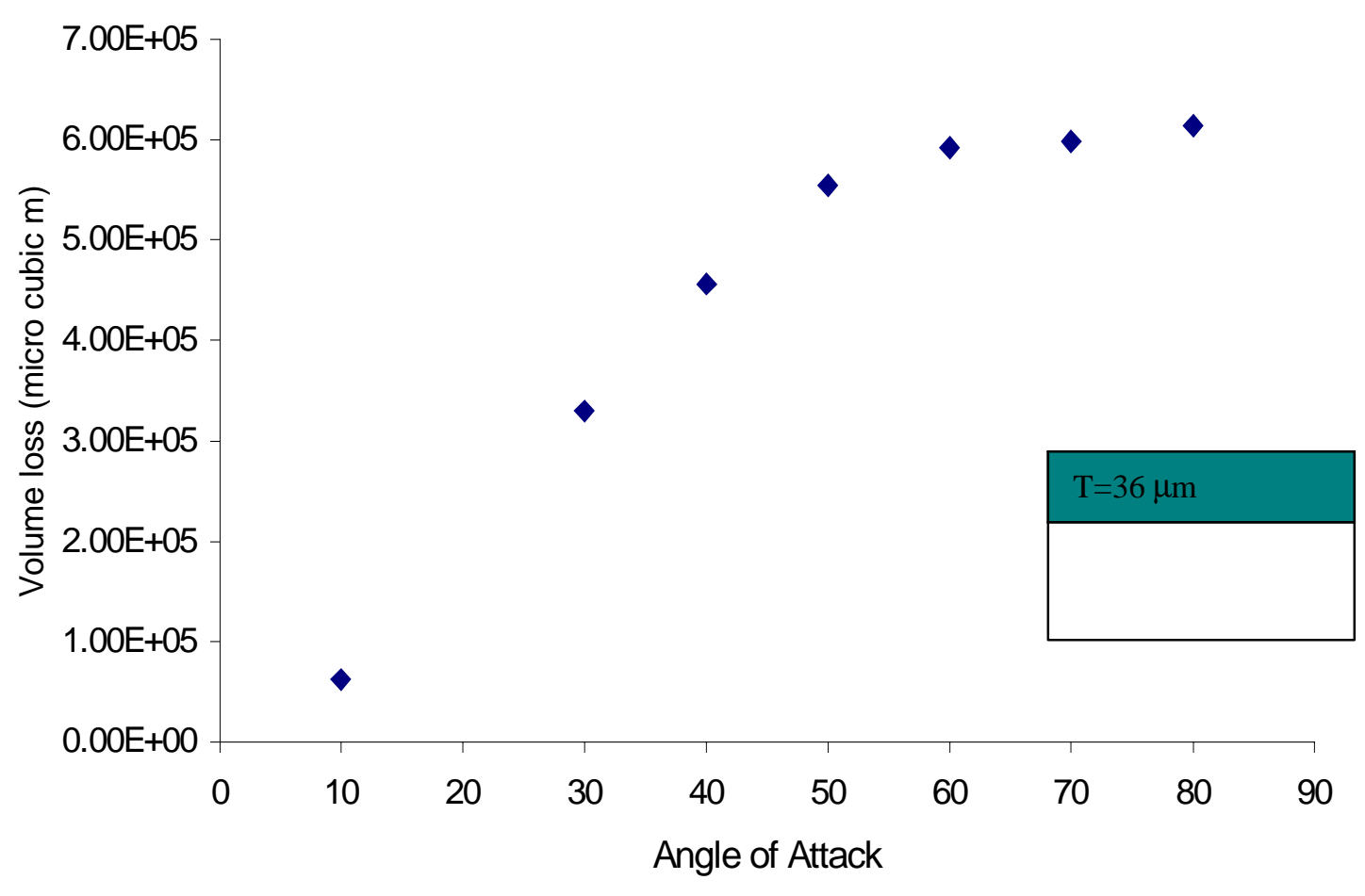

Iron Oxide System

Fig. 6.12 Volume loss Vs Angle of attack for $100 \mu \mathrm{m}$ particle at $570^{\circ} \mathrm{C}$

$\mathrm{T}$ is the thickness of the oxide layer. 


\section{Particle Impact \\ time $=0.0000 \mathrm{E}+00$}

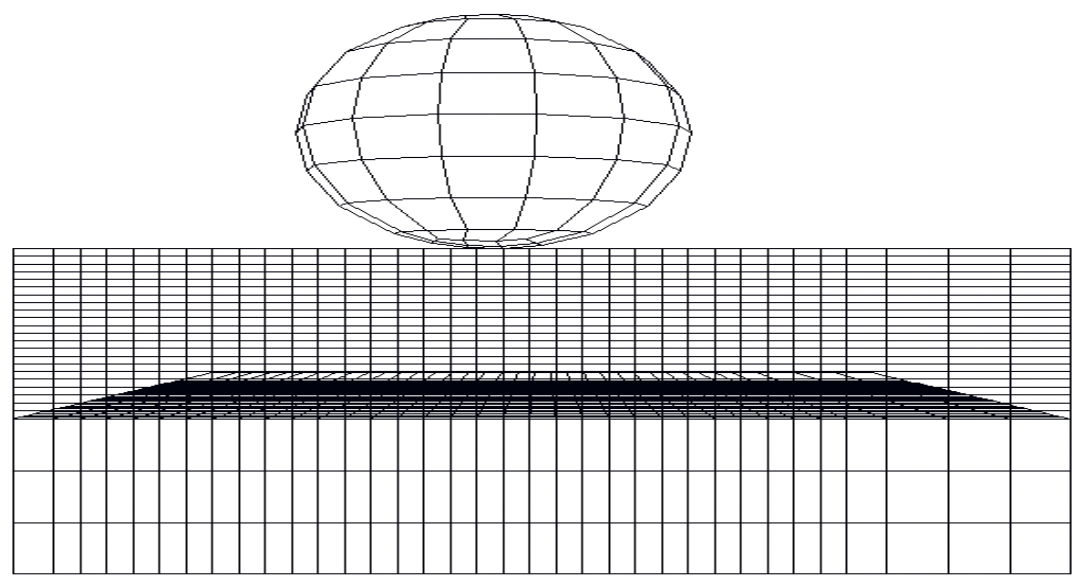

$\underline{\mathbf{x}} \uparrow_{z}^{\mathbf{y}}$

$\mathrm{N} / \mathrm{mm}^{2}$

time $=1.79885 \mathrm{E}-04$

ss $(v-m)$

fringe levels

$\min =0.000 E+00$ in element 27421

OOE +00

$1.805 E+04=$

$\max =4.512 \mathrm{E}+05$ in element 1833

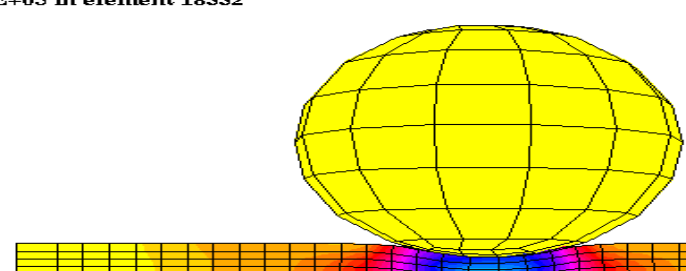

$3.609 \mathrm{E}+04=$

$5.414 E+04>$

$7.219 \mathrm{E}+04=$

$9.023 E+04>$

1.083E+05 >

$1.263 \mathrm{E}+05$ ?

$1.444 \mathrm{E}+05=$

$1.624 \mathrm{E}+\mathrm{0S}$ >

1.SOSE+05 >

1.985E+05 >

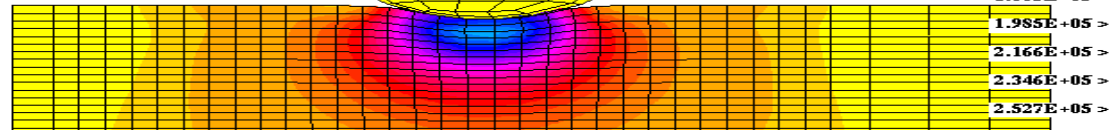

$2.527 \mathrm{E}+05=$

2.707E+05 =

$3.0685+05>$

3.248E+05 =

3.429 $1+05=$

$3.609 \mathrm{E}+05=$

$3.790 \mathrm{E}+05$ >

$3.970 \mathrm{E}+05$ =

4.151E+OS =

$4.331 \mathrm{E}+05>$

$\mathbf{x} \mathbf{z}$

$4.512 \mathrm{E}+05$

Fig. 6.13 Sequence of steps of particle impact on to target surface at $50 \mathrm{~m} / \mathrm{s}$ 
$\mathrm{N} / \mathrm{mm}^{2}$

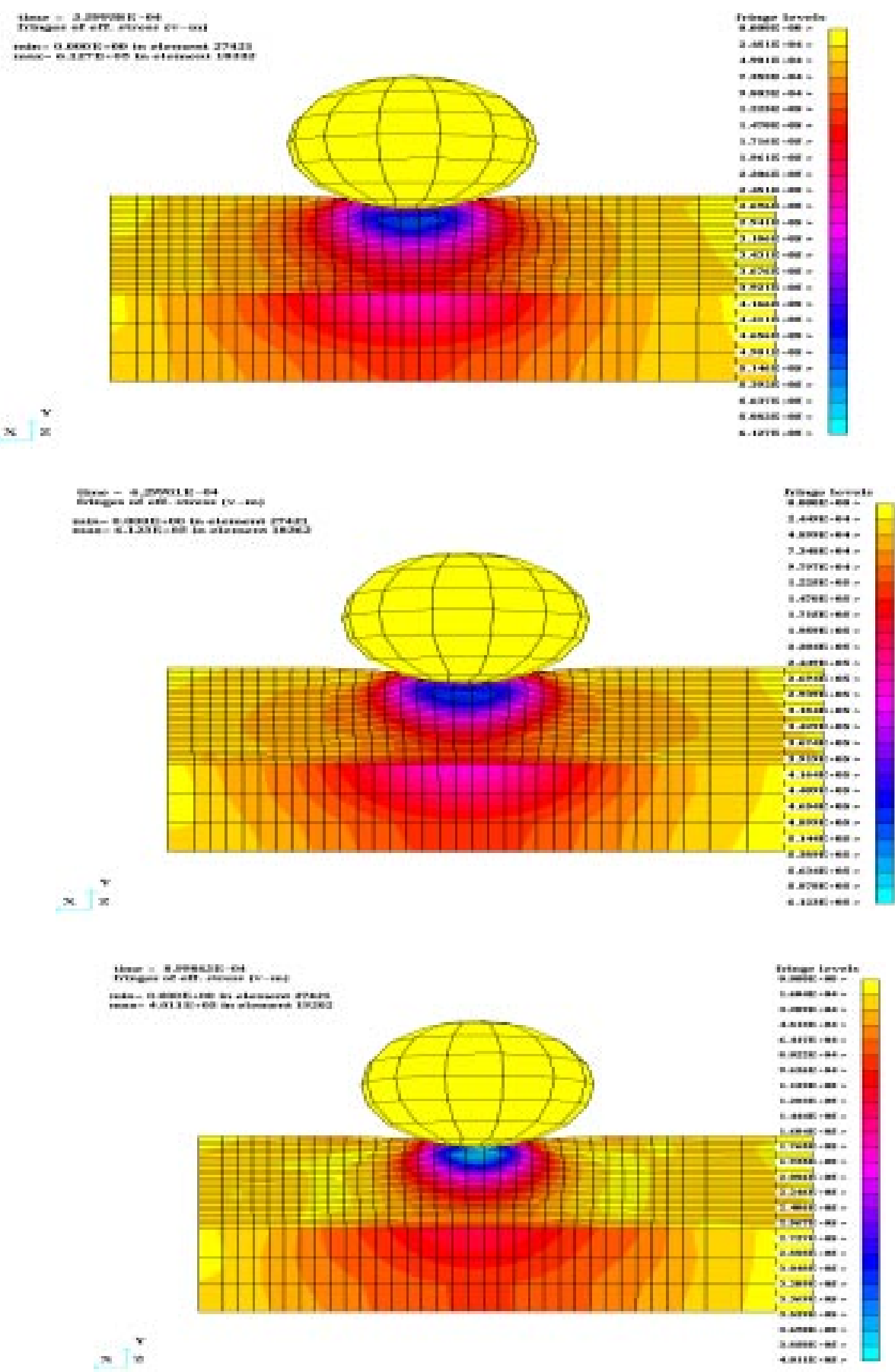

Fig. 6.14 Sequence of steps of particle impact on to target surface at $50 \mathrm{~m} / \mathrm{s}$ 
Temperature $674^{\circ} \mathrm{C}$

Angle of attack $90^{\circ}$

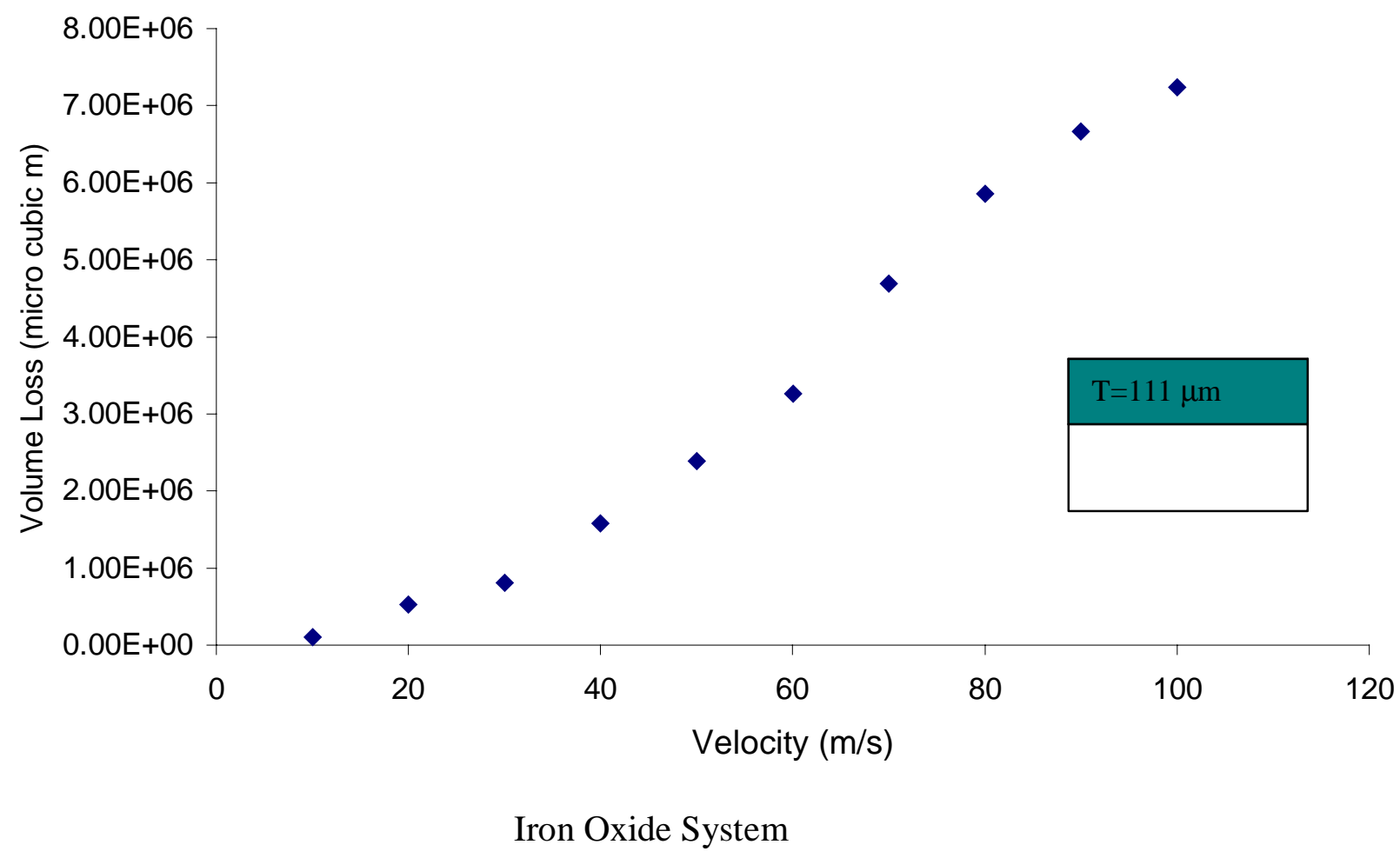

Fig. 6.15 Volume loss Vs Velocity for $100 \mu \mathrm{m}$ particle

$\mathrm{T}$ is the thickness of oxide scale 


\section{Volume Loss vs Angle of Attack}

Temperature $674{ }^{\circ} \mathrm{C}$

Velocity $50 \mathrm{~m} / \mathrm{s}$

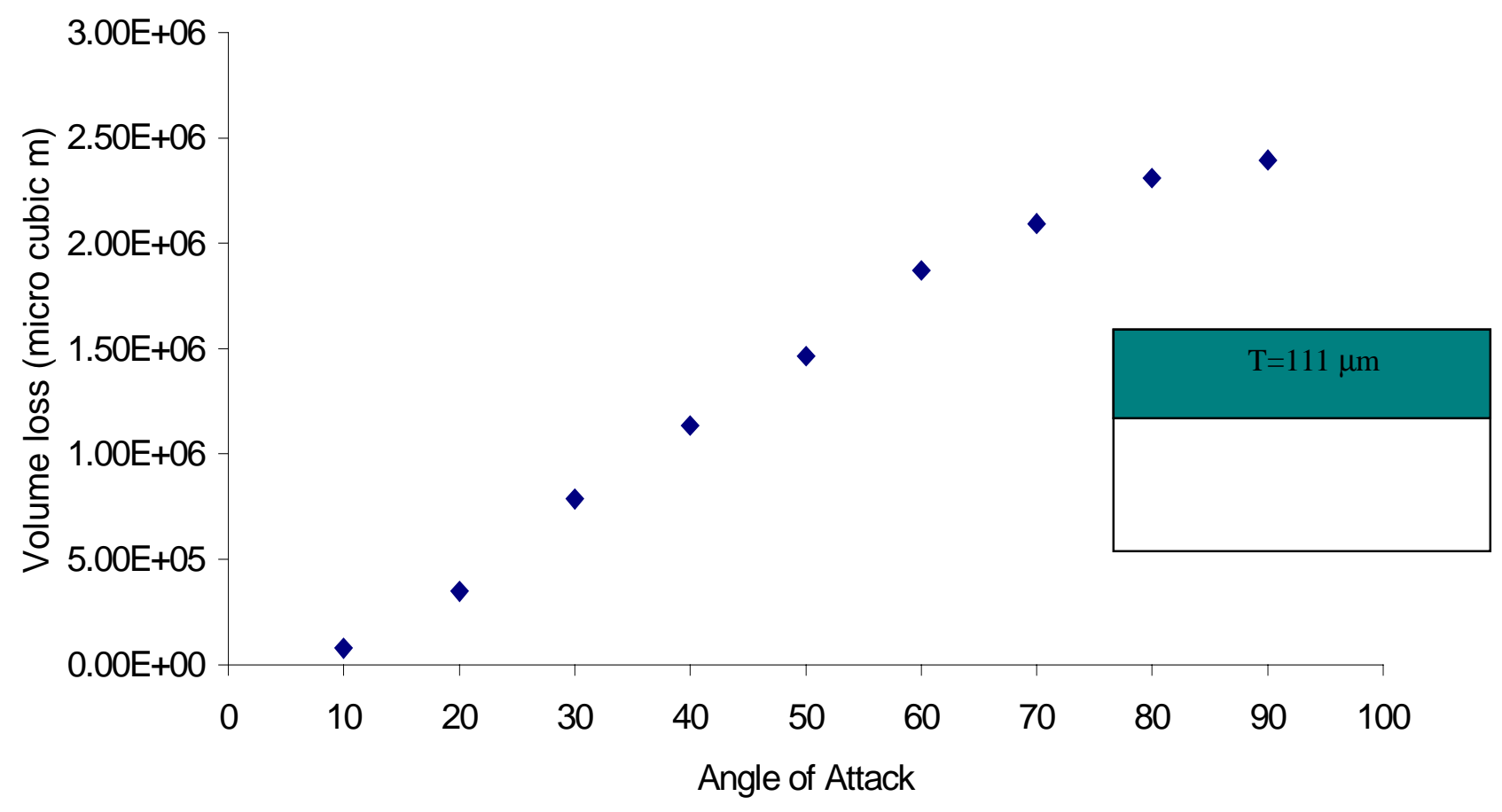

Iron Oxide System

Fig. 6.16 Volume loss Vs Angle of attack for $100 \mu \mathrm{m}$

$\mathrm{T}$ is the thickness of oxide scale 
Temperature $743{ }^{\circ} \mathrm{C}$

Angle of attack $90^{\circ}$

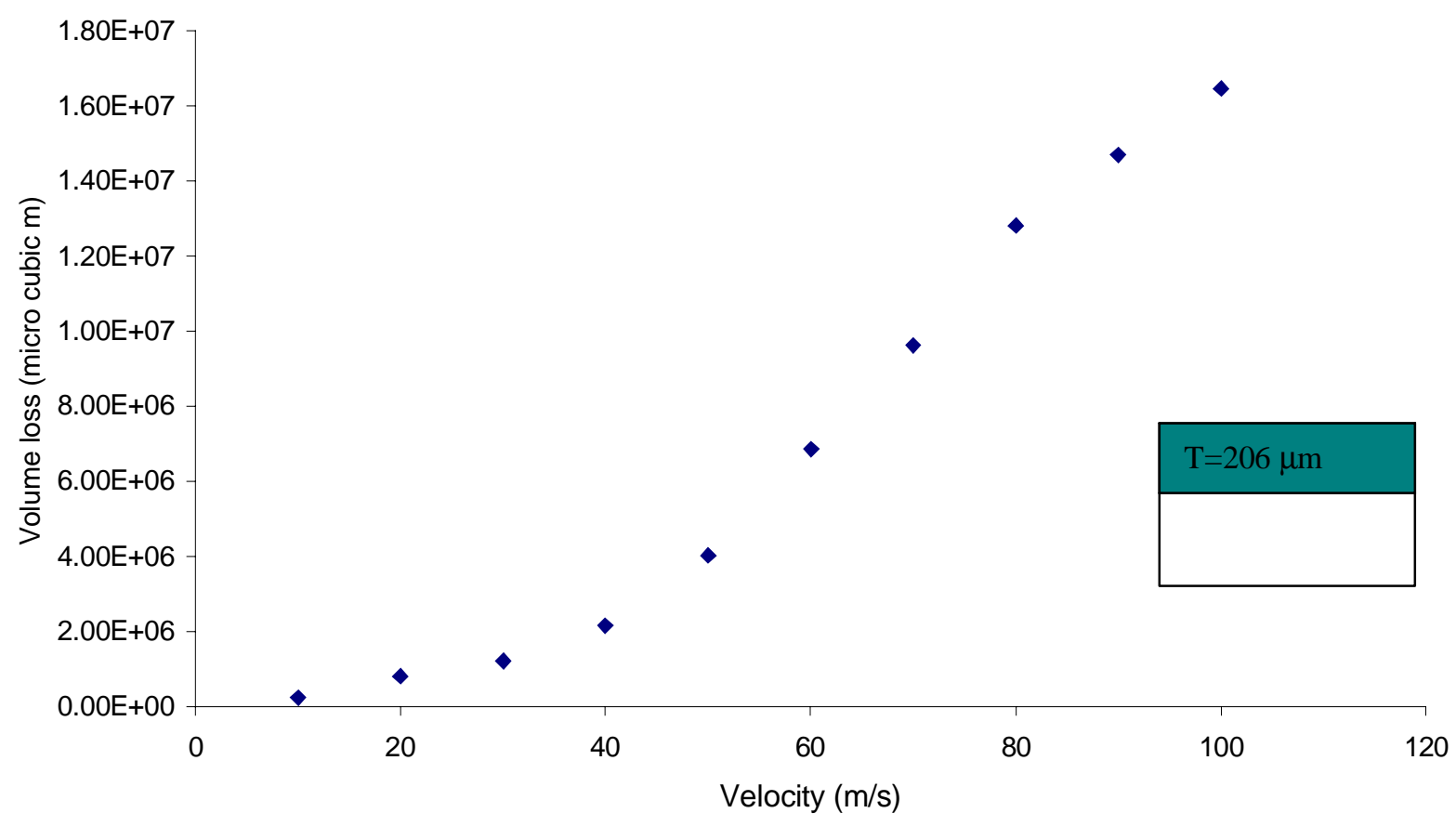

Iron Oxide System

Fig. 6.17 Volume loss Vs Velocity for $100 \mu \mathrm{m}$ particle

$\mathrm{T}$ is the thickness of oxide scale 


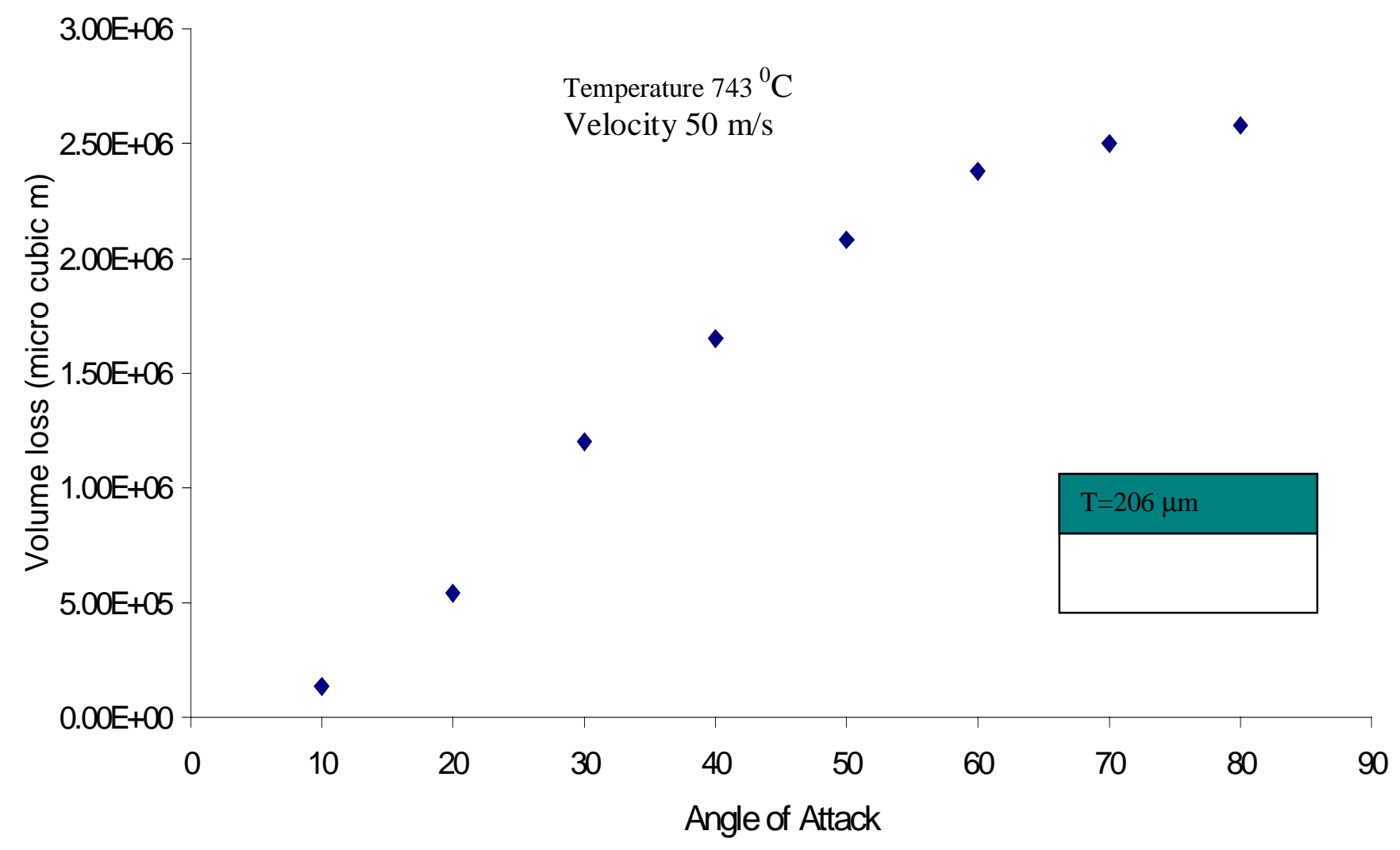

Iron Oxide System

Fig. 6.18 Volume loss Vs Velocity for $100 \mu \mathrm{m}$ particle

$\mathrm{T}$ is the thickness of the oxide scale 
Comparision of Velocity Effects on Volume Loss

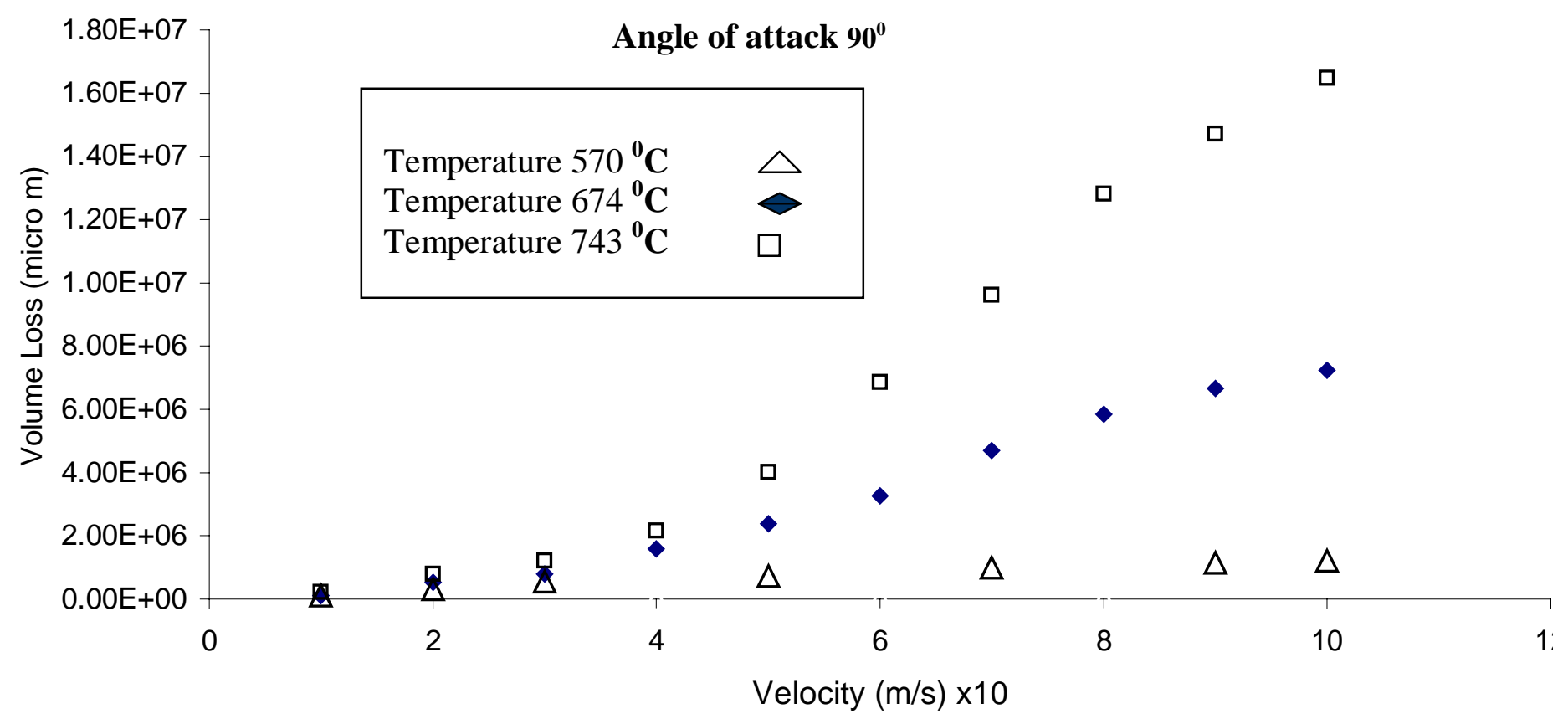

Iron Oxide System

Fig. 6.19 Comparison of Velocity Effects at three different temperatures 


\section{Comparision of Effects of Angle of Attack}

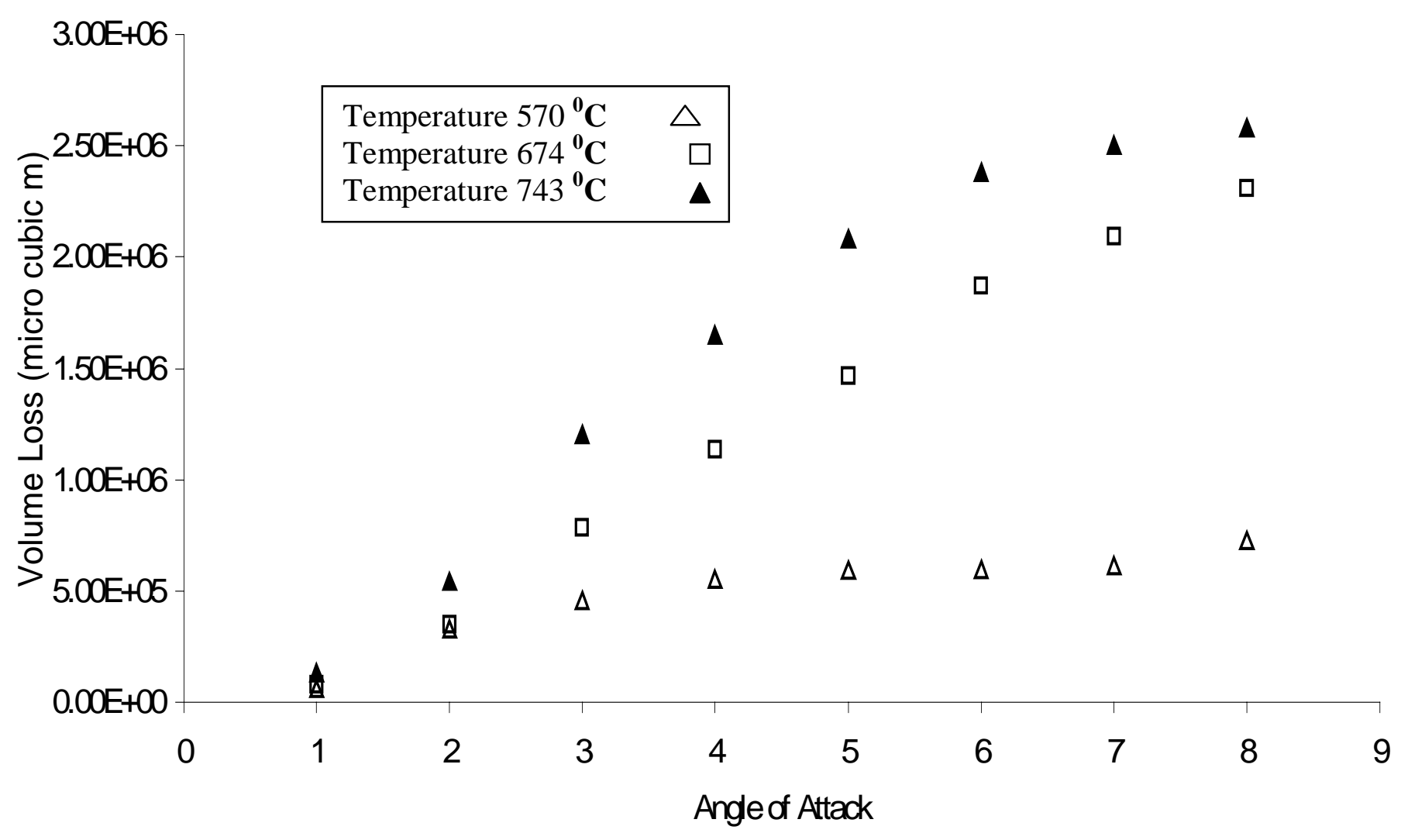

Iron Oxide System

Fig. 6.20 Comparison of Effects of Angle of Attack at three different temperatures 


\section{CHAPTER 7}

\section{CONCLUSIONS AND RECOMMENDATIONS}

\subsection{Conclusions}

The finite element results of aluminum oxide model showed good correlation with the experimental work of Levy [52]. The erosion loss increased with increase in size until $200 \mu \mathrm{m}$ and there after the volume loss was nearly constant. For the initial size of particle the mass and kinetic energy increases with size and the ability of the particle to penetrate through the target surface increased developing cracks and an increase in the volume loss. As the size of the particle increases beyond $200 \mu \mathrm{m}$ the diameter becomes the dominating factor decreasing the ability of the particle to penetrate the target surface. As predicted by Levy [52] this behavior continues until $500 \mu \mathrm{m}$ beyond which the volume loss decreases.

The validated model has been extended to the iron/iron oxide system. The analysis was performed at different temperatures. The effects of size of particles were performed at 674 and $743{ }^{\circ} \mathrm{C}$. The particle was impacted at normal incidence with $50 \mathrm{~m} / \mathrm{s}$. Unlike aluminum model the volume loss increases until $250 \mu \mathrm{m}$ and remains the same thereafter. This difference can be attributed to the difference of the oxide layer thickness, which is $111 \mu \mathrm{m}$ as compared to $50 \mu \mathrm{m}$ of aluminum model. The reason for this volume loss is the same as explained in the previous paragraph.

The other major parameter that was tested was velocity of the impacting particle. The analysis was performed for several velocities ranging from 10 to 100 $\mathrm{m} / \mathrm{s}$. The $100 \mu \mathrm{m}$ particle was impacted on to the target surface at normal incidence. 
The variation of volume loss was similar at all temperatures tested. The maximum volume loss was at $100 \mu \mathrm{m}$ owing to the maximum kinetic energy of the particle. The volume loss increased with increase in the velocity of the particle.

In the study on the influence of the angle of incidence, the $100 \mu \mathrm{m}$ particle was impacted on to a target surface at $50 \mathrm{~m} / \mathrm{s}$. The erosion loss was more at normal incidence, which proves the assumption that the iron oxide behaves as brittle material. The variation of erosion loss at shallow angles was more compared to higher angles, because erosion was due to sliding and impact. The variation was similar for all the temperatures. The results are in correlation with the work of Yalamanchili et al., [39].

The study of effect of temperature on erosion showed that the volume of iron oxide increased gradually with the temperature for $100 \mu \mathrm{m}$ impacting particle. This can be attributed that for smaller diameter the dominating factor was the kinetic energy of the impacting particle.

\subsection{Future Recommendations}

In the present work, iron/iron oxide interface properties were taken from the conclusions of Bruce et al.[46] which were based on vibration tests taken over a range. With the development of ultrasonic testing, better results can be accounted for better simulation. The present work dealt only with the erosion of brittle materials. The surface was free from previous impacts, but in real life equipment's, deterioration occurs after a series of impacts, a procedure has to be developed for erosion loss estimation. 
The properties of the materials and the interface might change after some hours of service, which are not available in the literature that should be obtained through experiments. The procedure adopted in this thesis can be extended to the multiple particle erosion. 


\section{BIBLIOGRAPHY}

1. Sorell, G., "Elevated Temperature Erosion-Corrosion of alloys in Sulfidizing Gas-Solids streams: Parametric Studies," Proceedings Corrosion-ErosionWear of Materials at Elevated Temperatures, Jan 27-29, 1986, pp. 204-229.

2. Sheldon, G.L. and Kanhere, A., "An Investigation of Impingement Erosion Using Single Particles," Wear vol. 21, 1972, pp. 195-209.

3. Kang, C.T., Pettit F.S., and Birks, N., "Mechanisms in the Simultaneous Erosion-Oxidation Attack of Nickel and Cobalt at High Temperatures," Met. Trans. A., vol. 18, 1987, pp. 1785.

4. Hogmark, S., Hammersten, A., and Soderberg, S., "On the Combined Effects of Corrosion and Erosion," Proceedings of $6^{\text {th }}$ International Conference on Erosion by Liquid and Solid Impact, Paper 37, 1983.

5. Evans, A.G., Crumley, G.B., and Demaray, R.E., "On the Mechanical Behavior of Brittle Coatings and Layers," Oxidation of Metals, Vol. 20, No. 516, 1983, pp. 193-216.

6. Stephenson, D.J., Nicholls, J.R., and Hancock, p., "Particle-Surface Interactions during the Erosion of Gas Turbine Material by Pyrolytic Carbon Particles," Corrosion Science, Vol. 25, No. 12, 1985, pp. 1181-1192.

7. Levy, A. and Man, Y.F., "Elevated Temperature Erosion-Corrosion of 9Cr1Mo Steel,” Wear, Vol. 111, 1986, pp. 135-159.

8. Van der Zwaag, S. and Field, J.E., "The Effect of Thin Hard Coatings on the Hertzian Field,” Philosophical Magazine A., Vol. 46, No.1, 1982, pp. 133150. 
9. Iain, Finnie., "Erosion of Surfaces by Solid Particles," Wear, Vol. 3, 1960, pp. 87-103.

10. Bitter, J.G.A., “ A Study of Erosion Phenomenon,” Wear, Vol. 6, 1963, pp. 521.

11. Neilson, J.H. and Gilchirst, A., "Erosion by a Stream of Solid Particles," Wear, Vol. 11, 1968, pp. 111-122.

12. Hutchings, I.M. and Winter, R.E., "Particle Erosion of Ductile Metals: A Mechanism of Material Removal,” Wear, Vol. 27, 1974, pp. 121-128.

13. Hutchings, I.M, "A Model for the Erosion of Metals by Spherical Particles at Normal Incidence,” Wear, Vol. 70, 1981, pp. 269-281.

14. Bellman Jr., R., and Levy, A., "Platelet Mechanism of Erosion of Ductile Metals," Proceedings of International Conference on Wear of Materials, ASME, 1981, pp. 564-576.

15. Rao, P.V. and Buckley, D.H., "Time Effect of Erosion by Solid Particle Impingement on Ductile Materials," Proceedings of Sixth International Conference on Erosion by Liquid and solid Impact, Paper 38, 1983.

16. Levy, A. and Man, Y.F., "Elevated Temperature Erosion-Corrosion of 9Cr1Mo Steel,” Wear, Vol. 111, 1986, pp. 135-159

17. Hutchings, I.M. and Levy, A.V., "Thermal Effects in the Erosion of Ductile Metals," Proceedings of Conference on Corrosion-Erosion-Wear of Materials at Elevated Temperatures, Levy, A.V., Ed., NACE/EPRI/LBL/DOE-FE, Berkeley, Jan 1986, pp. 121-133. 
18. Shimizu, K. and Noguchi, T., "Erosion Characteristics of Ductile Iron with Various Matrix Structures,” Wear, Vol. 176, 1994, pp. 255-260.

19. Levy, A.V., "Solid Particle Erosion and Erosion-Corrosion of Materials," ASM International, 1995, pp. 11-25.

20. Ruff A.W. and Wiederhorn, N., "Erosion by Solid Particle Impact," Treatise on Material Science and Technology, Vol. 16, 1979, pp. 69-126.

21. Finnie, I., "An Experimental Study of Erosion," Proceedings of Society for Experimental Stress Analysis, Vol. 17, No.2, 1960, pp. 65-70.

22. Sheldon, G.L. and Finnie, I., "The Mechanism of Material Removal in the Erosive Cutting of the Brittle Materials," Transactions of ASME, Journal of Engineering for Industry, Vol. 88, 1966, pp. 393-400.

23. Zambelli, G. and Levy, A.V., "Particulate Erosion of NiO Scale," Wear, Vol. 68, 1981, pp. 305-331.

24. Mehrotra, P.K., Sargent, G.A., and Conrad, H., "A model for the MultiParticle Erosion of Brittle Solids by Spherical Particles," Corrosion-Erosion Behavior of Materials, TMS-AIME, 1980, pp. 127-145.

25. Hockey, B.J., Wirderhorn, S.M., and Johnson, H., "Erosion of Brittle Materials by Solid Particle Impact," Fracture Mechanics of Ceramics, Vol. 3, Flaws and Testing, Plenum Press, pp. 379-402.

26. Evans, A.G., Gulden, M.E., and Rosenblatt, M., "Impact Damage in Brittle Materials in the Elastic-Plastic Response Regime," Proc. R. Soc. (London) A, Vol. 361, 1978, pp. 343-365. 
27. Wiederhorn, S.M., and Lawn, B.R., "Strength Degradation of Glass Impacted with Sharp Particles," Journal of American Ceramics Society., Vol. 62, 1979.

28. Wade, S. and Wantenabe, N., "Solid Particle Erosion of Brittle Materials (Part3) - The interaction with Material Properties of Target and that of Impingement Particle on Erosive Wear Mechanisms," Yogyo-Kyokai-Shi, 1987, vol. 95, No. 6, pp. 573-578.

29. Golightly, F.A., Stott, F.H., and Wood, G.C., "The Influence of Yttrium Additions on the Oxide Scale Addition to an Iron-Chromium-Aluminum Alloy," Oxidation of Metals, Vol. 10, No. 3, 1976, pp. 163-187.

30. Young, J.P. and Ruff, A.W., Transactions of ASME J. Eng. Mater. Tech. 99, 1977, pp. 121-125.

31. Hockey, B.J., Wiederhorn, S.M., and Johnson, H., "Fracture Mechanics of Ceramics, Flaws and Testing,” Vol. 3, 1978, Plenum Press, NewYork.

32. Goodwin, J.W., Sage, W,. and Tilly, G.P., "Study of Erosion by Solid Particles” Proc. Inst. Mech. Eng., Vol. 184, 1969, pp. 279-292.

33. Levy, A.V., "The Abrasion/Erosion and Erosion-Corrosion Characteristics of Steels," Wear of Materials, 1989, pp. 115-128.

34. Veluswamy, S. and Means K.H., "A Computational Material Model of Oxide Layer Erosion by Impact," ASME, Vol. 303, 1995, pp. 401-415.

35. Mills, D. and Mason, J.S., Wear, Vol. 44, 1977, pp. 311-328.

36. Misra, A. and Finnie, I., "On the Size effect in Abrasive and Erosive Wear," Wear, Vol. 65, 1981, pp. 359-373. 
37. Liebhard, M., and Levy A.V., "The effect of Erodent Particle Characteristics on the Erosion of Metals," Proceedings of International Conference on Wear of Materials, ASME, 1991, pp. 123-127.

38. Sheldon, G.L., Transactions ASME J. Basic Engineering, Vol. 92, 1970, pp. 619-626.

39. Yalamanchili Chandra and Means, K.H, "Computational model of brittle erosion."

40. Sheldon, G.L., and Finnie, I., "On the Ductile Behavior of Normally Brittle Materials during Erosive Cutting," Transactions of ASME, Journal of Engineering for Industry, Vol. 88, 1966, pp. 387-392.

41. Hutchings, I.M., "Deformation of Metal Surfaces by the Oblique Impact of Square Plates,” Int. J. Mech. Sci., Vol. 19, 1976, pp. 45-52.

42. Hutchings, I.M., Proceedings of ASTM Symp. Erosion Prevention, STP 664, 1978.

43. Ives, L.K. and Ruff, A.W., Wear, Vol. 46, pp. 149-162.

44. Grant, G., Tabakoff, W., and Airor, J., Wear, Vol. 12, 1975, pp. 471-478.

45. Schutze, M., "Stresses and Decohesion of Oxide Scales," Materials Science and Technology, Vol. 4, 1988, pp. 407-414.

46. Bruce, D., and Hancock, P., "Influence of mechanical properties of surface oxide films on oxidation mechanisms- I - II," Journal of the Institute of Metals, 1968, pp. 140-154.

47. Gulyeav, V.N., Zavod. Lab., Vol. 24, 1958, pp. 1375. 
48. Perters, F.K. and Engell, J.H., Arch. Eisenhuttenwesen, Vol. 30, 1959, pp. 275.

49. Mark, A.C, and Donald,D, "INGRID A 3D Mesh Generator For Modeling Nonlinear Systems,” User Manual, 1992.

50 \& 51. John, O. H, “LS-DYNA3D and LS-TAURUS,” User Manual, 1994.

52 Levy, A.V, "The Abrasion/Erosion And Erosion-Corrosion Characteristics of Steels," Wear of Materials, 1989, vol. 1, pp. 115-128.

53 Eugine,A.A and Theodore, B III, "Standard Handbook for Mechanical Engineers," Ninth Edition, Mc Graw Hill, New York. 


\section{APPENDIX A}

\section{Sample IS-DYNA3D Input File}

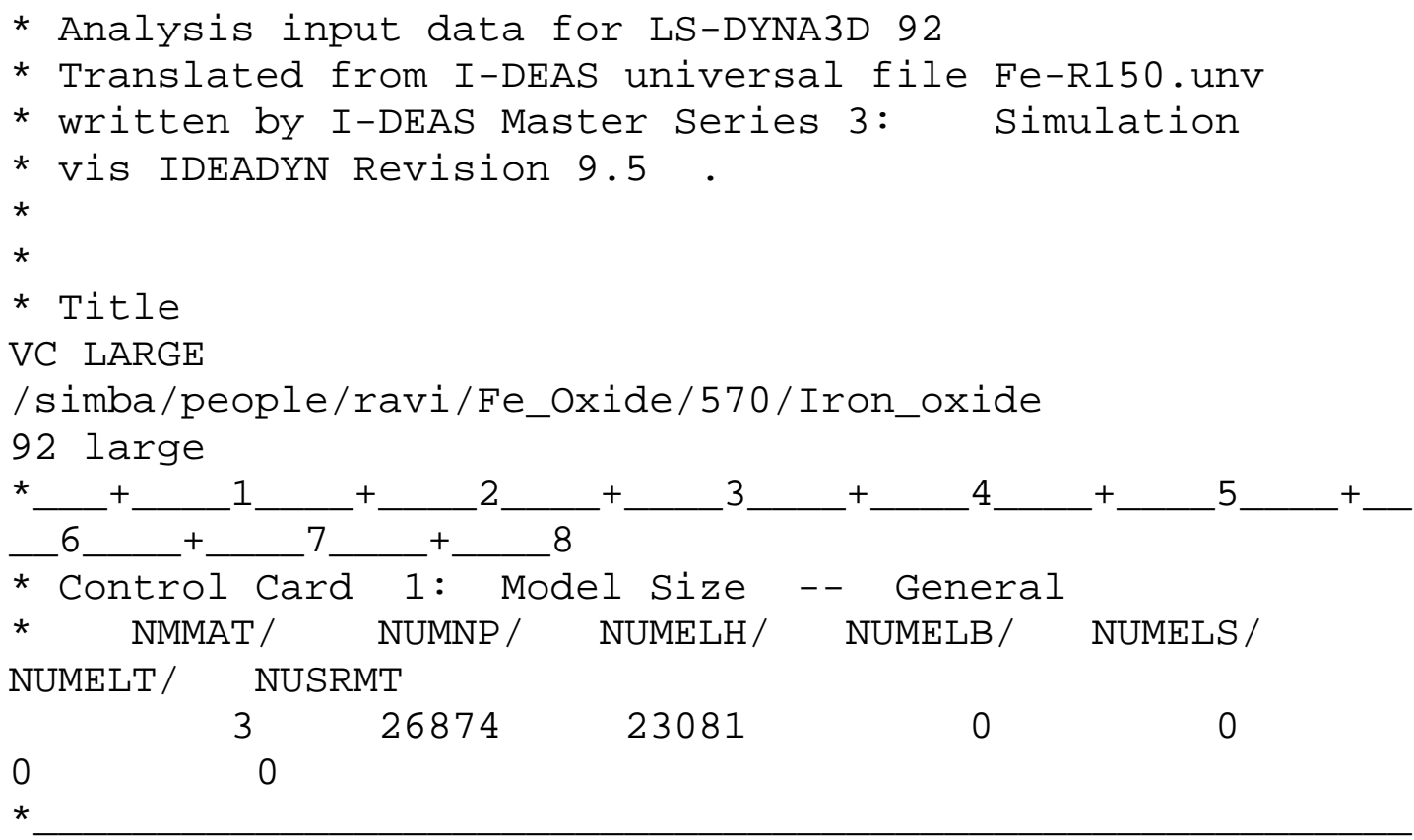

* Control Card 2: Model Size -- Boundary Conditions *NSPC/COOR/VEAC/NRBS/ RC/ RCE/ JOY

$\begin{array}{llllllll}0 & 0 & 0 & 0 & 0 & 0 & 0 & 0\end{array}$

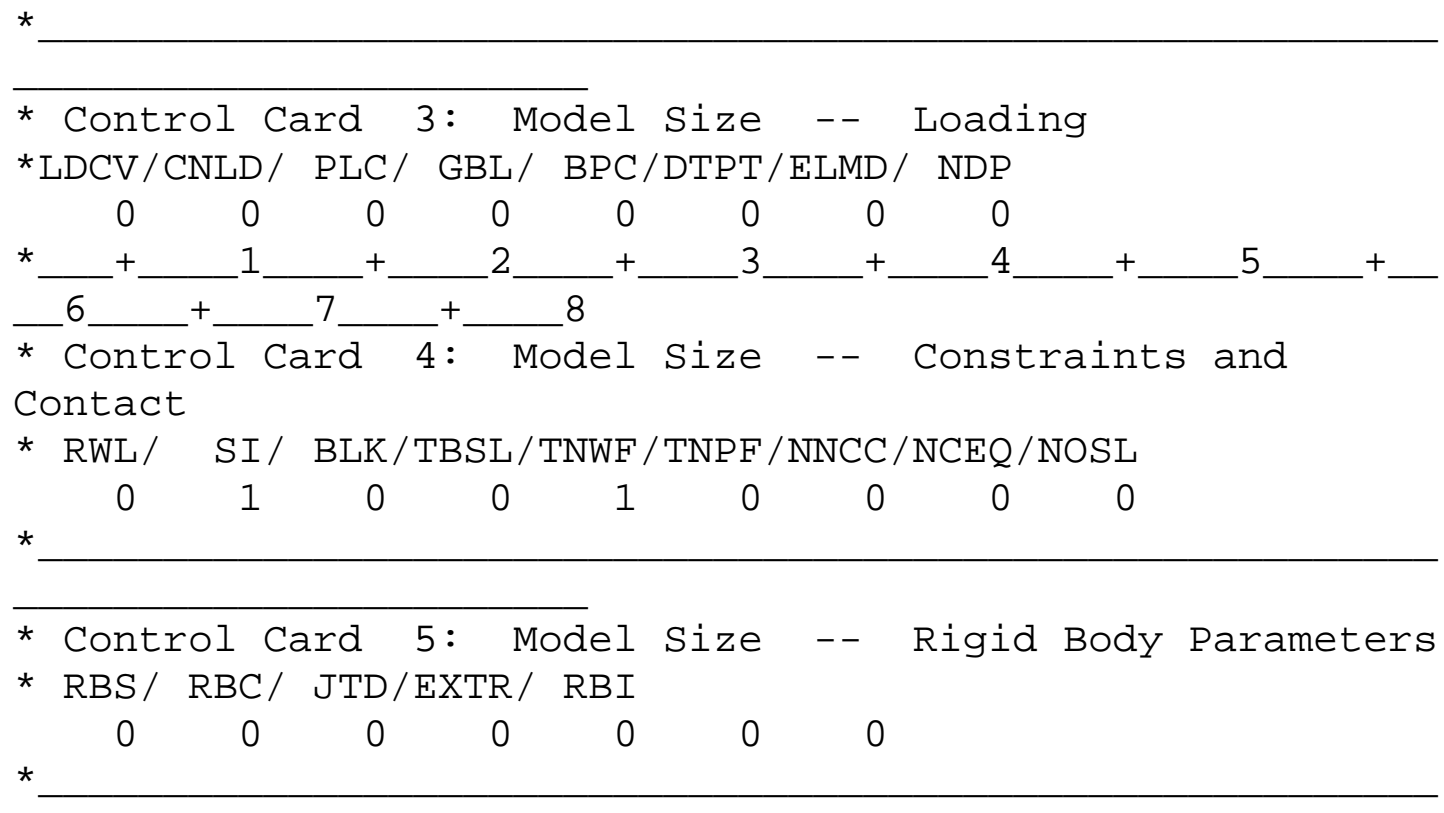


* Control Card 6: Model Size -- Discrete Elements and Seat Belts

*MTDE/CORD/ ELD/ MAS/ SBM/ SBE/SBSR/SBRT/SBSE/SBPT/ ACC

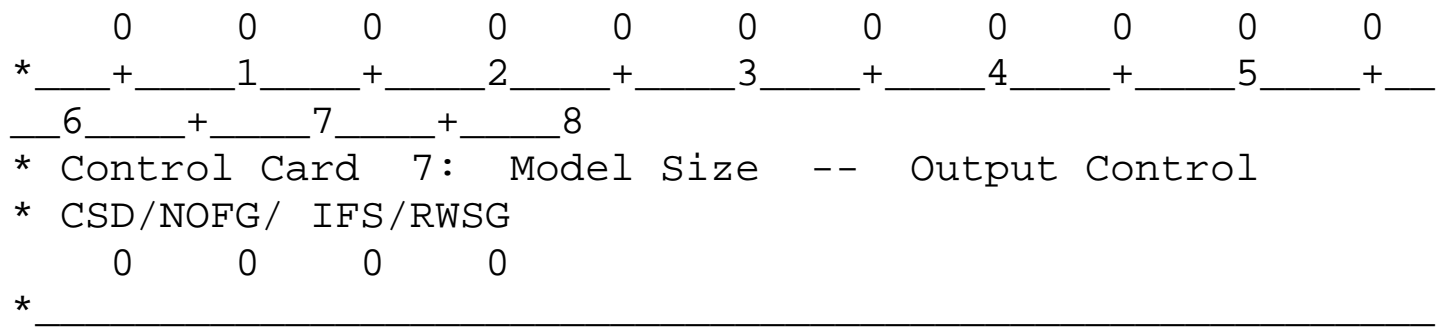

* Control Card 8: Model Size -- Termination

* ENDTIM /TERM.CYCL/ TSMIN /\%DE-RATIO
$9.000 \mathrm{E}-04$
$0.000 \mathrm{E}+00$
$0.000 \mathrm{E}+00$

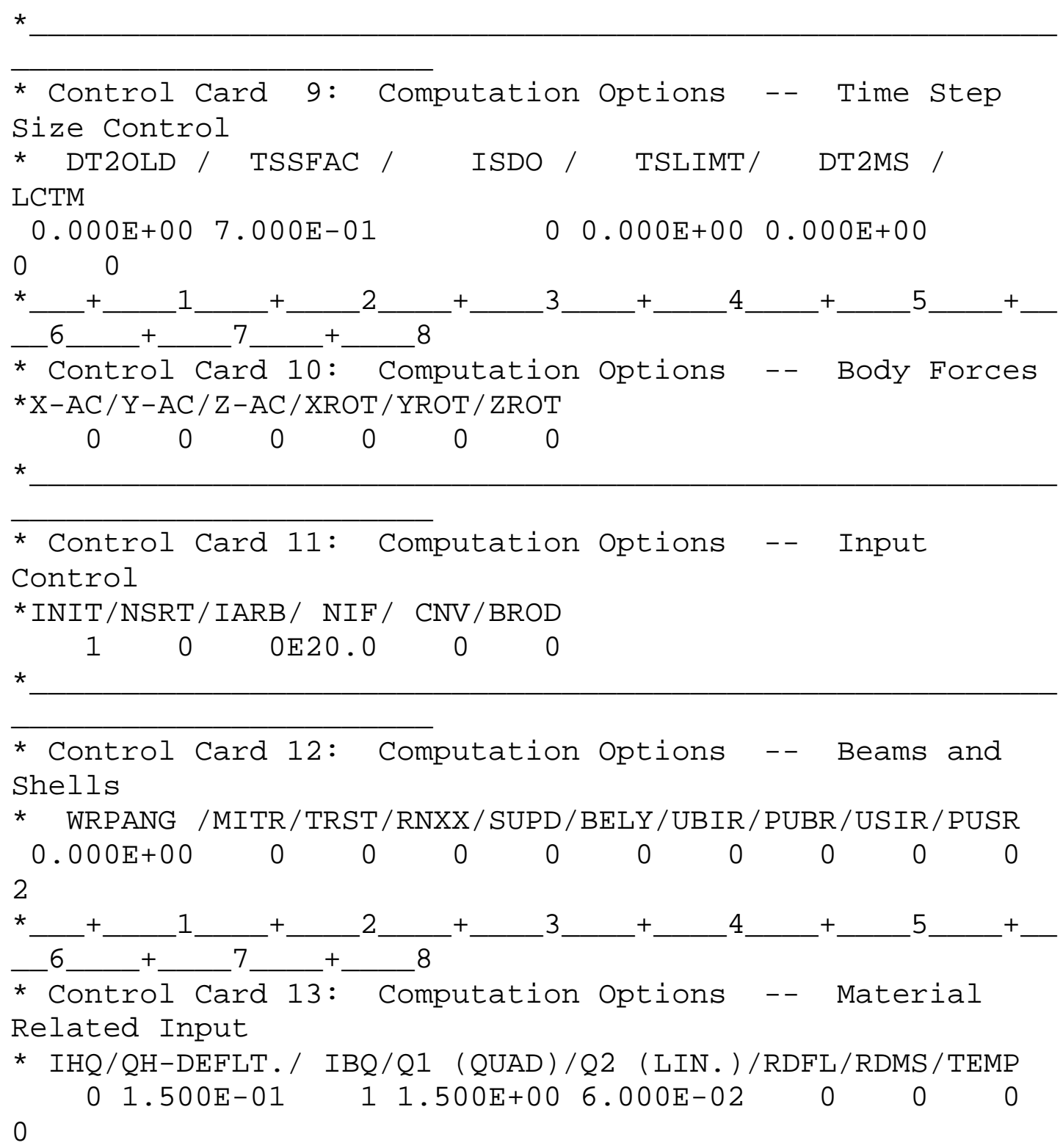




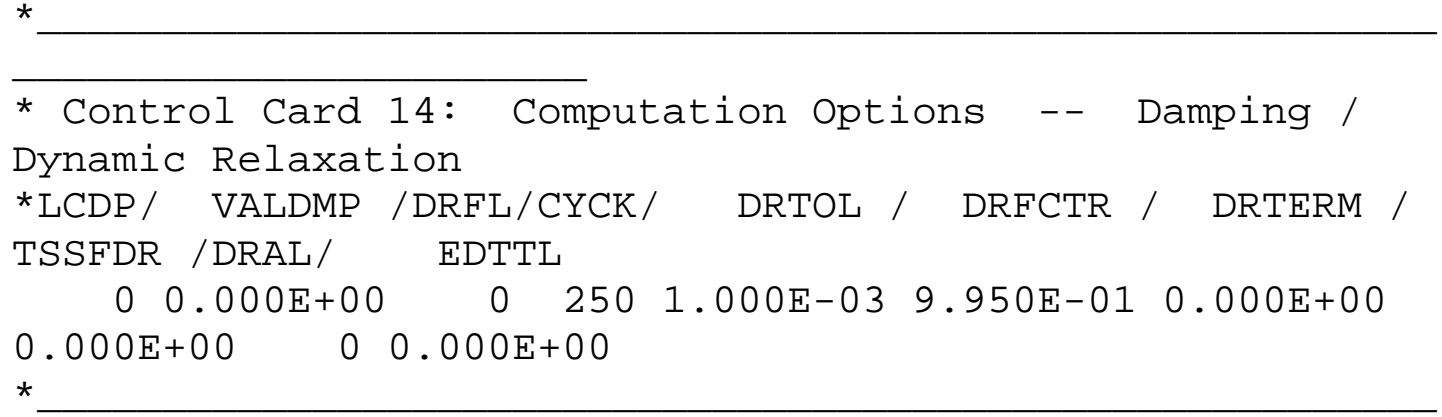

* Control Card 15: Computation Options -- Contact

* SLSFAC / RWPNAL /INIC/THIK/

$\mathrm{PSV} / \mathrm{STCC} / \mathrm{INIR} / \mathrm{SCIC} / \mathrm{SCIF} / \mathrm{IGEO} / \mathrm{BCS} / \mathrm{INTS}$

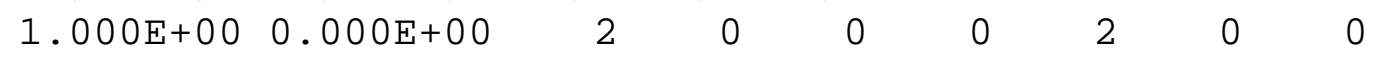

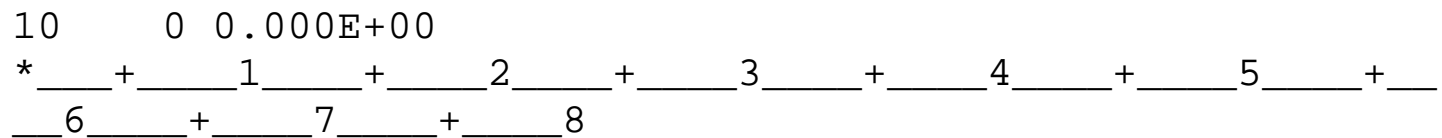

* Control Card 16: Computation Options -- Parallel and Subcycling

*NCPU/SORT/SUBS /

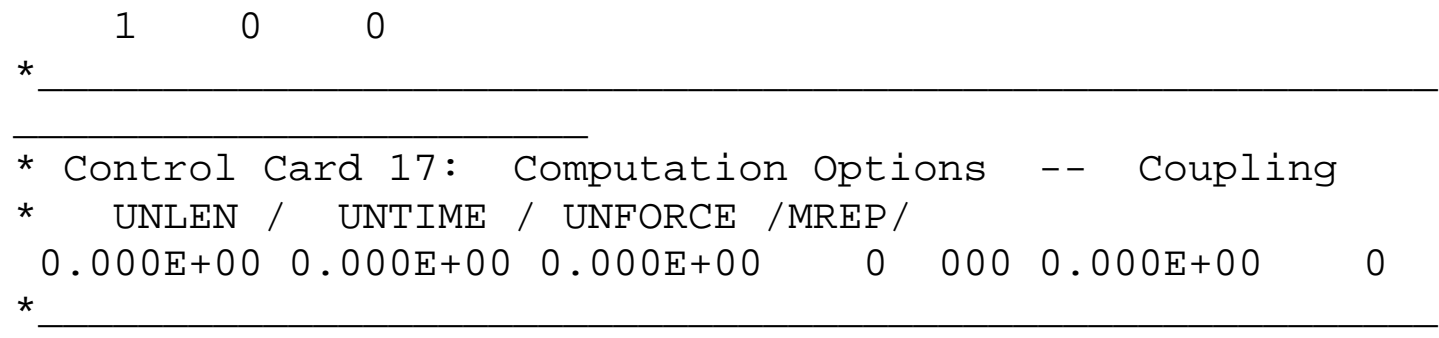

* Control Card 18: Computation Options -- Output Control

*POPT / TSPF / EDIT / RDEC / CBRE / ECHO/DEBG/RFUP / ACCA/OP IF /

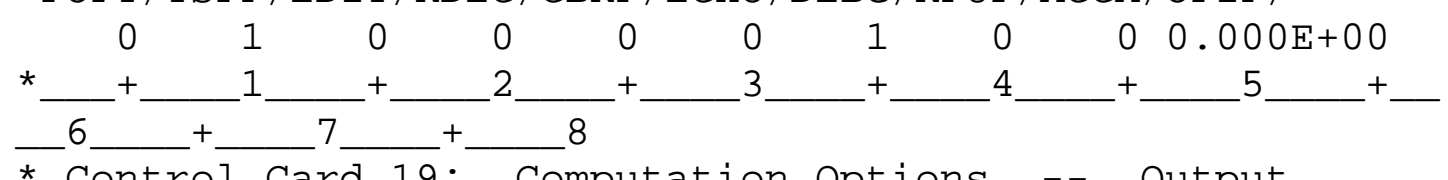

* Control Card 19: Computation Options -- Output

Energy

*HGEC / NRWO / S IED / RDED

$\begin{array}{llll}* & 0 & 2 & 0\end{array}$

$\star$

* Control Card 20: Computation Options -- TAURUS

Database Control I

*STATEDUMP / IFF-DUMP / THDT-DUMP /NDTH/NSTH/NSTB/NSTS /NSTT

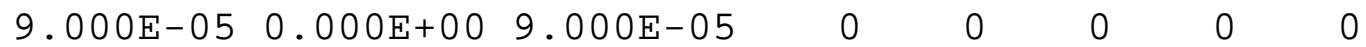
* 
* Control Card 21: Computation Options -- TAURUS Database Control II *DREL/NIPH/NIPS/SINT/STRN/STEN/EFPS / SRES/IETH/PSEP /

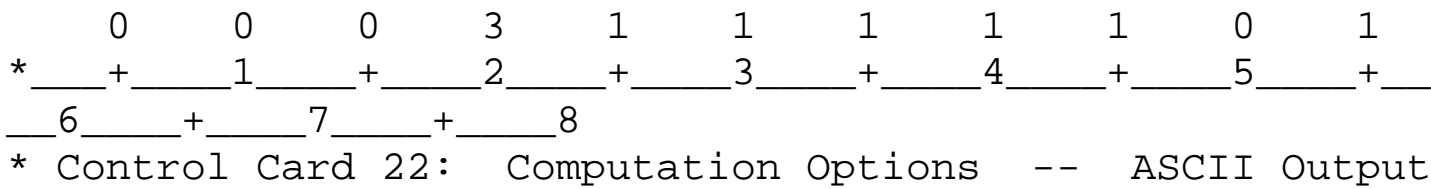
Control I

* SECFORC / RWFORC / NODOUT / ELOUT / GLSTAT / DEFORC / MATSUM / NCFORC

$0.000 \mathrm{E}+00 \quad 0.000 \mathrm{E}+00 \quad 0.000 \mathrm{E}+00 \quad 0.000 \mathrm{E}+00 \quad 9.000 \mathrm{E}-05$

$0.000 E+00 \quad 9.000 E-05 \quad 0.000 E+00$

* Control Card 23: Computation Options -- ASCII Output Control II

* RCFORC / DEFGEO / SPCFORC / SWFORC / ABStAt /

AVSFLT / NODFOR / BNDOUT

$0.000 \mathrm{E}+00 \quad 0.000 \mathrm{E}+00 \quad 0.000 \mathrm{E}+00 \quad 0.000 \mathrm{E}+00 \quad 0.000 \mathrm{E}+00$

$0.000 \mathrm{E}+00 \quad 0.000 \mathrm{E}+00 \quad 0.000 \mathrm{E}+00$

*

* Control Card 24: Computation Options -- ASCII Output Control III

* RBDOUt / GCEOUT / MPGS / MOVIE / SLEOUT /

SBTOUT /

$0.000 E+00 \quad 0.000 E+00 \quad 0.000 E+00 \quad 0.000 E+00 \quad 0.000 E+00$

$0.000 \mathrm{E}+00 \quad 0.000 \mathrm{E}+00$

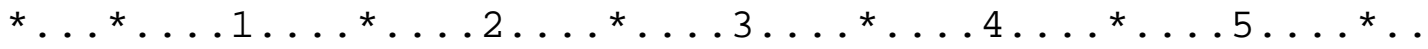
$\ldots 6 \ldots{ }^{\star} \ldots .7 \ldots{ }^{\star} \ldots . .8$

$\star$

*--------------------------- Material Cards ---------

----------------------- *

*

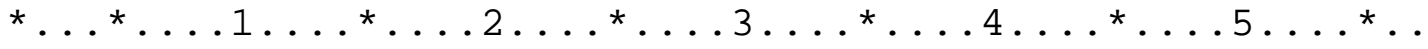
$\ldots 6 \ldots{ }^{\star} \ldots 7 \ldots{ }^{\star} \ldots . .8$

* MATERIAL MODEL 1

*Properties of the metal.

$$
1 \quad 17.810 \mathrm{E}+00 \quad 0 \quad 00.1500 \mathrm{E}+00
$$

$00.0000 \mathrm{E}+000.0000 \mathrm{E}+00 \quad 0 \quad 0 \quad 0$

material type \# 1 (elastic)

$\begin{array}{lllll}1.550 \mathrm{E}+08 & 0.000 \mathrm{E}+00 & 0.000 \mathrm{E}+00 & 0.000 \mathrm{E}+00 & 0.000 \mathrm{E}+00\end{array}$

$0.000 \mathrm{E}+00 \quad 0.000 \mathrm{E}+00 \quad 0.000 \mathrm{E}+00$

$\begin{array}{llllll}3.400 E-01 & 0.000 E+00 & 0.000 E+00 & 0.000 E+00 & 0.000 E+00\end{array}$

$0.000 \mathrm{E}+00 \quad 0.000 \mathrm{E}+00 \quad 0.000 \mathrm{E}+00$

$0.000 \mathrm{E}+00 \quad 0.000 \mathrm{E}+00 \quad 0.000 \mathrm{E}+00 \quad 0.000 \mathrm{E}+00 \quad 0.000 \mathrm{E}+00$

$0.000 \mathrm{E}+00 \quad 0.000 \mathrm{E}+00 \quad 0.000 \mathrm{E}+00$ 


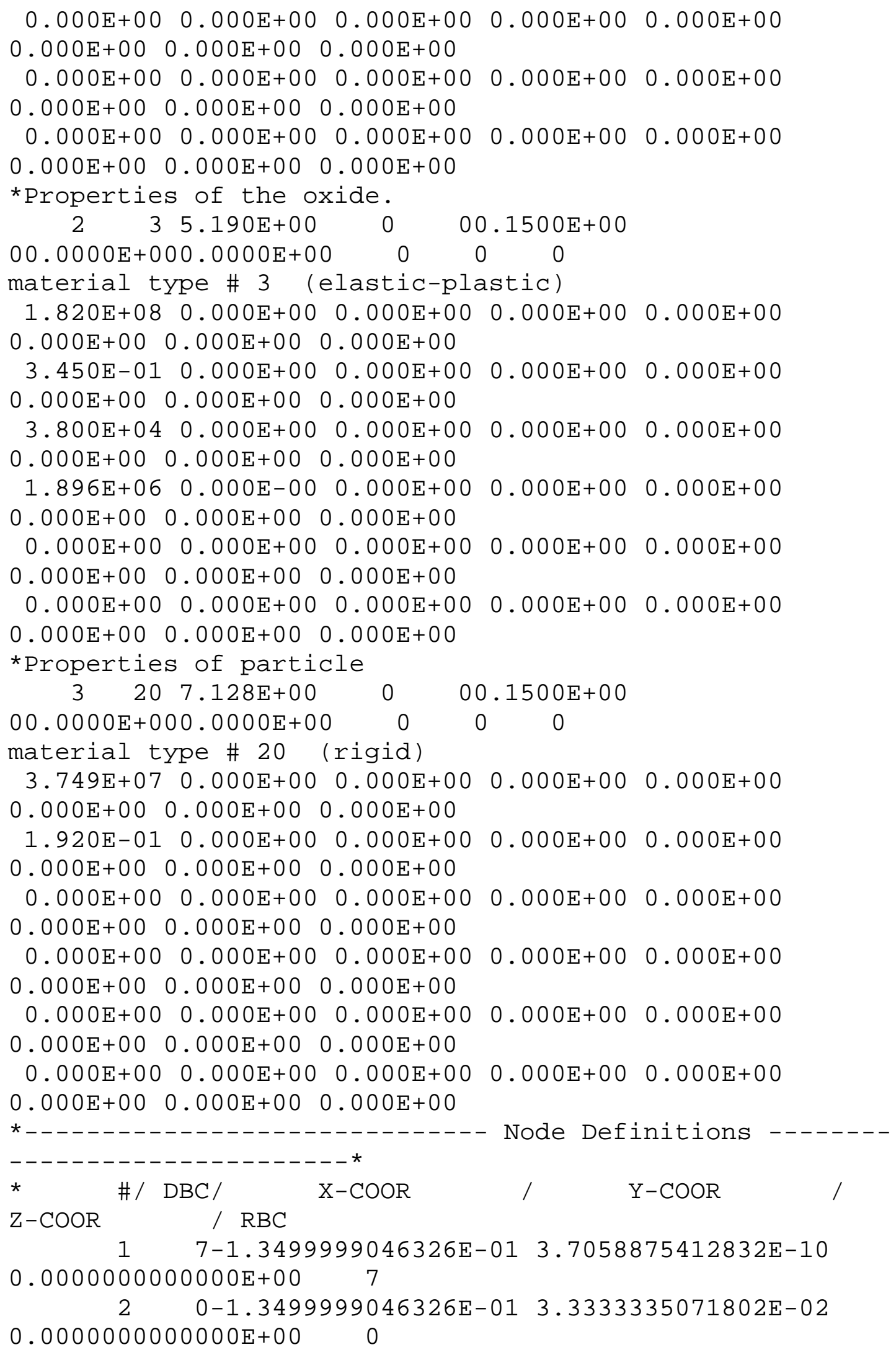




\begin{tabular}{|c|c|c|}
\hline \multirow{3}{*}{\multicolumn{2}{|c|}{$\begin{array}{cc}3 & 0-1.34999 \\
0.0000000000000 E+00\end{array}$}} & $6.6666670143604 \mathrm{E}-02$ \\
\hline & & \\
\hline & $7-1.583333313$ & $3.7058875412832 E-10$ \\
\hline .00000000 & $0000 \mathrm{E}+00$ & \\
\hline 5 & $0-1.583333313$ & $3.3333335071802 E-02$ \\
\hline .00000000 & $0000 \mathrm{E}+00$ & \\
\hline 6 & $0-1.5833333134651 \mathrm{E}-01$ & $6.6666670143604 \mathrm{E}-02$ \\
\hline .00000000 & $0000 E+00$ & \\
\hline 7 & $7-1.8166665732$ & $32 E-10$ \\
\hline 0.00000000 & $0000 \mathrm{E}+00$ & \\
\hline 8 & $0-1.8166665732861 \mathrm{E}-01$ & $3.3333335071802 \mathrm{E}-02$ \\
\hline 0.00000000 & $0000 \mathrm{E}+00$ & \\
\hline 9 & $0-1.8166665732861 \mathrm{E}-01$ & $6.6666670143604 \mathrm{E}-02$ \\
\hline 0.0000000 & $0000 \mathrm{E}+$ & \\
\hline 10 & $36 E-01$ & $3.7058875412832 \mathrm{E}-10$ \\
\hline 0.00000000 & $0000 \mathrm{E}+00$ & \\
\hline 11 & 9999821 & $3.3333335071802 E-02$ \\
\hline 0.00000000 & $0000 \mathrm{E}+00$ & \\
\hline 12 & $0-2.0499999821186 \mathrm{E}-01$ & $6.6666670143604 \mathrm{E}-02$ \\
\hline 0.00000000 & $0000 \mathrm{E}+\mathrm{C}$ & \\
\hline 13 & $7-1.1999999731$ & $832 E-10$ \\
\hline 0000 & $0000 \mathrm{E}+00$ & \\
\hline 14 & $0-1.1999999731^{7}$ & 3.333333507 \\
\hline & & \\
\hline
\end{tabular}




\begin{tabular}{|c|c|c|c|c|c|c|c|c|}
\hline & 4 & 1 & 831 & & 861 & 951 & 921 & 832 \\
\hline \multirow[t]{2}{*}{862} & 952 & & 922 & & & & & \\
\hline & 5 & 1 & 832 & & 862 & 952 & 922 & 833 \\
\hline \multirow[t]{2}{*}{863} & 953 & & 923 & & & & & \\
\hline & 6 & 1 & 833 & & 863 & 953 & 923 & 834 \\
\hline \multirow{2}{*}{864} & 954 & & 924 & & & & & \\
\hline & 7 & 1 & 834 & & 864 & 954 & 924 & 835 \\
\hline \multirow[t]{2}{*}{865} & 955 & & 925 & & & & & \\
\hline & 8 & 1 & 835 & & 865 & 955 & 925 & 836 \\
\hline \multirow[t]{2}{*}{866} & 956 & & 926 & & & & & \\
\hline & 9 & 1 & 836 & & 866 & 956 & 926 & 837 \\
\hline \multirow[t]{2}{*}{867} & 957 & & 927 & & & & & \\
\hline & 10 & 1 & 837 & & 867 & 957 & 927 & 838 \\
\hline \multirow[t]{2}{*}{868} & 958 & & 928 & & & & & \\
\hline & 11 & 1 & 838 & & 868 & 958 & 928 & 839 \\
\hline \multirow[t]{2}{*}{869} & 959 & & 929 & & & & & \\
\hline & 12 & 1 & 839 & & 869 & 959 & 929 & 840 \\
\hline \multirow[t]{2}{*}{870} & 960 & & 930 & & & & & \\
\hline & 13 & 1 & 840 & & 870 & 960 & 930 & 841 \\
\hline \multirow[t]{2}{*}{871} & 961 & & 931 & & & & & \\
\hline & 14 & 1 & 841 & & 871 & 961 & 931 & 842 \\
\hline 872 & 962 & & 932 & & & & & \\
\hline 15 & 1842 & 872 & 962 & 932 & 843 & 873963 & 933 & \\
\hline
\end{tabular}
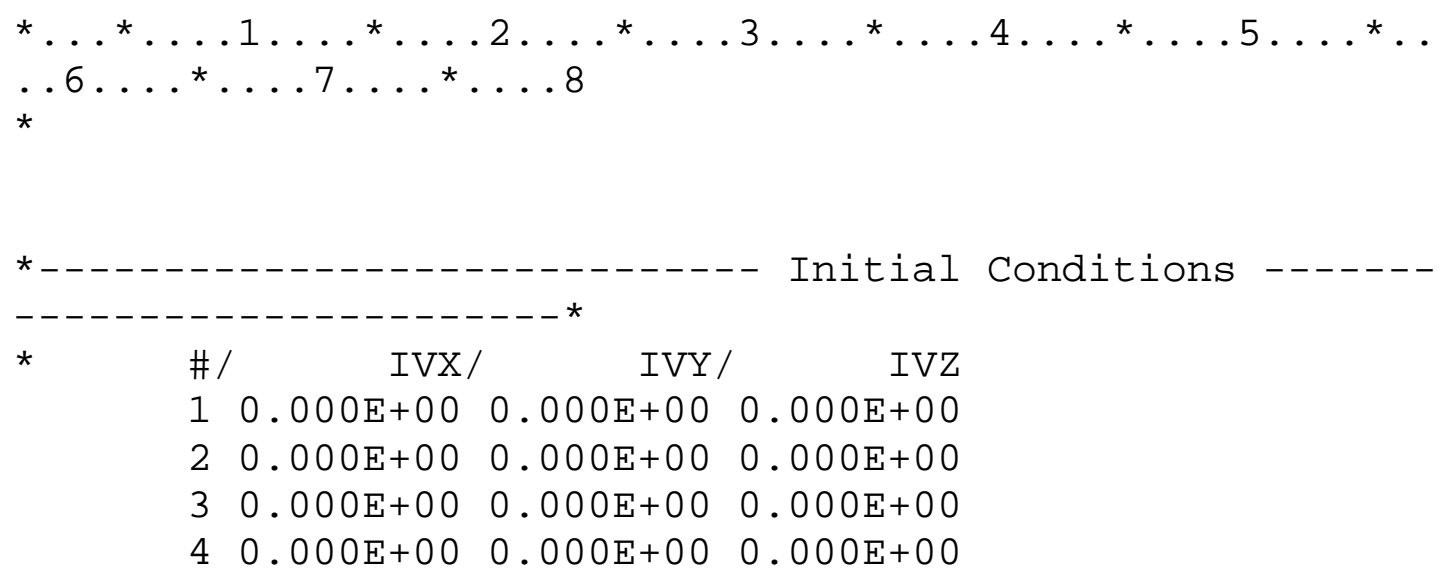


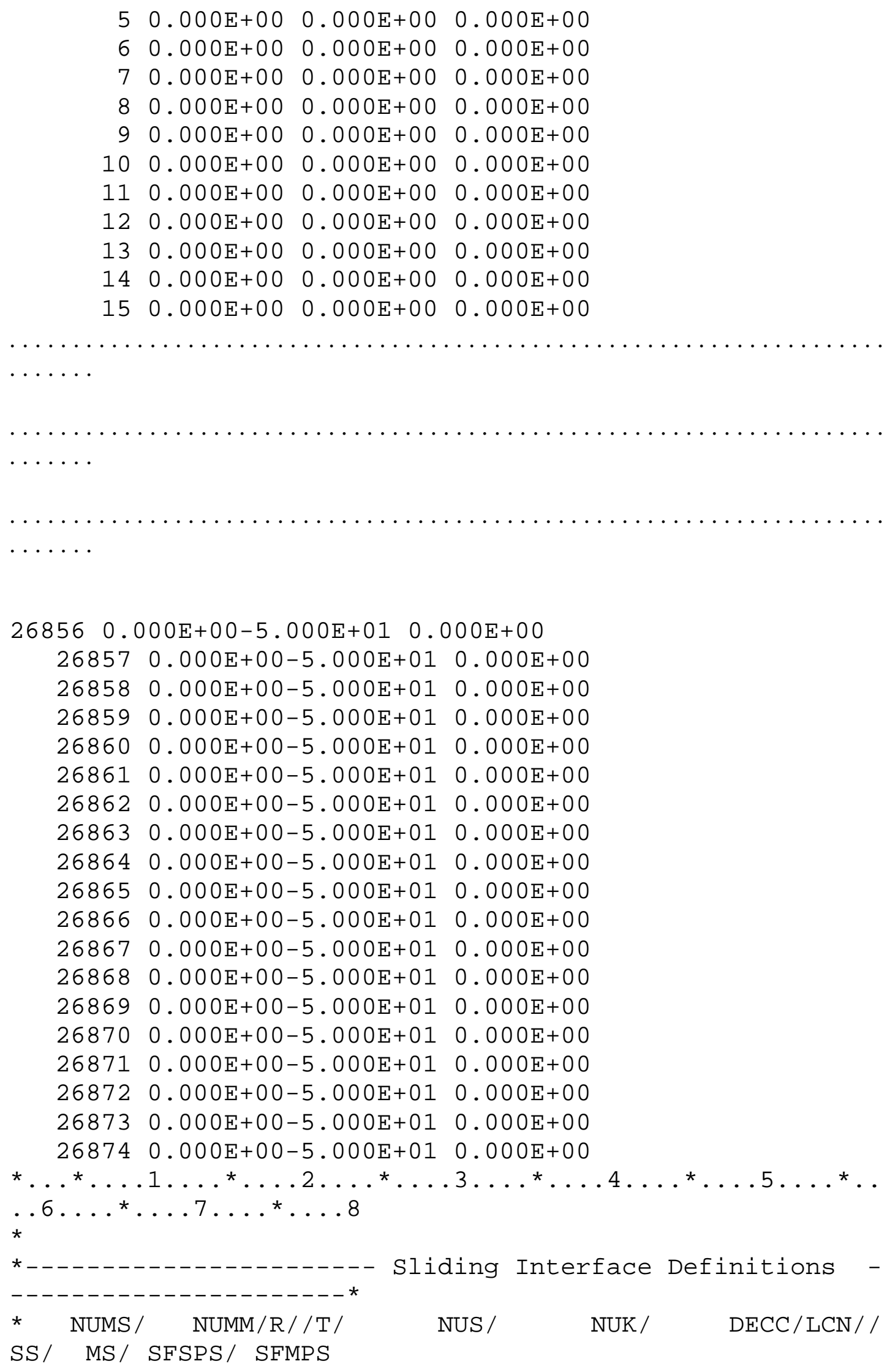




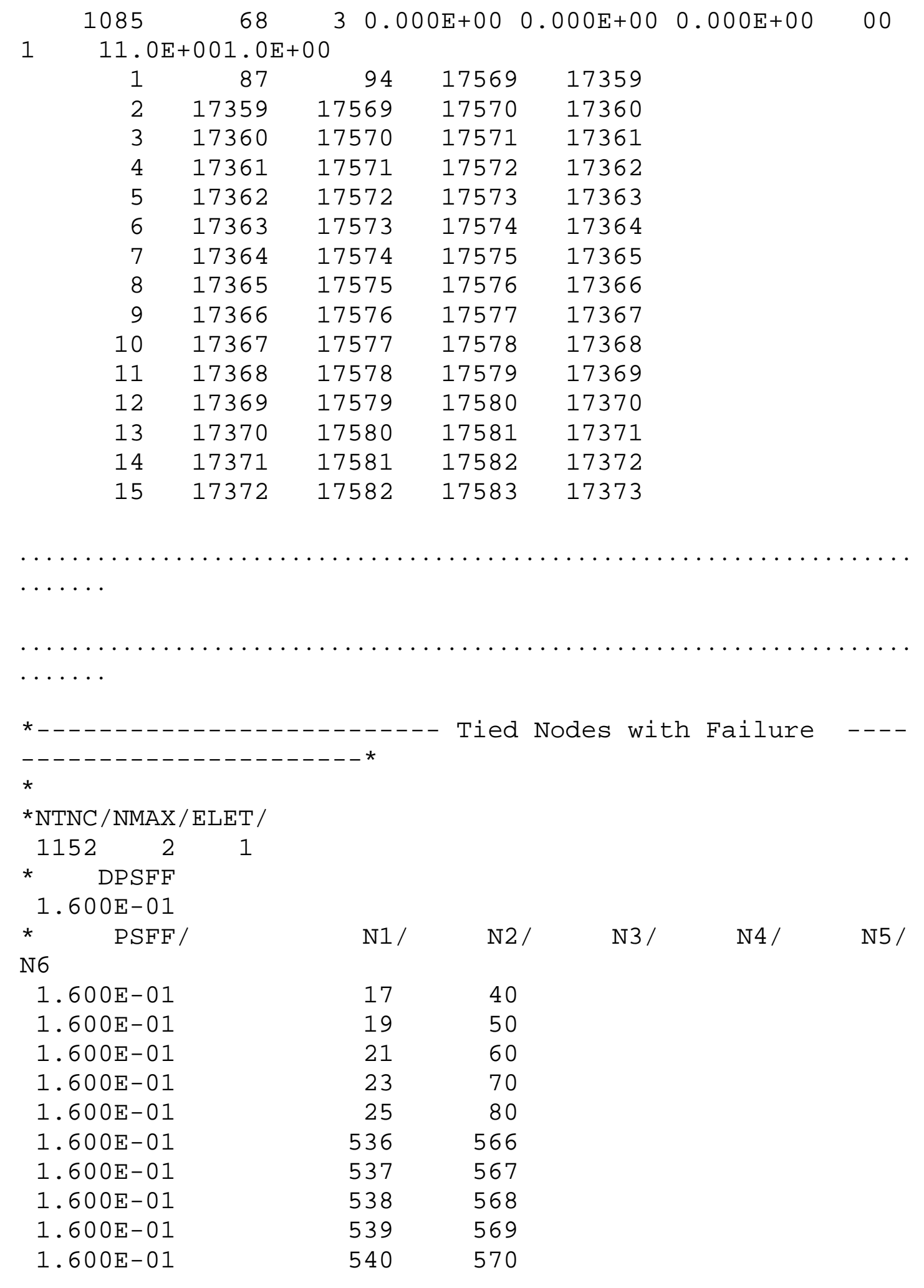




\section{APPENDIX B}

\section{c-Program to find out number of failed elements from HSPBULL file}

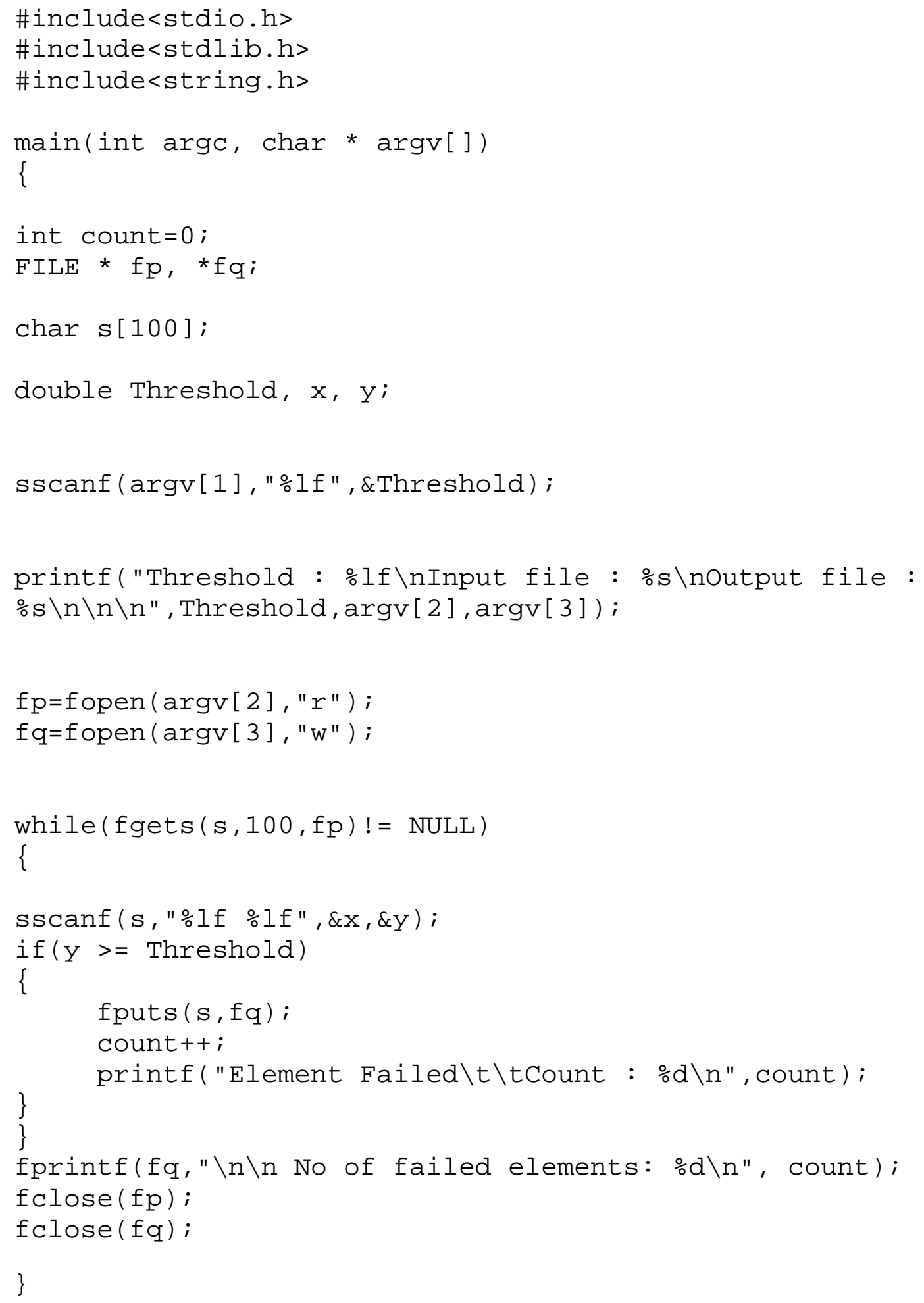




\section{APPROVAL OF THE EXAMINING COMMITTEE}

Kang, Bruce, Ph. D

Thompson, Gregory, Ph. D

Means, Kenneth, Ph. D

Committee Chairman

Date 